\title{
VALORES-TRABALHO E PREÇOS DE PRODUÇÃO EM SISTEMAS ECONÔMICOS SRAFFIANOS COM O SETOR AGRÍCOLA
}

\author{
MARINA SILVA DA CUNHA \\ Economista
}

Orientador: Prof. Dr. RODOLFO HOFFMANN

Tese apresentada à Escola Superior de Agricultura "Luiz de Queiroz", da Universidade de São Paulo, para obtenção do título de Doutor em Ciências: Área de concentração: Economia Aplicada.

PIRACICABA

Estado de São Paulo - Brasil

Julho - 1998 
Dados Internacionais de Catalogaçāo na Publicaçāo (CIP) DIVISÃO DE BIBLIOTECA E DOCUMENTAÇĀO - Campus “Luiz de Queiroz"/USP

Cunha, Marina Silva da

Valores-trabahtho e preços de produção em sistemas econômicos sraffianos com o setor agricola / Marina Silva da Cunha. - - Piracicaba, 1998.

$131 \mathrm{p}$.

Tese (doutorado) - - Escola Superior de Agricultura Luiz de Queiroz, 1998.

Bibliografia.

1. Economia aplicada 2. Indústria 3. Preço 4. Produção 5. Setor agricola 6. Teoria de Piero Sraffa 7. Trabalho I. Titulo 


\section{VALORES-TRABALHO E PREÇOS DE PRODUÇÃO EM SISTEMAS ECONÔMICOS SRAFFIANOS COM O SETOR AGRÍCOLA}

MARINA SILVA DA CUNHA

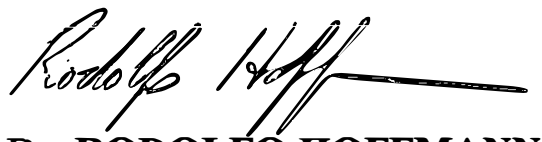

Prof. Dr. RODOLFO HOFFMANN

Orientador 
Ao meu marido, Fabiano

À minha filha, Ana Flávia

Aos meus pais, João e Aparecida

Aos meus irmãos, Hélio e Sirley

DEDICO. 


\section{AGRADECIMENTOS}

Ao prof. Rodolfo Hoffrnann, pelo exemplo, pela idéia que originou esse trabalho e pela orientação.

À Escola Superior de Agricultura "Luiz de Queiroz" - ESALQ/USP, pela oportunidade para a realização do curso.

À CAPES e a FAPESP, pela concessão de bolsa de estudo.

Aos profs. dos Departamentos de Economia e Sociologia Rural, Matemática e Estatística e Engenharia Rural, pelos conhecimentos transmitidos.

Aos profs. Pedro Carvalho de Mello, José Vicente Caixeta Filho e Joaquim José Martins Guilhoto, pelas críticas e sugestões oferecidas durante o seminário de curso e o exame de qualificação.

Aos funcionários do Departamento de Economia e Sociologia Rural, pela presteza no atendimento, Lu, Cris, Márcia, Maiele, Pedro, Helena, Valdecir e Elenice.

Aos colegas do curso de pós-graduação em Economia Aplicada, Estatística e Experimentação Agronômica e Irrigação e Drenagem, pela convivência, apoio e amizade.

Ao meu marido, Fabiano, pelo apoio e incentivo.

À todos aqueles que tenham de alguma maneira contribuído para a realização do presente trabalho. 


\section{SUMÁRIO}

Página

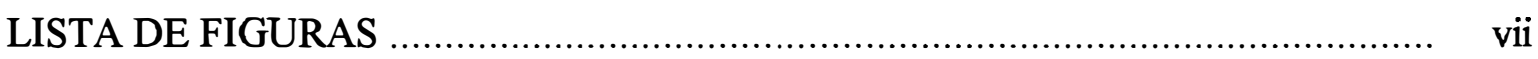

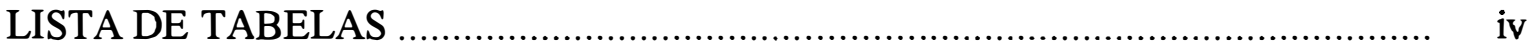

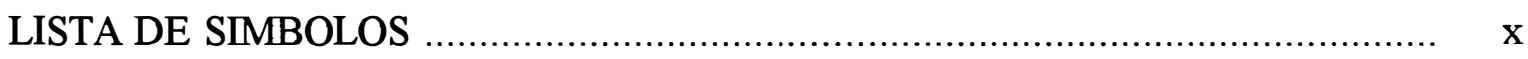

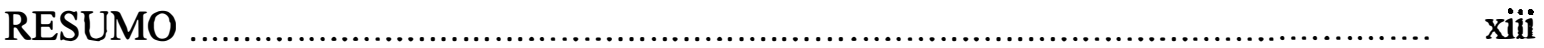

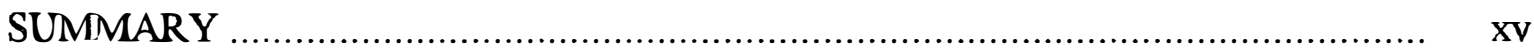

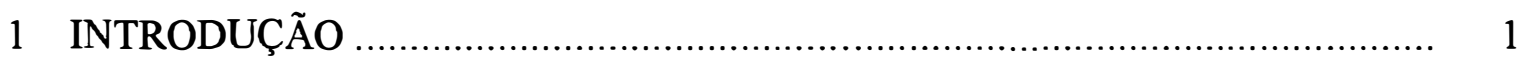

2 UM BREVE RETROSPECTO HISTÓRICO SOBRE A RENDA DA TERRA .. 5

2.1 François Quesnay ............................................................................. 5

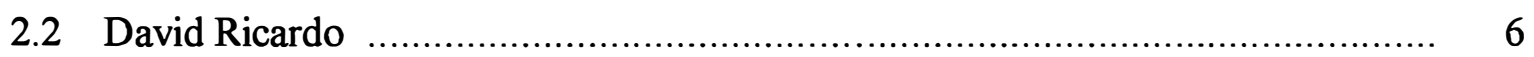

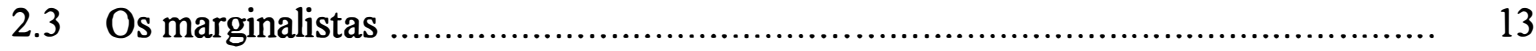

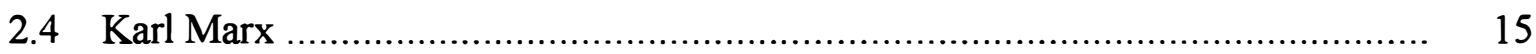

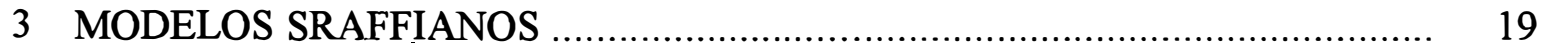

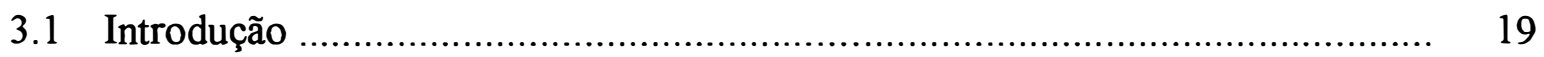

3.2 Modelos sraffianos com produção simples ................................................. 20

3.2.1 Modelo sraffiano ................................................................................ 21

3.2.2 Modelo sraffiano-marxista .................................................................. 25

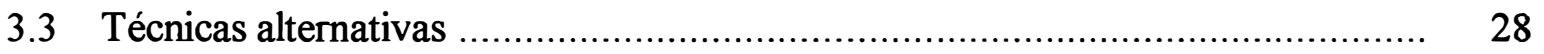

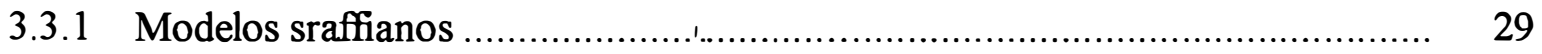

3.3.1.1 A escolha da técnica para uma mercadoria não-básica .............................. 30

3.3.1.2 A escolha da técnica para uma mercadoria básica ..................................... 32

3.3.1.3 A escolha da técnica em geral ............................................................ 35

3.3.1.4 A reversão de técnicas ................................................................ 35

3.3.2 Modelos marxistas ....................................................................... 37

4 MODELOS SRAFFIANOS COM O SETOR AGRÍCOLA ….......................... 46

4.1 Introdução: sistemas econômicos sraffianos ................................................... 46

4.2 Sistemas econômicos sraffiano-marxistas ..................................................... 50

4.2.1 Terras com diferentes qualidades ........................................................ 51 
4.2.1.1 Os valores-trabalho ............................................................................ 51

4.2.1.1.1 Primeira abordagem ...................................................................... 51

4.2.1.1.2 Segunda abordagem ................................................................... 53

4.2.1.1.3 Terceira abordagem .................................................................... 55

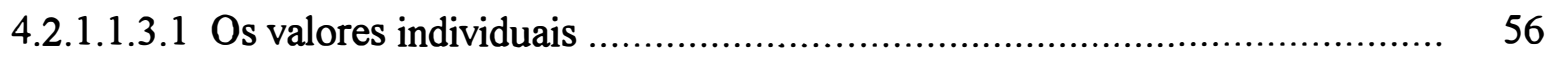

4.2.1.1.3.2 A mensuração da exploração ............................................................. 58

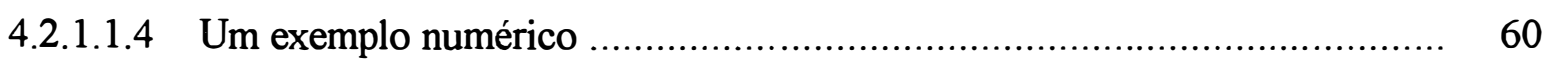

4.2.1.2 Os preços de produção ........................................................................ 70

4.2.1.2.1 A determinação da terra marginal ........................................................ 74

4.2.1.3 Ordem de eficiência e ordem de rentabilidade ............................................ 82

4.2.1.4 Reversão de técnicas .................................................................. 89

4.2.2 Terra homogênea …............................................................................ 97

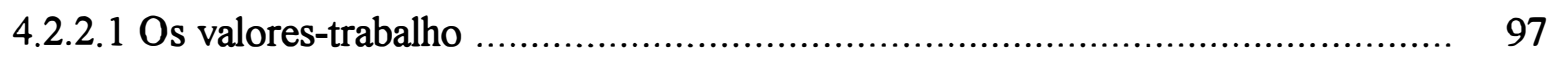

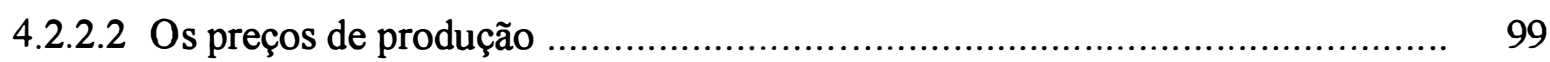

4.2.2.3 Mercadoria agrícola não-básica ......................................................... 104

4.2.2.3.1 A determinação do preço da mercadoria agrícola e da renda da terra ....... 104

4.2.2.3.2 O crescimento intensivo na produção da mercadoria agrícola .................. 107

4.2.2.3.3 As relações entre as variáveis distributivas ............................................. 108

4.2.2.4 Mercadoria agrícola básica .............................................................. 113

5 CONSIDERAÇÕES FINAIS _.................................................................... 121

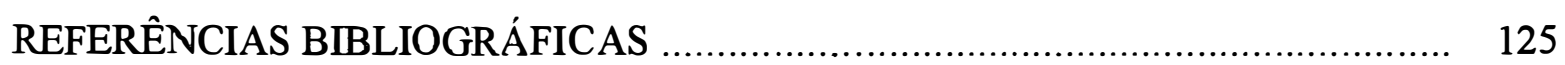




\section{LISTA DE FIGURAS}

Página

Figura 2.1 Vendas de produtos agrícolas e manufaturados entre as três classes, em bilhões

Figura 2.2 Pagamentos de renda e dos produtos agrícolas e manufaturados, em bilhões

Figura 2.3 Distribuição de renda no sistema ricardiano, em termos do produto marginal

Figura 3.1 A escolha da técnica para uma mercadoria não-básica 32

Figura 3.2 A escolha de técnicas de produção para uma mercadoria básica

Figura 3.3 Caso especial em que três técnicas se interceptam em um mesmo valor da taxa de lucro

Figura 4.1 Relações $\theta-r, w-r$ e $t-r$, modelo sraffiano-marxista em termos de preços de produção para terras de diferentes qualidades, primeiro exemplo numérico

Figura 4.2 Relações $V-\theta, \sigma-\theta$ e $\sigma-V$ para o modelo marxista com terras de diferentes qualidades, primeiro exemplo numérico

Figura 4.3 Relação $\sigma-r$ para os modelos com terras de diferentes qualidades marxista, primeiro exemplo numérico

Figura 4.4 Relações $\theta-r, w-r$ e $t-r$, modelo sraffiano-marxista em termos de preços de produção com terras de diferentes qualidades, segundo exemplo numérico

Figura 4.5 Relações $V-\theta, \sigma-\theta$ e $\sigma-V$, para o modelo marxista com terras de diferentes qualidades, Segundo exemplo numérico

Figura 4.6 Relação $\sigma-r$ para modelos com terras de diferentes qualidades, segundo o exemplo numérico

Figura 4.7 Relações $\theta-r, \quad w-r$ e $t-r$, modelo sraffiano-marxista em termos de preços de produção com terras de diferentes qualidades, terceiro 
exemplo numérico

Figura 4.8 Relações $V-\theta, \sigma-\theta$ e $\sigma-V$ para o modelo marxista com terras de diferentes qualidades, terceiro exemplo numérico

Figura 4.9 Relação $\sigma-r$ para modelos com terra de diferentes qualidades, segundo o exemplo numérico

Figura 4.10 A determinação do preço de uma mercadoria agrícola não-básica 105

Figura 4.11 Crescimento da demanda por cereal 107

Figura 4.12 Relações $\theta-r, w-r$ e $t-r$, modelo sraffiano-marxista em termos de preços de produção com terras homogêneas, primeiro exemplo numérico

Figura 4.13 Relações $V-\theta, \sigma-\theta$ e $V-\sigma$, para o modelo marxista com terras homogêneas, primeiro exemplo numérico

Figura 4.14 Relação $\sigma-r$ para modelos com terras homogêneas, segundo o exemplo numérico

Figura 4.15 Relações $\theta-r, w-r$ e $t-r$, modelo sraffiano-marxista em termos de preços de produção com terras homogêneas, segundo exemplo numérico.

Figura 4.16 Relação $w$-r em um modelo sraffiano-marxista em termos de preços de produção.

Figura 4.17 Relação $\varphi$-r em um modelo sraffiano-marxista em termos de preços de produção

Figura 4.18 Relação $\sigma-r$ para o modelo marxista com terra homogênea, segundo o exemplo numérico

Figura 4.19 Relação $\sigma-r$ para modelos com terra homogênea, segundo o exemplo numérico 


\section{LISTA DE TABELAS}

Página

Tabela 4.1 Capital constante, capital variável, valor do produto e mais-valia para as mercadorias industrial e agrícola

Tabela 4.2 Capital constante, capital variável, valor do produto e mais-valia, nas terras $\alpha$ e $\beta$

Tabela 4.3 Capital constante, capital variável, valor do produto e mais-valia, para as mercadorias industrial e agrícola, considerando apenas a terra $\alpha .64$

Tabela 4.4 Capital constante, capital variável, valor do produto e mais-valia, para as mercadorias industrial e agrícola, considerando apenas a terra $\beta$ 


\section{LISTA DE SÍMBOLOS}

\begin{tabular}{|c|c|c|}
\hline símbolo & descrição & Unidade \\
\hline $\mathbf{A}$ & matriz de coeficientes técnicos, com elementos $a_{i j}$ & \\
\hline B & Matriz com as produções totais & \\
\hline b & $\begin{array}{l}\text { vetor-linha dos coeficientes de trabalho, onde o elemento genérico } b_{j} \\
\text { representa a mão-de-obra utilizada para produzir cada unidade da } \\
\text { mercadoria } j\end{array}$ & Horas \\
\hline$C$ & capital constante & Valor-trabalho \\
\hline d & $\begin{array}{l}\text { vetor-coluna com as quantidades físicas da cesta de bens que constitui } \\
\text { o salário real de subsistência por trabalhador }\end{array}$ & Física \\
\hline D & $\begin{array}{l}\text { matriz diagonal com as quantidades totais das mercadorias produzidas } \\
\text { no sistema econômico }\end{array}$ & Física \\
\hline$d_{i}$ & pagamento ao fator $x_{i}$ & Monetária \\
\hline$e_{1}, e_{2} \mathrm{e} e_{3}$ & medidas da exploração & \\
\hline$f$ & mercadoria básica & \\
\hline$f_{i}$ & $=\partial f / \partial x_{i} .($ primeira derivada $)$ & \\
\hline$f(N)$ & função de produção & \\
\hline$f(0)$ & função de produção quando $N=0$ & \\
\hline$f^{\prime}(1)$ & primeira derivada de $f(N)$, quando $N=1$ & \\
\hline$f^{\prime \prime}(N)$ & segunda derivada de $f(N)$ & \\
\hline$g$ & mercadoria não-básica & \\
\hline $\mathbf{H}$ & matriz diagonal com as áreas de terra $h_{m}$ & ha \\
\hline$H_{m}$ & área de terra do tipo $m$ & ha \\
\hline $\mathbf{h}$ & vetor-linha com as áreas de terra & ha \\
\hline$i, j, k$ e $m$ & Índices & \\
\hline I & matriz identidade & \\
\hline $\bar{K}$ & capital existente & Física \\
\hline$K$ & capital circulante & Física \\
\hline$L_{j}$ & quantidade de trabalho utilizada na atividade $j$ & $\begin{array}{l}\text { Tempo de } \\
\text { trabalho }\end{array}$ \\
\hline$M$ & mais-valia & Valor-trabalho \\
\hline$n_{a}$ & indice, número total de mercadorias industriais & \\
\hline$n_{z}$ & $\begin{array}{l}\text { indice, número total de qualidades de terra ou técnicas empregada na } \\
\text { terra homogênea }\end{array}$ & \\
\hline
\end{tabular}




\begin{tabular}{|c|c|c|}
\hline$n$ & índice & \\
\hline $\bar{N}$ & número de trabalhadores existentes & Indivíduo \\
\hline$N$ & número de trabalhadores empregados & Indivíduo \\
\hline $\mathbf{p}$ & vetor de preços de produção & Monetária \\
\hline$p$ & preço do produto & Monetária \\
\hline$P$ & $=X-S-W$ & Monetária \\
\hline $\mathbf{p}^{*}$ & vetor-linha com preços de produção & Monetária \\
\hline $\mathbf{Q}$ & $\begin{array}{l}\text { matriz dos fluxos fisicos intersetoriais, onde cada elemento } q_{i j} \\
\text { representa a quantidade da mercadoria } i \text { que entra na produção da } \\
\text { mercadoria } j\end{array}$ & Física \\
\hline $\mathbf{q}$ & $\begin{array}{l}\text { vetor-coluna com as quantidades produzidas das mercadorias, com } \\
\text { elementos } q_{j}\end{array}$ & Física \\
\hline $\mathbf{q}^{*}$ & vetor com as quantidades produzidas no sistema padrão & Física \\
\hline$r^{*}$ & taxa de lucro & \\
\hline$r$ & taxa de lucro & \\
\hline$R$ & taxa de lucro máxima & \\
\hline $\mathbf{s}$ & $\begin{array}{l}\text { vetor-coluna com } n_{z} \text { elementos }\left(s_{m}=\operatorname{com} m=1, \ldots, n_{z}\right) \text { com as } \\
\text { quantidades disponíveis de terra }\end{array}$ & ha \\
\hline$S$ & renda total & Física \\
\hline$T$ & total de trabalho empregado & $\begin{array}{l}\text { Tempo de } \\
\text { trabalho }\end{array}$ \\
\hline $\mathbf{t}$ & vetor-linha com elementos $t_{m}$ com a renda da terra & Monetária/há \\
\hline$X$ & quantidade de cereal produzida no ano & Física \\
\hline $\bar{x}$ & salário de subsistência & Física \\
\hline$x$ & taxa de salário & \\
\hline $\mathbf{v}$ & vetor-linha com os valores-trabalho por unidade de cada mercadoria & Valor-trabalho \\
\hline$v_{w}$ & trabalho necessário & Valor-trabalho \\
\hline$v_{w}$ & solução de um problema de programação linear & Valor-trabalho \\
\hline $\mathbf{v}_{o}$ & vetor com valores ótimos & Valor-trabalho \\
\hline$v_{z}$ & valor-trabalho da mercadoria agrícola & Valor-trabalho \\
\hline$V$ & capital variável & Valor-trabalho \\
\hline$v_{m}$ & valor-trabalho na terra de qualidade $m$ & Valor-trabalho \\
\hline $\mathbf{v}_{t}$ & $\begin{array}{l}\text { vetor-linha com } n_{z} \text { elementos com os valores-sombra (valores- } \\
\text { trabalho ótimos) }\end{array}$ & Valor-trabalho \\
\hline
\end{tabular}




\begin{tabular}{|c|c|c|}
\hline$\overline{\mathbf{v}}$ & vetor-linha com $n_{a}+1$ elementos com os valores-trabalho médios & Valor-trabalho \\
\hline$v_{N \mathbf{d}}$ & trabalho necessário de todos os trabalhadores & Valor-trabalho \\
\hline$v_{\mathrm{d}}$ & trabalho necessário de um trabalhador & Valor-trabalho \\
\hline$w$ & salário uniforme & Monetária \\
\hline$W$ & total de salários pagos & Física \\
\hline $\mathbf{y}^{*}$ & vetor com o produto líquido do sistema padrão & Física \\
\hline $\mathbf{y}_{w}$ & $\begin{array}{l}\text { cesta de mercadorias ou parcela do produto líquido consumida por } \\
\text { todos os trabalhadores do sistema econômico }\end{array}$ & Física \\
\hline$y=f\left(x_{1}, x_{2}\right)$ & função de produção & \\
\hline$y_{i}$ & componente do vetor de produto líquido $y$ & Física \\
\hline$Z^{0}=\mathbf{b}^{0} \mathbf{q}$ & solução de um problema de programação linear de maximização & \\
\hline$\lambda_{m}$ & autovalor máximo de $\mathbf{A}$ & \\
\hline$\eta$ & $\begin{array}{l}\text { vetor-coluna com } n \text { elementos representando a fração de cada } \\
\text { indústria que irá compor o sistema padrão }\end{array}$ & \\
\hline$\omega$ & valor da força de trabalho & $\begin{array}{l}\text { Tempo de } \\
\text { trabalho }\end{array}$ \\
\hline$\sigma$ & taxa de mais-valia & \\
\hline$\alpha, \beta, \gamma$ e $\varepsilon$ & Índices & \\
\hline $\mathbf{l}_{z}$ & vetor-linha com elementos iguais a 1 & \\
\hline$\pi$ & taxa de lucro de Marx & \\
\hline$\theta$ & constante & \\
\hline $\mathbf{0}$ & Vetor-linha com $n_{a}$ elementos iguais a zero & \\
\hline
\end{tabular}




\title{
VALORES-TRABALHO E PREÇOS DE PRODUÇÃO EM SISTEMAS ECONÔMICOS SRAFFIANOS COM O SETOR AGRÍCOLA
}

\author{
Autor : MARINA SILVA DA CUNHA \\ Orientador : RODOLFO HOFFMANN
}

\section{RESUMO}

Este trabalho desenvolve uma extensão da abordagem sraffiana, considerando um modelo com a economia dividida em dois setores, o setor industrial e o agrícola. Partindo de um sistema em unidades fisicas é possível determinar valores-trabalho e preços de produção.

Inicialmente é realizada uma revisão dos modelos sraffianos e sraffiano-marxistas com produção simples e com técnicas alternativas. Posteriormente, seguindo Sraffa, considerando a produção da mercadoria agrícola, são analisados sistemas em que existem várias qualidades de terra e sistemas em que existem vários métodos ou técnicas de produção empregadas em uma terra homogênea.

São analisados três métodos de determinação dos valores-tabalho e conclui-se que aquele que utiliza a sugestão de Morishima, com programação linear, é o mais consistente com a teoria do valor-trabalho.

Com base na abordagem sraffiana e na contribuição de Morishima para a análise dos valores-trabalho, podemos verificar que, havendo um setor agrícola com escassez de algum tipo de terra, a existência de uma taxa de mais-valia positiva é condição necessária mas não suficiente para a existência de lucros positivos. Além disso, os valores verdadeiros são sempre positivos.

Refutamos três afirmações presentes no trabalho de 1980 de Morishima e Catephores. Primeiro, em um sistema econômico onde terras escassas são cultivadas a taxa de mais-valia calculada para um trabalhador individual pode ser maior do que aquela calculada para todos os trabalhadores do sistema, diferentemente do que pensavam Morishima e Catephores. Segundo, nesse sistema econômico os valores ótimos, da mesma maneira que os valores verdadeiros individuais, não são aditivos. E, por fim, a soma dos valores individuais verdadeiros de cada mercadoria multiplicados pelas respectivas 
quantidades do seu produto líquido no sistema pode ser menor que o valor verdadeiro do produto líquido do sistema.

Por se tratar de uma abordagem formal, o modelo sraffiano-marxista em termos de preços de produção possui alguns aspectos não analisados por Marx. Primeiro, a ordem de eficiência das terras não representa uma característica naturalmente dada, mas depende da distribuição de renda e da demanda por cereal na economia. Segundo, a ordem de eficiência não corresponde, em geral, à ordem de rentabilidade das terras. 


\title{
LABOUR VALUES AND PRICES OF PRODUCTION IN SRAFFIAN ECONOMIC SYSTEMS WITH AN AGRICULTURAL SECTOR
}

\author{
Author : MARINA SILVA DA CUNHA \\ Adviser : RODOLFO HOFFMANN
}

\section{SUMMARY}

This work develops an extension of sraffian's approach, considering a model where the economy is divided in two sectors, the industrial and the agricultural. From a system in physical units it is possible to determine labour values and prices of production.

Initially a review of sraffian's and sraffians marxian' models with simple production and with alternative techniques is realized. After that, following Sraffa, the production of agricultural commodities is considered, analysing systems where there are several qualities of land and systems where there are several methods or techical of production used in a homogeny land.

Three methods of labour values determination are analysed and we can conclude that Morishima's suggestion, with linear programming is the most consistent with the marxist theory.

Based in sraffian's approach and in Morishima's contribution for the labour value analysis, we can verify when there is an agricultural sector with scarcity of some kind of land, the existence of positive surplus-value is a necessary condition, but is not a sufficient condition to positive profits. Besides, the effective values are allways positive.

We refute three affirmations in Morishima and Catephores' work, of 1980. Firstly, in an economic system where scarce lands are cultivated the surplus-value is calculated for an individual worker, it can be higher than the one which is calculated for all workers of the system, differently of Morishima and Catephores' affirmation. Secondly, in this economic system the optimum values are not aditive, and the same happens to the true values. Finally, 
the sum of true individual values of each commodities multiplied by the respective amounts of its net product on the system, can be smaller than true value of product of system.

The sraffian marxian's model, in terms of price of production, has some aspects which were not analysed by Marx. Firstly, the order of efficiency of lands does not represent a natural characteristic, but it depends on income distribution and on the demand for cereal in the economy. Secondly, the order of efficiency does not correspond, in general, to the order of rentability of the lands. 


\section{INTRODUÇÃO}

O principal trabalho de Piero Sraffa, intitulado Produção de mercadorias por meio de mercadorias, foi publicado em 1960. Segundo Steedman (1977), a preocupação central deste livro são as relações entre salários, lucros e preços, para dadas condições de produção, supondo uniformes em toda a economia o salário, a taxa de lucro e o preço de cada mercadoria.

Este trabalho teve repercussões tanto na escola marginalista quanto na escola marxista. A partir desta publicação desenvolveu-se uma crítica formal à teoria marginalista, como indicava o subtítulo do livro: Prelúdio a uma crítica da teoria econômica. A polêmica resultante foi denominada por Harcourt (1972) de Controvérsias de Cambridge sobre a teoria do capital, e discutiu vários aspectos da teoria econômica neoclássica, tais como a distribuição de renda, a mensuração do capital e a escolha de técnicas. $^{1}$

$\mathrm{Na}$ escola marxista surgiram trabalhos utilizando modelos sraffianos visando uma abordagem formal do problema marxista da transformação dos valores em preços. Tais trabalhos usam modelos que podem ser denominados sraffiano-marxistas. Ao contrário do que é feito no esquema original de Sraffa, nos modelos sraffiano-marxistas o custo do pagamento da mão-de-obra (o capital variável de Marx) é incluído no montante sobre o qual se calculam os lucros. Segundo Médio (1973), esta abordagem tornou possível uma prova formal da consistência da teoria do valor de Marx.

\footnotetext{
${ }^{1}$ Segundo Harcourt (1972), o início deste debate foi o artigo de 1953 escrito por Joan Robinson, intitulado "The production function and the theory of capital" (uma reprodução do mesmo pode ser encontra em Harcourt \& Laing (1971)), inspirada no prefácio escrito por Sraffa para a edição das Obras de Ricardo, originalmente publicada em 1950 (ver Sraffa, 1982).
} 
Para Morishima e Catephores (1980) este problema da transformação constitui-se de dois subproblemas: a transformação da taxa de exploração na taxa de lucro e a transformação dos valores em preços de produção.

Para Roncaglia (1978), existem muitas interpretações possíveis para o sistema sraffiano. Primeiro, o livro de Sraffa representa um retorno às idéias dos economistas clássicos. Neste sentido, os autores que seguiram as idéias de Sraffa, adicionando a hipótese de igualdade entre quantidade produzida e demandada de cada mercadoria, foram denominados neo-ricardianos por Rowthorn (1982). ${ }^{2}$

Uma segunda interpretação segue do fato de que Sraffa não faz referência implícita ou explicita à igualdade entre quantidade demandada e produzida. Assim, não existe uma implicação, nem uma necessidade, da lei de Say. Com isto, a abordagem keynesiana e sraffiana são compatíveis. Consequentemente, os neo-ricardianos podem ser classificados como pós-keynesianos. ${ }^{3}$

Em terceiro, o sistema sraffiano pode ser considerado como um caso especial de um modelo de equilíbrio geral, quando é adicionada ao mesmo a suposição de retornos constantes e outros conceitos da economia neoclássica. ${ }^{4}$

Um exemplo da retomada do pensamento clássico em Sraffa é a sua análise da utilização da terra na produção de mercadorias, uma vez que pode ser considerada como uma formulação matemática das idéias de Ricardo (Gibson \& McLeud, 1983). Seguindo Ricardo, Sraffa analisa dois casos: o primeiro em que existem várias qualidades de terra, o que dá origem à renda extensiva; e o segundo em que existem vários métodos ou técnicas de produção empregadas em uma terra homogênea, implicando uma renda de caráter intensivo.

\footnotetext{
${ }^{2}$ Este artigo foi publicado pela primeira vez na New Left Review, julho-agosto de 1974.

${ }^{3}$ Ver Lichtenstein (1983).

${ }^{4}$ De acordo com Tolipan (1990), Hahn representa um exemplo da insistência em tratar o modelo sraffiano como um caso especial de equilibrio geral com retornos constantes à escala e curvas de Engels lineares. [Hahn, F. Revival of political economy: the wrong issues and the wrong argument. Economic Record, sep. 1975; e Hahn, F. The neo-ricardians. Cambridge Journal of Economics, 6: 353-74, 1982]. Ver, também, Barros Lisboa (1993).
} 
$\mathrm{Na}$ abordagem sraffiana, processos de produção utilizando a terra, que é um meio de produção não produzido, têm sido analisados como o inverso dos processos com produtos conjuntos, isto é, aqueles bens que não podem ser produzidos separadamente, como couro e carne bovina. Estes podem ser vistos como um único processo de produção produzindo vários produtos, enquanto o primeiro tem sido examinado como o caso de vários processos de produção (terras de diferentes qualidades ou várias técnicas de cultivo em uma terra de qualidade homogênea) que produzem um único produto (Pasinetti, 1980).

Neste sentido, a terra pode ser analisada em um modelo com produção simples com processos ou técnicas alternativas para a produção da mercadoria agrícola, isto é, um modelo em que cada processo ou técnica produz apenas uma mercadoria e a mercadoria agrícola pode ser produzida por mais de um processo ou técnica. Existe uma analogia entre a questão da escolha da técnica e os modelos com a terra como insumo. Como veremos, nos modelos que incluem o setor agrícola, a determinação da margem (extensiva ou intensiva) é uma maneira de abordar a questão da escolha da técnica (Woods, 1990).

Após a publicação de "Produção ..." vários autores passaram a estudar e desenvolver o que Sraffa tinha escrito sobre sistemas de produção com a terra como insumo. Contudo, o setor agrícola ainda não foi analisado nos modelos sraffianomarxistas. Com isto, o principal objetivo do presente trabalho constitui-se em desenvolver e analisar sistemas econômicos sraffiano-marxistas que incluam o setor agrícola, considerando tanto a determinação dos preços de produção como dos valorestrabalho.

Para atingir este objetivo dividimos este trabalho, incluindo a introdução, em cinco capítulos.

O segundo capítulo, de caráter introdutório, apresenta um breve histórico do tratamento dado ao tema renda da terra na evolução do pensamento econômico. Este capítulo analisa os desenvolvimentos do tema realizados por três economistas (Quesnay, Ricardo e Marx) e por uma escola do pensamento econômico (escola marginalista). 
O terceiro capítulo apresenta uma revisão dos modelos sraffianos. O capítulo inicia discutindo a abordagem excedentária dada à teoria da distribuição e do valor, comum aos autores clássicos, Marx e Sraffa. Em seguida, é sistematizada uma revisão dos modelos sraffiano e sraffiano-marxista com produção simples. O capítulo termina com uma análise dos processos ou técnicas alternativas em modelos sraffianos e marxistas.

A análise de processos com técnicas alternativas na teoria do valor-trabalho ocorreu juntamente com a discussão da produção conjunta. Morishima (1973; 1974; 1976) analisou estes temas segundo uma nova definição de valor-trabalho, os valores verdadeiros, dados pela solução de um problema de programação linear de minimização do tempo de trabalho necessário para obter determinado produto líquido. Steedman (1975) formulou um exemplo numérico em termos dos valores efetivos, em que verifica que na presença de produção conjunta e técnicas alternativas podem coexistir uma taxa de mais-valia negativa com uma taxa de lucro positiva. Os valores efetivos de Steedman são aditivos mas podem ser negativos. Por outro lado, os valores verdadeiros de Morishima são sempre positivos mas não são aditivos.

O quarto capítulo trata dos modelos sraffianos e sraffiano-marxistas com os setores industrial e agrícola. O capítulo inicia apresentando o modelo de Sraffa em termos de preços de produção, com estes dois setores. Posteriormente, é realizada uma análise incorporando o meio de produção terra nos modelos sraffiano-marxistas, considerando os dois casos discutidos por Sraffa, ou seja, terras de diferentes qualidades e terras homogêneas onde são utilizadas várias técnicas ou métodos de produção.

Após o desenvolvimento e análise do modelo sraffiano-marxista, teremos elementos que possibilitarão identificar as principais diferenças e similaridades existentes entre os resultados deste modelo e o que Marx pensava sobre o tema. Isto será feito no último capítulo, dedicado às considerações finais. 


\section{UM BREVE RETROSPECTO HISTÓRICO SOBRE A RENDA DA TERRA}

\subsection{François Quesnay}

A preocupação com a categoria econômica renda da terra teve início com a fisiocracia, que considerava a agricultura o centro do sistema econômico e o único setor gerador de excedente econômico (Lenz, 1981).

No livro Tableau Économique de François Quesnay (1986), o mais importante representante da fisiocracia, o sistema econômico era composto por três classes: a classe produtiva (cidadãos ligados à atividade agrícola), a classe proprietária (donos de terra) e a classe estéril (cidadãos ligados a outras atividades que não a agrícola). ${ }^{5}$

A renda ou produto líquido do cultivo da terra constituía-se no pagamento à classe proprietária feito pela classe produtiva, “ ... depois que esta descontou, da reprodução que faz renascer cada ano, as riquezas necessárias ao reembolso de seus adiantamentos anuais e à manutenção de suas riquezas de exploração." (Quesnay, 1986, p.257)

Para Hunt (1987) os produtores de mercadorias industriais eram chamados de classe estéril não porque deixavam de produzir, mas porque o valor de seu produto era tomado como sendo igual ao seu custo de produção. Por outro lado, os agricultores geravam a renda ou o excedente econômico do sistema.

Como exemplo, vamos considerar o primeiro Quadro Econômico analisado por Quesnay, que representa, basicamente, um modelo de uma economia, mostrando os

\footnotetext{
${ }^{5}$ A edição original do Tableau Économique, de Quesnay (1694-1774), é de 1758, e pode ser considerada como a primeira formulação de um esquema de análise de insumo-produto (Pasinetti, 1977).
} 
processos de produção, circulação da moeda e das mercadorias e a distribuição de renda. Este modelo supõe que a produção ocorre em ciclos anuais e que toda a produção é consumida durante o mesmo ano ou é transferida como insumo para o período seguinte. Considere que, em um determinado ano, a classe produtiva, com um adiantamento de 2 bilhões, produz 5 bilhões, e que a classe estéril, com 1 bilhão, produz 2 bilhões, como apresentam as figuras 2.1 e 2.2 . A classe produtiva vende 1 bilhão em produtos para a classe proprietária e outro bilhão para a classe estéril. A classe proprietária compra 1 bilhão em produtos da classe estéril, a qual gasta o mesmo montante em compras com a classe produtiva. Com estes 3 bilhões, a classe produtiva paga dois bilhões como renda da terra à classe proprietária e compra 1 bilhão em manufaturas da classe estéril. Os 2 bilhões restantes da classe produtiva são utilizados como adiantamentos para o período seguinte. Dos 2 bilhões de produtos comprados pela classe estéril, 1 é gasto para a subsistência de seus agentes e o outro para a reposição de seus adiantamentos para o ano seguinte. Assim, o produto bruto do sistema é 7 bilhões, dos quais 5 bilhões são gastos com a despesa ou o consumo total do sistema e os 2 bilhões restantes constituem-se no produto líquido ou renda do sistema. ${ }^{6}$

\subsection{David Ricardo}

Na escola clássica a discussão sobre a renda da terra adquiriu mais ou menos relevância, de acordo com cada pensador. Adam Smith (1723-1790) considerava a renda

\footnotetext{
${ }^{6}$ Quanto à moeda necessária para a circulação deste produto Quesnay (1986, p.262) diz: “...As somas em dinheiro que passam a cada classe distribuem-se nela pela circulação de uma soma total que recomeça cada ano. Podemos supor essa soma de dinheiro maior ou menor em sua totalidade e a circulação mais ou menos rápida, porque a rapidez de circulação do dinheiro pode suprir, em grande parte, o volume de dinheiro. Por exemplo, em um ano em que, sem que tivesse havido diminuição na reprodução, houvesse grande aumento do preço dos produtos, quer por facilidades concedidas ao comércio, quer por qualquer outra razão, não seria necessário que houvesse aumento da massa pecuniária para o pagamento das compras desses produtos. Entretanto, passariam pelas mãos dos compradores e dos vendedores maiores somas de dinheiro, que fariam com que a maioria acreditasse que a massa de dinheiro amoedado teria aumentado muito no reino. Assim, essa aparência equivalente à realidade é muito misteriosa para o vulgo."
} 


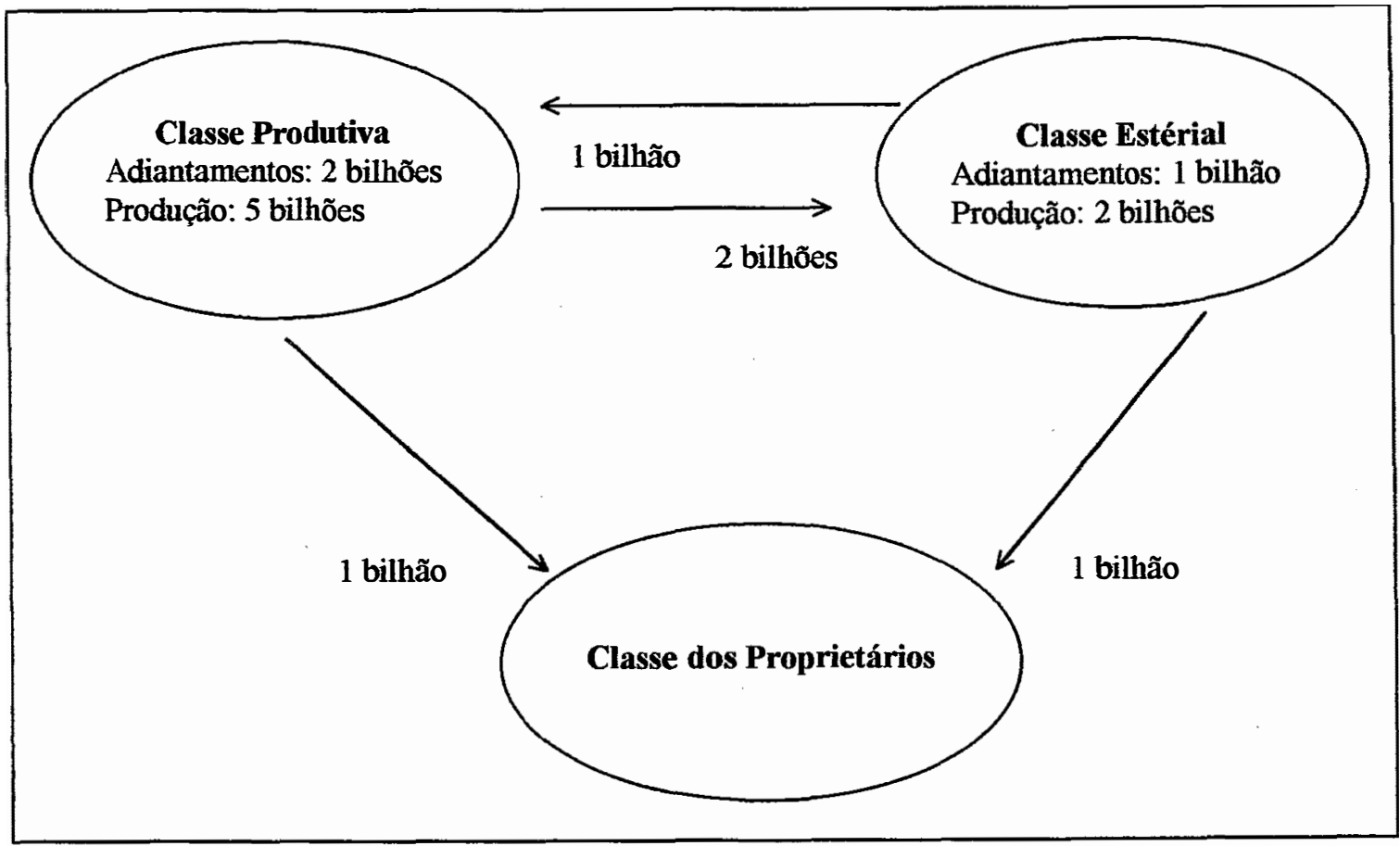

Figura 2.1 Vendas de produtos agrícolas e manufaturados entre as três classes, em bilhões

Fonte: Baseado em Quesnay (1983).

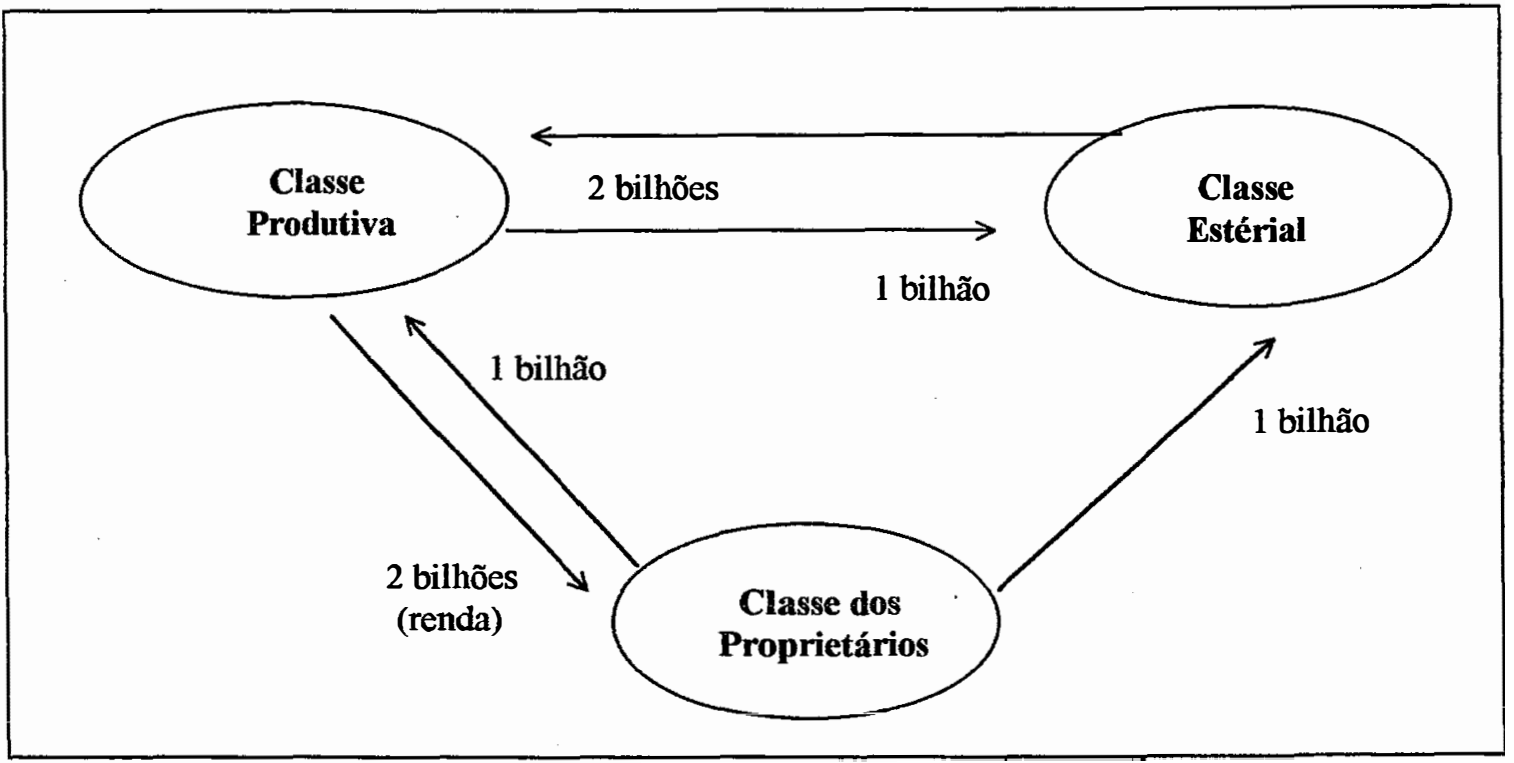

Figura 2.2 Pagamentos de renda e dos produtos agrícolas e manufaturados, em bilhões. Fonte: baseado em Quesnay (1983). 
da terra como um excedente da produção, além do necessário para pagar o lucro normal do agricultor e os insumos utilizados na produção. "A renda da terra, considerada como o preço pago pelo uso da terra, é naturalmente a maior que o arrendatário pode permitirse pagar, nas circunstâncias efetivas da terra. Ao ajustar as cláusulas do arrendamento, o dono da terra faz o possível para deixar ao arrendatário uma parcela da produção não superior ao que é suficiente para pagar ao arrendatário o capital do qual ele fornece as sementes, paga a mão-de-obra, compra e mantém o gado e outros instrumentos e dispositivos agrícolas, juntamente com o lucro normal do capital empregado, segundo a taxa vigente na região." (Smith, 1983, p. 151)

Com Ricardo (1772-1823) o tratamento da renda da terra na escola clássica atinge seu ápice e se insere no contexto da determinação das leis que regulam a distribuição da riqueza e da formulação do valor (Flichman, 1977). ${ }^{7}$

"O produto da terra - tudo que se obtém de sua superficie pela aplicação combinada de trabalho, maquinaria e capital - se divide entre três classes da sociedade, a saber: o proprietário da terra, o dono do capital necessário para seu cultivo e os trabalhadores cujos esforços são empregados no seu cultivo.

Em diferentes estágios da sociedade, no entanto, as proporções do produto total da terra destinadas a cada uma dessas classes, sob os nomes de renda, lucro e salário, serão essencialmente diferentes, o que dependerá principalmente da fertilidade do solo, da acumulação de capital e de população, da habilidade, a engenhosidade e dos instrumentos empregados na agricultura.

Determinar as leis que regulam essa distribuição é a principal questão da Economia Política ..." (Ricardo, 1982, p.39)

Segundo Ricardo (1982, p.65), a renda da terra “... é a porção do produto da terra paga ao seu proprietário pelo uso das forças originais e indestrutíveis do solo."

\footnotetext{
${ }^{7}$ Para Hunt (1987), a teoria da renda da terra de Ricardo de seu livro Principios de economia politica e da tributação, de 1817, representa uma elaboração coerente da idéia presente em seu Ensaio[ RICARDO, D. Ensaio acerca da influência de um baixo preço do cereal sobre os lucros do capital. In: Napoleoni (1981)].
} 
Assim, a remuneração recebida por benfeitorias realizadas na terra, que estiverem além da fertilidade natural, não seria considerada renda.

Para Ricardo, se a terra fosse ilimitada na quantidade e uniforme na qualidade, não haveria renda, com exceção para o caso de vantagens de localização. A renda deveria ser paga uma vez que essas características não ocorram. Quando as terras de fertilidade secundária passam a ser cultivadas, imediatamente surge renda nas terras de primeira qualidade. A renda na terra de segunda qualidade aparece quando a terra de terceira qualidade passa a ser cultivada, ocorrendo, concomitantemente, um aumento da renda na terra de primeira qualidade. Neste sentido, a renda da terra possui um caráter de renda extensiva.

Por outro lado, segundo Ricardo (1982, p.67), antes que todas as terras de qualidade inferior sejam cultivadas, pode ocorrer o emprego de mais capital nas terras de melhor qualidade já em uso. $\mathrm{O}$ produto obtido pode não crescer proporcionalmente com a quantidade de capital empregado, contudo, pode crescer em magnitude superior àquela obtida caso o capital fosse empregado na terra de qualidade inferior, ainda inculta. “... Se, com um capital de 1.000 libras, um arrendatário obtém 100 quarters de trigo e se, com o emprego de outro montante de 1.000 libras, obtém uma quantidade adicional de 85 quarters, o proprietário da terra poderá, ao fim do contrato, obrigá-lo a pagar 15 quarters, ou um valor equivalente, como renda adicional, pois não pode haver duas taxas

de lucro ..." Como no caso anterior, o último capital empregado não paga renda. $\dot{C}$ om isto, a renda passa a assumir um outro caráter, o de renda intensiva.

Segundo o autor, existia uma ordem de cultivo das terras, segundo a qual as terras com melhores qualidades seriam primeiro cultivadas. $\mathrm{O}$ valor de troca das mercadorias agrícolas seria regulado pela maior quantidade de trabalho necessário para produzi-las, estabelecido na terra marginal. Assim, o valor das mercadorias era regulado pela quantidade de trabalho utilizada naquela porção de terra que não paga renda.

Concluindo o capítulo sobre a renda, Ricardo $(1982$, p.73) afirma: “... espero haver dito o suficiente para mostrar que qualquer fato que diminua a desigualdade entre os produtos obtidos com sucessivas porções de capital empregadas na mesma terra ou em 
novas terras tende a reduzir a renda, e que qualquer fator que aumente aquela desigualdade necessariamente produz o efeito oposto, tendendo a elevá-la."

Pasinetti (1977) apresentou uma formalização das principais idéias de Ricardo, inclusive a renda da terra, considerando um sistema econômico simplificado com apenas uma mercadoria (o cereal). ${ }^{8}$

Este modelo supõe que o processo de produção da mercadoria é anual e que o único tipo de capital é aquele necessário para formar um fundo para pagar o salário adiantado aos trabalhadores.

Assim, a característica deste modelo é que na produção de cereal existe uma homogeneidade entre capital e produto, uma vez que o capital (salário pago anualmente) é considerado como constituído inteiramente de cereal (Vivo, 1987).

Vamos indicar a quantidade de cereal produzida no ano por $X$, o número de trabalhadores empregados por $N$, a renda total por $S$, o capital circulante por $K$, a taxa de salário por $x$ e o total de salários pagos por $W$. Assim, a teoria Ricardiana pode ser representada através do seguinte conjunto de equações

$$
X=f(N)
$$

onde,

$$
\begin{array}{r}
f(0) \geq 0 \\
f^{\prime}(1) \geq \bar{x} \\
f^{\prime \prime}(N)<0 \\
S=f(N)-N f^{\prime}(N) \\
W=N x
\end{array}
$$

\footnotetext{
8 A primeira versão deste modelo está no seguinte trabalho: PASINETTI, L. L., A mathematical formulation of the ricardian system, in: Review of economic studies, p.78-98, 1959-60. Este modelo pode ser generalizado para o caso de $n$ setores.
} 


$$
\begin{aligned}
& K=W \\
& P=X-S-W
\end{aligned}
$$

A eq. (2.1) representa uma função de produção, que possui três características: o produto é não-negativo; se apenas um trabalhador está empregado, a quantidade de cereal produzida deve exceder ou igualar-se a uma determinada quantidade de produto, $\bar{x}$, chamada de "salário de subsistência", caso contrário o sistema econômico não seria viável; e a produção está sujeita a rendimentos decrescentes à escala. Estas características estão representadas nas eqs. (2.1a), (2.1b) e (2.1c), respectivamente.

Caso existam diferentes tipos de terra, com diferentes níveis de fertilidade, os capitalistas começam cultivando a terra mais fértil. Contudo, se a população cresce, demandando mais alimentos, as terras menos férteis passam a ser cultivadas. Consequentemente, as terras mais férteis passam a produzir um "produto líquido" ou "renda". O total desta renda está representado pela eq. (2.2). ${ }^{9}$ Sendo que, para que o sistema acima possa ser solucionado deve-se, ainda, incluir duas equações

$$
\begin{aligned}
& N=\bar{N} \\
& K=\bar{K}
\end{aligned}
$$

onde $\bar{N}$ e $\bar{K}$ são, respectivamente, o número de trabalhadores e a quantidade de capital existentes.

Seguindo o pensamento de Malthus (1766-1834), Ricardo acreditava que este modelo só estaria em um equilíbrio "natural" se $x=\bar{x}$, ou seja, se o salário estivesse no nível de subsistência. Assim, se $x>\bar{x}$ a população irá aumentar e o contrário ocorrerá se $x<\bar{x}$. Tomando este mecanismo demográfico, Pasinetti substitui a eq. (2.6) por

$$
x=\bar{x}
$$

\footnotetext{
${ }^{9}$ Esta equação representa a renda extensiva. Contudo, este modelo pode incluir, conjuntamente, a renda extensiva e intensiva.
} 
Com isto, o sistema passa a ter sete equações e sete incógnitas, com todas as variáveis expressas em termos fisicos.

A figura 2.3 mostra a distribuição do produto total em renda, salário e lucro, considerando uma situação de equilíbrio onde o número de trabalhadores empregados é $\bar{N}$.

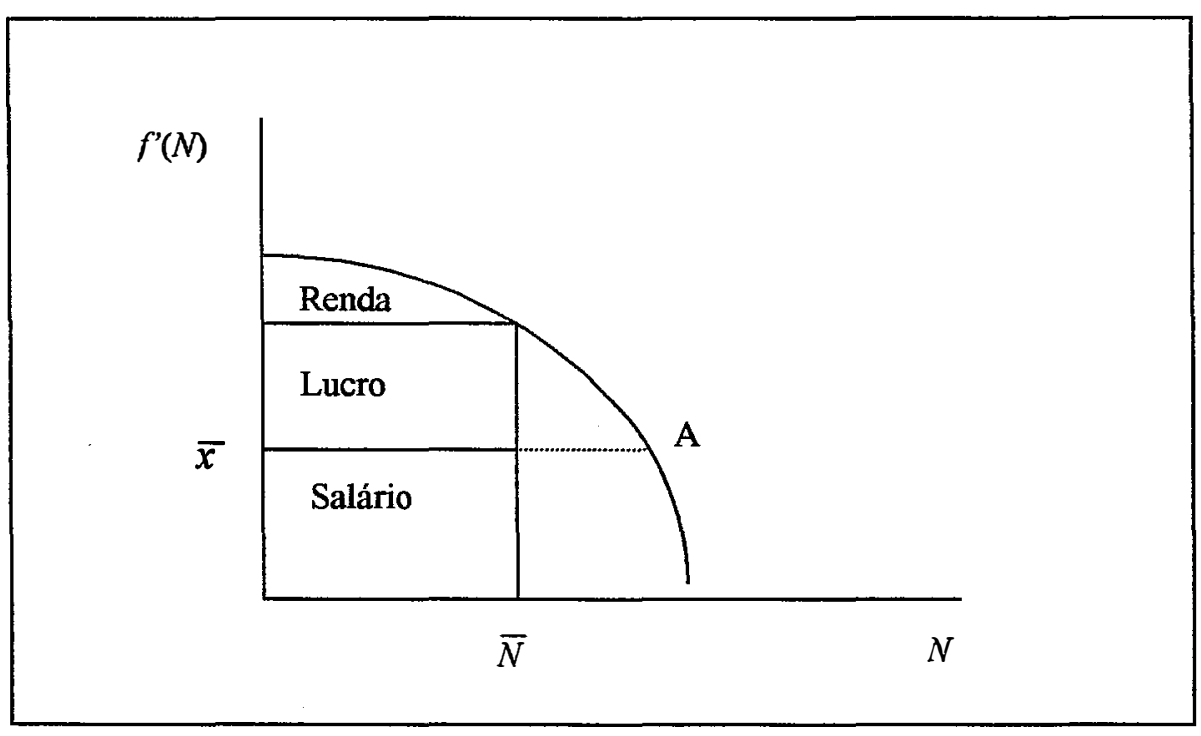

Figura 2.3 Distribuição de renda no sistema ricardiano, em termos do produto marginal.

Fonte: Pasinetti (1977).

Para Ricardo, os salários fazem parte dos "meios de produção". Assim, o excedente ou o produto líquido do sistema econômico é dividido entre lucro e renda da terra. Se todo o lucro e a renda são consumidos o sistema se reproduz a cada período, no mesmo nível. Contudo, se os lucros são acumulados, transformados em capital circulante, o sistema entra em um processo dinâmico de reprodução. Neste caso, podem ocorrer duas situações. Se com o aumento de capital o fundo de salários aumenta e, consequentemente, o salário, a população aumentará. Com isto, novas terras menos férteis serão cultivadas para suprir o aumento da demanda por alimentos. $\mathrm{O}$ nível de atividade irá se expandir até o ponto onde existam lucros para serem acumulados. Se, por outro lado, o salário mantiver-se fixo e a expansão do nível de produção levar ao cultivo de lotes menos férteis, o lucro irá, paulatinamente, se reduzir. Este modelo tende a um 
estado estacionário em que a taxa de lucro é zero e tudo que é produzido é dividido entre salário e renda (ponto A da figura 2.3). ${ }^{10}$

\subsection{Os marginalistas}

A categoria renda da terra foi tratada com destaque pelos economistas clássicos, atingindo maior relevância no trabalho de David Ricardo. Não obstante, com o advento da economia política neoclássica a renda da terra deixa de ter uma especificidade no estudo da economia, transformando-se em um simples pagamento ao fator terra, juntamente com as remunerações aos outros fatores de produção, trabalho e capital (Sechaczewski \& Serra, 1980 e Flichman, 1977).

Jonh Bates Clark é considerado o fundador da teoria da produtividade marginal (Blaug, 1990). ${ }^{11}$ Desenvolveu sua teoria considerando uma economia em estado estacionário, com concorrência perfeita, informação perfeita e mobilidade perfeita de fatores. Mas, embora Clark tenha dito que cada fator de produção recebe uma renda igual ao valor de seu produto marginal, foram escritores posteriores que provaram rigorosamente esta sua afirmação (Hunt, 1987). ${ }^{12}$

Wicksteed, no seu livro Essay on the coordination of the laws of distribution, de 1894, descobriu o teorema do esgotamento do produto, que mostra que se cada fator fosse remunerado de acordo com o seu produto marginal o produto total seria esgotado integralmente. Contudo, segundo Blaug (1990), foi Flux quem fez uma demonstração

\footnotetext{
${ }^{10}$ No entanto, Ricardo acreditava que a acumulação cessaria antes mesmo que a taxa de lucro chegasse ao seu nível mínimo. Segundo Pasinetti (1977), esta teoria de acumulação de capital, embora simples ou rudimentar, é a mais pessimista da história.

${ }^{11}$ O principal trabalho de Clark foi o livro Theory of Distribution of Wealth de 1899.

${ }^{12}$ A teoria da produtividade marginal foi constnuída no período de 1871 a 1936 , por vários autores e em vários países: Menger (1840-1921) e Böhm-Bawerk (1851-1914) na Austria; Jevons (1835-1882), Edgeworth (1845-1926), Wicksteed e Marshall (1842-1942) na Inglaterra; Pantaleoni (1857-1924), Pareto (1848-1923) e Barone (1859-1924) na Itália; Clark (1847-1938) e Inving Fisher (1867-1947) nos Estados Unidos; Wicksell (1851-1926) e Cassel (1866-1945) na Suécia. Entre os mais importantes destacam-se: Wicksteed, Marshall, Wicksell e Clark (ver Quadrio-Curzio (1987), Blaug (1990) e Pasinetti (1877)).
} 
formal desse teorema, relacionando-o com o Teorema de Euler sobre as funções homogêneas. Flux considerou uma função de produção linearmente homogênea e, portanto, rendimentos constantes à escala.

Uma outra contribuição importante foi a de Wicksell (no livro Value, Capital and Rent de 1893), com sua análise da teoria da renda da terra Ricardiana (Pasinetti, 1977). Ricardo analisou dois tipos de renda da terra, a extensiva, que surge quando terras menos férteis passam a ser cultivadas, e a intensiva, que resulta de aplicações crescentes de capital e trabalho na mesma terra. Mas, apenas a renda intensiva é relevante para a análise marginalista, uma vez que a renda extensiva não supõe, necessariamente, uma mudança na proporção dos fatores, fundamental no cálculo do produto marginal.

Quadrio-Curzio (1987) salienta que a teoria da produtividade marginal pode ser considerada como uma consequência da teoria Ricardiana da renda intensiva e dos retornos intensivos decrescentes.

Diferentemente de Wicksteed, que acreditava que o teorema do esgotamento do produto era sempre válido, Wicksell foi o primeiro a compreender que este teorema só era válido em condições de equilíbrio, para o ponto de tangência de uma função de produção com uma função de produção linearmente homogênea (Blaug, 1990).

Segundo Marshal (1982, p.239), a renda da terra “... não é um fato singular, mas simplesmente a espécie principal de um vasto gênero de fenômenos econômicos, e ... a teoria da renda da terra não constitui uma doutrina econômica isolada, mas apenas uma das principais aplicações de um corolário particular da teoria geral da procura e da oferta". ${ }^{13}$

A seguir vamos fazer uma síntese da teoria da produtividade marginal. ${ }^{14}$

Consideremos $y=f\left(x_{1}, x_{2}\right)$ uma função de produção de uma firma, $d_{i}$ o pagamento ao fator $x_{i}$ e $p$ o preço do produto da firma. ${ }^{15}$ Como regra temos que, a remuneração de um fator de produção é igual ao valor de seu produto marginal, ou seja

\footnotetext{
${ }^{13}$ Os Principios de Economia de Marshall foi editado pela primeira vez em 1890.

${ }^{14}$ Esta formalização da teoria da produtividade marginal está baseada em Silberberg (1978).
} 


$$
p P M_{i}=p f_{i}=d_{i}
$$

onde, $f_{i}=\partial f / \partial x_{i}$. Contudo, esta análise é parcial, isto é, cada fator está sendo analisado independentemente.

Se o pagamento de cada fator $x_{i}$ é dado por $d_{i}=p f_{i}$, então, o pagamento total deste fator é $d_{i} x_{i}=p f_{i} x_{i}$. Assim, o total de pagamentos dos dois fatores de produção é

$$
p f_{1} x_{1}+p f_{2} x_{2}=p\left(f_{1} x_{1}+f_{2} x_{2}\right)
$$

Mas, pelo teorema de Euler, se a função de produção for homogênea de grau um temos $^{16}$

$$
f_{1} x_{1}+f_{2} x_{2} \equiv y=f\left(x_{1}, x_{2}\right)
$$

Das eqs. (2.9) e (2.10), obtemos

$$
d_{1} x_{1}+d_{2} x_{2}=p f_{1} x_{1}+p f_{2} x_{2}=p\left(f_{1} x_{1}+f_{2} x_{2}\right)=p y
$$

ou, o custo total é igual à receita total e o produto da firma é totalmente exaurido com o pagamento de todos os fatores de produção.

Marshall (1982) definiu um outro tipo de remuneração denominado quase-renda, que aparece no curto prazo como consequência de desajustes entre a oferta e a demanda, ligados a situações de escassez na oferta de fatores de produção. Contudo, no longo prazo esta remuneração tende a desaparecer devido à eliminação destes desajustes através do mercado.

\subsection{Karl Marx}

O primeiro estudo realizado por Marx (1818-1883) sobre a teoria da renda da terra encontra-se no volume II das "Teorias da mais-valia", escrito de 1861 a $1863 .{ }^{17}$ No

\footnotetext{
${ }^{15}$ Podemos, por exemplo, considerar $y=f\left(x_{1}, x_{2}\right)$ como a função de produção de uma propriedade agrícola e $x_{1}$ a terra e, consequentemente, $d_{1}$ a renda da terra.

${ }^{16}$ Ver Silberberg (1978) ou Chiang (1982).
} 
livro III de $O$ capital, uma publicação póstuma em 1894, realizada por Frederic Engels, encontra-se a versão final e mais elaborada do autor sobre o tema.

Marx (1985, p. 723) também tratou a renda da terra com destaque, afirmando que “... é mister estudar a moderna forma da propriedade fundiária, por ser nosso propósito sobretudo examinar as relações específicas de produção e de circulação, oriundas da aplicação do capital na agricultura. Sem isso seria incompleta a análise do capital."

A renda fundiária aparece como a forma em que se realiza economicamente a propriedade fundiária. $\mathrm{O}$ arrendatário paga uma quantia ao proprietário pelo aluguel do solo.

Para este autor toda renda fundiária é mais-valia, produto excedente, uma sobra acima do lucro. Assim, para se compreender a renda fundiária, forma particular e específica da mais-valia, deve-se recorrer não só às condições gerais da criação da maisvalia, como também às condições individuais da agricultura e que fazem com que, do seu montante, uma parte se separe em forma de renda da terra (Lenz, 1981).

Marx analisa dois tipos de renda fundiária: a renda diferencial, formada pela renda diferencial I e II, e a renda absoluta.

Quando Marx (1985, p.734) inicia o estudo da renda diferencial, estabelece a seguinte hipótese: os produtos que pagam renda são vendidos aos preços de produção, como as demais mercadorias. “ ... Assim, os preços de venda são iguais aos elementos do custo (o valor do capital consumido, constante e variável), acrescidos de um lucro determinado pela taxa geral de lucro, incidente sobre o capital global adiantado, consumido ou não."

A renda fundiária advém do lucro suplementar, originário do monopólio de uma força natural que não é disponível a todos. Segundo Marx $(1985$, p.736) “.... esse lucro suplementar é igual à diferença entre o preço individual de produção desses produtores favorecidos e o preço geral, social de produção, regulador do mercado de todo o ramo

${ }^{17}$ Marx, K. Teorias da mais-valia: história crítica do pensamento econômico: São Paulo, DIFEL, 1980 1985. 
de produção. Essa diferença é igual ao que sobra, subtraindo-se do preço geral de produção da mercadoria, o preço individual de produção."

A renda fundiária apresenta-se como renda diferencial $I$, “... quando duas quantidades iguais de capital e trabalho se aplicam em extensões de terras iguais, com resultados desiguais.” (Marx, 1985, p. 744)

Para Marx existem algum fatores que interferem na igualdade ou desigualdade dos solos, além da fertilidade e localização: 1) distribuição dos impostos, 2) desenvolvimento diverso da agricultura e 3) desigualdade na repartição do capital entre os arrendatários.

Marx (1985, p.771) inicia o capítulo sobre a renda diferencial II fazendo o seguinte questionamento: "Qual a diferença se quantidades de capital de produtividade diversa se aplicarem sucessivamente no mesmo terreno, em vez de serem empregadas paralelamente em terrenos diferentes, supostos invariáveis os resultados ?"

De acordo com Marx (1985, p.775), a renda diferencial I é a base para a renda diferencial II. Esta acrescenta às diferenças de fertilidade “... as desigualdades na maneira como se reparte entre os arrendatários o capital (e a capacidade de crédito)." Com isto, a renda diferencial II supõe a I, configurando-se como uma outra expressão desta.

Para Bryan (1990) a teoria da renda diferencial de Marx difere da teoria de Ricardo em dois aspectos fundamentais. Primeiro, foram desenvolvidas em termos de diferentes teorias do valor e, segundo, diferentes noções de margens. Para Fine (1979), no tratamento da margem intensiva, no caso da renda diferencial II, Marx trabalha com incrementos de capital de tamanho normal ou médio e, na renda intensiva, Ricardo utiliza incrementos infinitesimais.

No entanto, tanto Fine (1979) como Bryan (1990) enfatizam que as rendas diferenciais I e II, de Marx, e as rendas extensiva e intensiva, de Ricardo, podem ser consideradas, respectivamente, como categorias equivalentes de análise.

Uma outra diferença na abordagem de Ricardo e Marx é que este não admite que haja terras cultivadas sem renda, argumentando que não haveria motivos que justificariam o proprietário ceder a terra gratuitamente ao arrendatário. Para Marx isto seria uma atitude filantrópica. Assim introduziu o conceito de renda absoluta. 
A renda absoluta da terra teria origem no próprio movimento do modo de produção capitalista, considerando a economia como um todo, abrangendo todos os setores. “...Vejamos em que consiste a essência da renda absoluta. Para igual taxa de mais-valia ou para exploração igual do trabalho, capitais de igual magnitude produzem em diversos ramos, de acordo com as diferenças na composição média, quantidades diferentes de mais-valia. Na indústria, essas quantidades diversas de mais-valia se igualam no nível do lucro médio e se repartem uniformemente pelos capitais individuais como se fossem partes alíquotas do capital social. A propriedade fundiária impede que assim se nivelem os capitais empregados na terra e se apodera de parte da mais-valia que de outro modo entraria nesse nivelamento que dá a taxa geral de lucro; é o que se dá quando a produção precisa de terra, seja para a agricultura, seja para a indústria extrativa. A renda representa então parte do valor, mais particularmente da mais-valia das mercadorias, a qual em vez de caber à classe capitalista que a tirou dos trabalhadores, pertence aos proprietários que a extraíram dos capitalistas. Aqui estamos supondo que o capital agrícola mobiliza mais trabalho que o capital não-agrícola, desde que sejam iguais as respectivas magnitudes. O grau ou a existência mesmo dessa discrepância depende do desenvolvimento relativo da agricultura em confronto com a indústria. Pela natureza das coisas, essa discrepância decresce necessariamente com o progresso da agricultura, a não ser que a proporção com que a parte variável diminui, comparada com a constante, seja ainda maior para o capital industrial que para o agrícola." (Marx, 1985, p.886)

Assim, segundo Silva (1987), para que exista a renda absoluta, Marx supõe que o valor dos produtos agrícolas é superior a seu preço de produção. Está implícita nesta suposição que a composição orgânica do capital agrícola é inferior à média da agricultura e indústria. Contudo, com o desenvolvimento do capitalismo, haveria uma diminuição nas discrepâncias entre as composições orgânicas da agricultura e da indústria, levando, paulatinamente, ao desaparecimento da renda absoluta. 


\section{MODELOS SRAFFIANOS}

\subsection{Introdução}

Segundo Garegnani (1977), a abordagem sraffiana da teoria da distribuição e do valor segue a estrutura da teoria clássica (ou teoria do excedente), que tem como núcleo o seguinte conjunto de dados exógenos: ${ }^{18}$

(i) o tamanho e a composição do produto (ou produto social);

(ii) o salário real, ou seja, as quantidades fisicas das mercadorias que compõem a cesta de bens consumida pelos trabalhadores, e

(iii) o conjunto de técnicas disponíveis.

No entanto, como ressalta Garegnani (1977), no caso do sistema econômico sraffiano o salário real [item (ii)] pode ser considerado como uma variável endógena no sistema, e a taxa de lucro aparecer como um dado ou variável exógena. O sistema econômico sraffiano-marxista possui como ponto de partida o mesmo conjunto de dados exógenos acima.

A existência deste conjunto de dados permite a determinação da taxa de lucro (ou salário, no caso do sistema econômico sraffiano) e dos preços relativos. No sistema econômico sraffiano-marxista pode-se determinar os valores-trabalho e a taxa de maisvalia. Com isto, é possível investigar as relações entre as variáveis independentes e dependentes do sistema. Para Garegnani (1977), a existência do excedente (igual ao produto total menos o consumo necessário) como uma grandeza de caráter residual têm

\footnotetext{
${ }^{18}$ Garegnani (1977) subdivide em duas categorias as abordagens da teoria da distribuição e do valor: a dominante, da oferta e da procura, e a teoria do excedente.
} 
como base lógica a noção de que o salário real (ou taxa de lucro) e o nível do produto podem ser determinadas antes mesmo da própria magnitude do excedente. Na determinação destas variáveis exógenas entram em jogo forças institucionais e políticas.

Conforme Garegnani (1977), o tratamento do salário como um dado exógeno e sua determinação separada deve-se à idéia de um salário definido pela subsistência e por forças econômico-sociais, encontrada em Quesnay, Smith, Ricardo e Marx.

Por fim, a justificativa para o tratamento separado da determinação do produto social e de sua divisão encontra-se nos elementos básicos das análises de Quesnay, Smith, Malthus, Ricardo e Marx. Para Garegnani (1977), em geral, existem dois elementos que explicam o volume do produto social: “( $i)$ o estágio alcançado pela acumulação de capital, que governa o número de trabalhadores produtivos empregados; (ii) as condições técnicas da produção que regulam o produto fisico que pode ser obtido dos trabalhadores empregados (e são também consideradas como dependentes do estágio de acumulação alcançado)."

Cabe ainda salientar, conforme notado por Garegnani (1977), que o tratamento deste núcleo como variáveis exógenas não implica a negação das influências entre estas mesmas variáveis, e entre estas e as variáveis endógenas do sistema.

\subsection{Modelos sraffianos com produção $\operatorname{simples~}^{19}$}

Examinaremos neste item o modelo sraffiano e o modelo sraffiano-marxista com produção simples, ou seja, cada indústria produz uma única mercadoria. São feitas, as seguintes suposições: (i) a economia se encontra em estado estacionário, ou seja, a cada ano produz-se a mesma quantidade fisica de cada mercadoria; (ii) existe produção simples; (iii) todos os meios de produção necessários para a produção de cada mercadoria são consumidos durante o período de produção e devem ser inteiramente repostos, ou seja, todo capital é capital circulante; (iv) todas as técnicas apresentam o

\footnotetext{
${ }^{19}$ Este item foi escrito utilizando basicamente Passinetti (1977) e Hoffmann (1983 e 1995).
} 
mesmo período de produção; (v) todo excedente é distribuído na forma de salários e lucros e (vi) a força de trabalho é homogênea. ${ }^{20}$

\subsubsection{Modelo sraffiano}

Seja $\mathbf{Q}$ a matriz dos fluxos fisicos intersetoriais, onde cada elemento $q_{i j}$ representa a quantidade da mercadoria $i$ que entra na produção da mercadoria $j$ e seja $\mathbf{q}$ o vetorcoluna com as $\boldsymbol{n}$ produções totais $\left(q_{j}, \operatorname{com} \boldsymbol{j}=1, \ldots, n\right)$. Obtemos a matriz $\mathbf{A}$ de coeficientes técnicos de produção normalizando cada coluna da matriz $\mathbf{Q}$ pela correspondente quantidade produzida da mercadoria $j, q_{j}$. Seja $\mathbf{b}$ o vetor-linha dos coeficientes de trabalho, onde o elemento genérico $b_{j}$ representa a mão-de-obra, em horas de trabalho, utilizada para produzir cada unidade da mercadoria $j$.

Para que a economia possa reproduzir-se é necessário que a quantidade gasta de cada insumo, na matriz insumo-produto, não seja superior à quantidade produzida da mesma mercadoria. Por outro lado, para que exista um excedente, ou produto líquido, é necessário que a quantidade gasta, para pelo menos uma mercadoria, seja estritamente inferior à sua quantidade produzida. Podemos sintetizar isto por

$$
\begin{array}{ll} 
& \mathbf{q} \geq \mathbf{A q} \\
\text { ou, } & \mathbf{q}-\mathbf{A q} \geq \mathbf{0} \\
\text { ou, ainda, } & (\mathbf{I}-\mathbf{A}) \mathbf{q} \geq \mathbf{0}
\end{array}
$$

Por outro lado, é excluída a possibilidade de utilização de quantidades negativas de insumos e de trabalho, de maneira que

$$
\mathbf{A} \geq 0, \mathrm{e} \quad \mathbf{b} \geq 0
$$

E por fim, é claro que q é estritamente positivo:

\footnotetext{
${ }^{20}$ Para Garegnani (1977) a suposição de um salário uniforme é uma consequência de que, em todas as indústrias, os salários sejam formados por uma mesma "mercadoria salário composta" à qual pode ser atribuído um mesmo preço resultante dos preços das mercadorias que a compõe.
} 


$$
\mathbf{q}>0
$$

Seja $\mathbf{p}^{*}$ o vetor-linha de preços de produção e $r^{*}$ a taxa de lucro uniforme máxima no sistema, supondo que os trabalhadores não participam do excedente. ${ }^{21}$ Então, podemos escrever

$$
\begin{aligned}
& \mathbf{p}^{* \mathbf{A}}\left(1+r^{*}\right)=\mathbf{p}^{*} \\
& \mathbf{p}^{* \mathbf{A}}=\frac{1}{1+r^{*}} \mathbf{p}^{*}
\end{aligned}
$$

Assim, $\frac{1}{1+r^{*}}$ é uma raiz característica de $\mathbf{A}$ e $\mathbf{p}^{*}$ é o vetor característico correspondente. Supondo A irredutível, de acordo com os teoremas de Perron-Frobenius, $\mathbf{p}^{*}$ é estritamente positivo. ${ }^{22 ;}$ Além disso, $\frac{1}{1+r^{*}}$ é o autovalor máximo de A, indicado por $\lambda_{m}$.

Vamos considerar, a seguir, de acordo com Sraffa (1985), que os salários são pagos no final do período de produção, abandonando a idéia dos autores clássicos de um salário adiantado do capital, e que participam do excedente, ou seja, $0<r<r^{*}$. Assim, o vetor de preços de produção pode ser indicado através do seguinte sistema

$$
\mathbf{p A}(1+r)+\mathbf{b} w=\mathbf{p}
$$

ou, $\quad \mathbf{p}=\mathbf{b}[\mathbf{I}-(1+r) \mathbf{A}]^{-1} w$

ou, ainda, $\quad \mathbf{p}=\frac{1}{1+r} \mathbf{b}\left[\frac{1}{1+r} \mathbf{I}-\mathbf{A}\right]^{-1} w$

\footnotetext{
${ }^{21}$ A utilização do termo preços de produção segue uma sugestão de Sraffa (1985).

${ }^{22}$ Sobre os teoremas de Peron-Frobenius ver Pasinetti (1977).

${ }^{23}$ Sraffa (1985) denomina de básica uma mercadoria que entra na produção de todas mercadorias, direta ou indiretamente. Caso contrário a mercadoria é denominada não-básica. A matriz A é dita irredutível quando todas equações referentes às mercadorias não-básicas foram separadas previamente do sistema, sendo consideradas apenas as equações referentes às mercadorias básicas.
} 
onde $w$ é o salário uniforme pago em unidades monetárias. Este sistema possui $n$ equações e $n+2$ incógnitas: $n$ preços, $w$ e $r$. Fixando uma das mercadorias como numerário, resta, ainda, um grau de liberdade no sistema. Sraffa (1985) opta por completar o sistema escolhendo uma das variáveis distributivas, salário ou taxa de lucro, como variável exógena.

$$
\text { Como } r<r^{*} \text { segue que } \frac{1}{1+r}>\frac{}{1+r^{*}} \text { e, consequentemente, }
$$

$\left[\frac{1}{1+r} \mathbf{I}-\mathbf{A}\right]^{-1}>0$, concluindo-se que o vetor de preços de produção é estritamente positivo.

Sraffa (1985) retoma a discussão de Ricardo (1982) sobre uma medida invariável de valor, separando em dois o problema que Ricardo buscava resolver. ${ }^{24}$ Ricardo tentou estabelecer uma medida que, ao mesmo tempo, fosse invariável para mudanças tanto na tecnologia de produção como na distribuição de renda. Sraffa abandonou a primeira exigência e solucionou o problema para uma medida que fosse invariável para mudanças na distribuição, dada uma tecnologia. Sraffa constrói um sistema artificial formado por frações das indústrias do sistema original, de maneira que nesse sistema hipotético o vetor das quantidades produzidas seja proporcional ao vetor das quantidades de insumos. Esse sistema econômico artificial é denominado sistema padrão.

Considere uma matriz diagonal $\mathbf{D}$ com as quantidades totais das mercadorias produzidas no sistema econômico e um vetor-coluna $\eta$ com $n$ elementos representando a fração de cada indústria que irá compor o sistema padrão. $O$ vetor das quantidades produzidas desse sistema é $\mathbf{q}^{*}=\mathbf{D} \eta$ e o vetor de insumos é Aq*. Por fim, indicando por $1+R$ a relação entre a produção e os insumos, tem-se:

$$
\mathbf{A q}^{*}(1+R)=\mathbf{q}^{*}
$$

ou, $\quad \mathbf{A q}^{*}=\frac{1}{1+R} \mathbf{q}^{*}$

\footnotetext{
${ }^{24}$ Ver Roncaglia (1978), Possas (1983) e Tolipan (1990).
} 
Agregando a este sistema mais uma equação com a quantidade de trabalho utilizada, representada por $\mathbf{b D} \eta$, o sistema fica com $n+1$ equações e $n+1$ incógnitas ( $n$ coeficientes de $\eta$ e $R$ ). Neste caso, o vetor de quantidades produzidas $\mathbf{q}^{*}$ é um autovetor correspondente ao autovalor máximo de $\mathbf{A}, \frac{1}{1+R}$.

Se A é irredutível, a única solução aceitável é $\lambda_{m}=\frac{1}{1+R}=\frac{1}{1+r^{*}}$, garantindo $\mathbf{q}^{*}$ estritamente positivo. A condição de viabilidade deste sistema é que $R \geq 0$, e, consequentemente, $\lambda_{m} \leq 1$.

$\mathrm{O}$ vetor com o produto líquido do sistema padrão é dado por $\mathbf{y}^{*}=(\mathbf{I}-\mathbf{A}) \mathbf{q}^{*}$. Considerando o sistema (3.6), temos que $\mathbf{A} \mathbf{q}^{*}=\lambda_{m} \mathbf{q}^{*}$. Substituindo esse resultado na expressão do vetor de produto líquido obtemos a mercadoria padrão, como segue

$$
\mathbf{y}^{*}=\left(1-\lambda_{m}\right) \mathbf{q}^{*}=\left(1-\frac{1}{1+R}\right) \mathbf{q}^{*}=\frac{R}{1+R} \mathbf{q}^{*}
$$

Podemos, ainda, estabelecer uma relação linear entre salário e taxa de lucro, utilizando um numerário tal que a quantidade de trabalho empregada no sistema padrão $\left(\mathbf{b q}^{*}=T\right)$ seja numericamente igual ao valor monetário do produto líquido desse sistema $(\mathbf{p y} *)$. Então

$$
\mathbf{b q}^{*}=\mathbf{p y}^{*}=\left(1-\lambda_{m}\right) \mathbf{p q}^{*}
$$

Pós-multiplicando o sistema (3.5) pelo vetor das quantidades $\mathbf{q}^{*}$, segue que:

$$
\mathbf{p A q} *(1+r)+\mathbf{b q}^{*} w=\mathbf{p q} *
$$

Fazendo as substituições necessárias e lembrando que $\lambda_{m}=\frac{1}{1+R}$, podemos obter $^{25}$

$$
r=R(1-w)
$$

${ }^{25} \mathbf{A q}^{*}$ e bq ${ }^{*}$ por $\lambda_{m} \mathbf{q}^{*}$ e $\left(1-\lambda_{m}\right) \mathbf{p q}{ }^{*}$, respectivamente. 
A equação (3.10) relaciona inversamente a taxa de lucro ao salário. Esta relação ficou conhecida como a fronteira de distribuição de Sraffa (Possas, 1985).

\subsubsection{Modelo sraffiano-marxista}

Diferente de Sraffa, Marx (1985) considera que o salário é adiantado pelos capitalistas no início do período de produção, como uma parte do capital. Assim, segundo Médio (1973), a taxa de lucro se aplica também ao valor dos salários. ${ }^{26}$

Seja d um vetor-coluna com as quantidades físicas da cesta de bens que constitui o salário real de subsistência por trabalhador. Os preços de produção são dados pelo seguinte sistema de equações:

$$
(\mathbf{p A}+\mathbf{b} w)(1+r)=\mathbf{p}
$$

Mas,

$$
w=\mathbf{p d}
$$

Então,

$$
\begin{aligned}
& (\mathbf{p A}+\mathbf{p d b})(1+r)=\mathbf{p} \\
& \mathbf{p}\left[\frac{1}{1+r} \mathbf{I}-(\mathbf{A}+\mathbf{d b})\right]=\mathbf{0}
\end{aligned}
$$

Como o salário real é estabelecido previamente, este sistema permite a determinação da taxa de lucro e dos preços relativos.

Antes de prosseguir vamos mostrar que os preços de produção na eq. (3.13) são estritamente positivos. Na eq. (3.13') observamos que $\frac{1}{1+r}$ é o autovalor da matriz.

\footnotetext{
${ }^{26}$ Este trabalho de Médio foi pioneiro na tentativa de aplicar a abordagem sraffiana ao problema da transformação. Em um trabalho anterior de Morishima e Seton já existia alguma contribuição no sentido de incorporar as idéias da transformação de valores em preços em uma análise de insumo-produto, sem, contudo, utilizar idéias srafffianas. Ver Morishima, M. \& Seton, F. "Agregation in Leontief matrices and the labor theory of value", Econometrica, v. 29, p.203-20, 1961.
} 
$(\mathbf{A}+\mathbf{d b})$, também semipositiva e irredutível. $\mathrm{O}$ vetor de preços de produção é o respectivo autovetor à esquerda, estritamente positivo. Além disso, $\frac{1}{1+r}$ deve ser o autovalor máximo de $(\mathbf{A}+\mathbf{d b})$.

A condição para o sistema de equações (3.13') ter outras soluções além da trivial é que

$$
\left|\frac{1}{1+r} \mathbf{I}-(\mathbf{A}+\mathbf{d b})\right|=0
$$

Vamos, agora, introduzir o sistema de valores-trabalho. Definindo $\mathbf{v}$ como o vetor-linha dos valores-trabalho por unidade de cada mercadoria, temos,

$$
\begin{array}{ll} 
& \mathbf{v A}+\mathbf{b}=\mathbf{v} \\
\text { ou, } & \mathbf{v}(\mathbf{I}-\mathbf{A})=\mathbf{b} \\
\text { ou, ainda } & \mathbf{v}=\mathbf{b}(\mathbf{I}-\mathbf{A})^{-1}
\end{array}
$$

O trabalho direto total empregado neste sistema é bq. Por outro lado, o valortrabalho do produto nacional líquido é $\mathbf{v}(\mathbf{I}-\mathbf{A}) \mathbf{q}$, e lembrando a eq. (3.15'), temos

$$
\mathbf{v}(\mathbf{I}-\mathbf{A}) \mathbf{q}=\mathbf{b q}
$$

ou seja, o total de trabalho direto empregado é igual ao valor-trabalho do produto líquido nacional.

O valor da força de trabalho por unidade de tempo é dado por

$$
\omega=\mathbf{v d}
$$

Para Marx, o trabalhador recebia apenas uma parcela do resultado do uso de sua força de trabalho, ou seja, existia um excedente, o que ocorre se $\omega<1$.

Então, da eq. (3.17) podemos rescrever (3.15) como

$$
\mathbf{v A}+\omega \mathbf{b}+(1-\omega) \mathbf{b}=\mathbf{v}
$$

Define-se a taxa de mais-valia como 


$$
\sigma=\frac{1-\omega}{\omega}
$$

Segue que,

$$
\omega \sigma=1-\omega
$$

Substituindo $1-\omega$, eq. (3.19'), e o valor da força de trabalho total, eq. (3.17), na eq. (3.18) obtemos o sistema de valores ${ }^{27}$

$$
\begin{array}{ll} 
& \mathbf{v A}+\mathbf{v d b}+\sigma \mathbf{v d b}=\mathbf{v} \\
\text { ou, } & (1+\sigma) \mathbf{v d b}=\mathbf{v}(\mathbf{I}-\mathbf{A}) \\
\text { ou, ainda, } \quad & \mathbf{v d b}(\mathbf{I}-\mathbf{A})^{-1}=\frac{1}{1+\sigma} \mathbf{v}
\end{array}
$$

Como d e b são vetores, a característica da matriz db é um e segue-se que a característica da matriz $\mathbf{d b}(\mathbf{I}-\mathbf{A})^{-1}$ também é um. Consequentemente, temos que $\frac{1}{1+\sigma}$ é o único autovalor da matriz $\mathbf{d b}(\mathbf{I}-\mathbf{A})^{-1}$ diferente de zero.

No caso do sistema de equações (3.20’), a condição para a existência de outras soluções, além da trivial, é que

$$
\left|\frac{1}{1+\sigma} \mathbf{I}-\left(\frac{1}{1+\sigma} \mathbf{A}+\mathbf{d b}\right)\right|=0
$$

Uma vez que

\footnotetext{
${ }^{27}$ Pós-multiplicando (3.20) pelo vetor-coluna das quantidades produzidas no sistema econômico, $\mathbf{q}$, temos
} $\mathbf{v A q}+\mathbf{v d b q}+\sigma \mathbf{v d b q}=\mathbf{v q}$ ou $($ capital constante total $)+($ capital variável total $)+($ total de mais-valia $)=($ valor total $)$ 


$$
\frac{1}{1+\sigma} \mathbf{A}<\mathbf{A}
$$

comparando as equações (3.14) e (3.21) concluímos que

$$
\frac{1}{1+\sigma}<\frac{1}{1+r}
$$

ou,

$$
\sigma>r
$$

Um caso particular ocorre quando $\sigma=0$ e consequentemente $r=0$. A proposição que diz que "a taxa de lucro é positiva se, e somente se, a taxa de mais-valia for positiva" corresponde ao teorema fundamental Marxista. ${ }^{28}$

Vamos obter agora uma expressão que mostra a transformação de valores (v) em preços de produção $(\mathbf{p})$.

Primeiramente, consideremos o salário completo, $\mathbf{p d}(1+\sigma)$, como numerário, e substituímos o mesmo em (3.13'). Em seguida, pós-multiplicando a equação resultante por $(\mathbf{I}-\mathbf{A})^{-1}$ e lembrando (3.15"), obtemos

$$
\mathbf{p}=\frac{1+r}{1+\sigma} \mathbf{v}\left[\mathbf{I}-r \mathbf{A}(\mathbf{I}-\mathbf{A})^{-1}\right]^{-1}
$$

Esta expressão mostra a transformação de valores em preços de produção.

\subsection{Técnicas alternativas}

Quando uma mercadoria é produzida por mais de uma técnica ou método de produção, falamos em processos ou técnicas alternativas. A análise deste assunto nos modelos sraffianos pode ser realizada, como veremos a seguir, como uma extensão do modelo com produção simples. Por outro lado, a incorporação deste tema nos modelos marxistas ocorreu juntamente com a discussão do capital fixo e dos produtos conjuntos.

\footnotetext{
${ }^{28}$ Para Morishima (1973), este teorema pode ser considerado como o coração e alma da filosofia marxista, pois considera que a exploração é necessária para a continuidade e existência da economia capitalista, pois ela não pode sobreviver se a taxa de lucro de equilíbrio não for positiva.
} 
Os produtos conjuntos são aqueles que não podem ser produzidos separadamente. Na teoria econômica, o interesse pelos produtos conjuntos decorre principalmente da necessidade de analisar o capital fixo. Como salienta Sraffa (1985, p. 229): "O interesse dos produtos conjuntos situa-se não tanto nos conhecidos exemplos da lã e da carne de ovelha ou do trigo e da palha, como em ser o gênero do qual o capital fixo é a espécie mais destacada." O capital fixo pode ser tratado como uma mercadoria que é simultaneamente um insumo e um produto de uma indústria.

\subsubsection{Modelos sraffianos}

No último capítulo de seu livro, Sraffa retoma o modelo com produção simples e retira o pressuposto de existência de apenas uma técnica disponível para a produção de cada mercadoria, incorporando, desse modo, a possibilidade de ocorrência de técnicas alternativas em um mesmo setor. O conjunto de todos as técnicas alternativas conhecidas em um dado momento no tempo é definido como a tecnologia do sistema econômico (Pasinetti, 1977).

O critério de escolha da técnica adotado por Sraffa (1985) foi o da minimização dos custos de produção. Segundo Pasinetti (1977) este critério é automaticamente imposto sobre os produtores que operam em um sistema competitivo maximizando os lucros. Como afirma Sraffa (1985, p. 243), quando analisa duas técnicas alternativas para a produção de uma mercadoria: "A qualquer nível da taxa geral de lucro, o método que produz a um preço mais baixo é, naturalmente, o mais lucrativo dos dois para um produtor que constrói uma nova instalação."

Este critério depende não apenas das condições técnicas de produção, mas, também, da distribuição de renda entre salários e lucros. Além disso, apenas uma técnica pode ser utilizada e, portanto, observada de cada vez (Pasinetti, 1977). ${ }^{29}$

\footnotetext{
${ }^{29} \mathrm{Com}$ exceção, como veremos, para os pontos de mudança de técnica, em que pode ocorrer uma combinação entre as técnicas que produzem um mesmo produto. Isto ocorre porque neste ponto os preços determinados por cada técnica são iguais.
} 
A questão da escolha da técnica será primeiro tratada através de um caso mais simples, em que se admite processos alternativos apenas para uma mercadoria não-básica. Posteriormente será considerado o caso em que apenas uma mercadoria básica possui processos alternativos, e, por fim, será feita uma generalização, para o caso em que podem ocorrer processos alternativos para as mercadorias básicas e não-básicas do sistema.

\subsubsection{A escolha da técnica para uma mercadoria não-básica}

A escolha da técnica de uma mercadora não-básica pode ser feita de maneira simples, considerando apenas a indústria correspondente, em contraste com o caso mais geral que será analisado mais adiante.

Vamos considerar o problema da existência de técnicas alternativas para uma mercadoria não-básica, indicada por $i=g$. Supõe-se, para simplificar, que para a produção desta mercadoria não seja utilizada nenhuma mercadoria não-básica. As mercadorias básicas deste sistema são indicadas por $i=1, \ldots, n-1$. Existe uma única técnica de produção para cada mercadoria básica, enquanto que para a produção da mercadoria não-básica existe um conjunto de técnicas alternativas, totalizando $n_{g}$ técnicas. Incorporando técnicas alternativas no sistema econômico sraffiano, eq. (3.5), a tecnologia do sistema pode ser representada por:

$$
\mathbf{p A}_{j}(1+r)+\mathbf{b}_{j} w=\mathbf{p}
$$

onde $j=1, \ldots, n_{g}$ indica a técnica utilizada na produção da mercadoria $g$.

Como a mercadoria $g$ é não-básica e todos os seus meios de produção são básicos, o vetor de preços de produção das mercadorias básicas será determinado, dada uma das variáveis distributivas, por exemplo a taxa de lucro, independentemente da técnica escolhida para produzir a mercadoria $g$.

Vamos supor que $r$ é a taxa de lucro uniforme, $w$ o salário uniforme em termos de uma mercadoria básica, $\mathbf{a}_{j} \mathrm{o}$ vetor de coeficientes técnicos da mercadoria não-básica, $b_{j}$ a quantidade de trabalho gasta na produção de uma unidade da mercadoria $g$ com a técnica 
$j$ e $p$ o preço de produção da mercadoria não-básica. Então, é possível obter o custo de produção para cada técnica alternativa de produção da mercadoria $g$, ou seja:

$$
\mathbf{p a}_{j}(1+r)+b_{j} w=p_{j}
$$

onde $j=1, \ldots, n_{g}$. Observa-se que todas as variáveis do lado esquerdo já estão dadas, ou seja, $\mathbf{p}$ e $w$ já foram determinadas no resto do sistema de preços. Assim, dada a taxa de lucro, o problema da escolha da técnica para a mercadoria $g$ é reduzido à simples comparação entre os $n_{g}$ preços $\left(p_{j}\right)$ na indústria $g$, e à escolha da técnica com o mínimo custo, $p_{k}$. Assim, temos

$$
p_{k} \leq p_{j}
$$

$\operatorname{com} j=1, \ldots, k, \ldots, n_{g}$. Com isto, a escolha da técnica é uma função da taxa de lucro.

Vamos supor um exemplo com três técnicas alternativas, indicadas por $\alpha, \beta$ e $\gamma$, em que a taxa de lucro varia entre 0 e $R$. As curvas mostrando a variação dos três preços correspondentes às três técnicas alternativos estão traçadas na figura 3.1.

A escolha entre as técnicas depende do nível da taxa de lucro. O método $\gamma$ é obsoleto em toda a faixa de variação economicamente significativa da taxa de lucro. Quando $r$ está entre 0 e $r_{1}$, temos que $p_{\alpha}<p_{\beta}$, consequentemente a técnica de mínimo custo é a $\alpha$. Por outro lado, para $r$ entre $r_{1}$ e $r_{2}$ a técnica $\beta$ torna-se a de mínimo custo, $\operatorname{com} p_{\beta}<p_{\alpha}$. Por fim, quando $r$ está entre $r_{2}$ e $R$ a técnica $\alpha$ volta a ser a mais lucrativa e $p_{\alpha}<p_{\beta}$. Nos pontos de interseção entre as duas técnicas $\alpha$ e $\beta, r_{1}$ e $r_{2}$, temos que $p_{\alpha}=p_{\beta}$. Neste caso ambas as técnicas são igualmente lucrativas, podendo ou coexistir lado a lado, através de uma combinação entre as duas técnicas, ou ser utilizada apenas uma delas, isoladamente. 


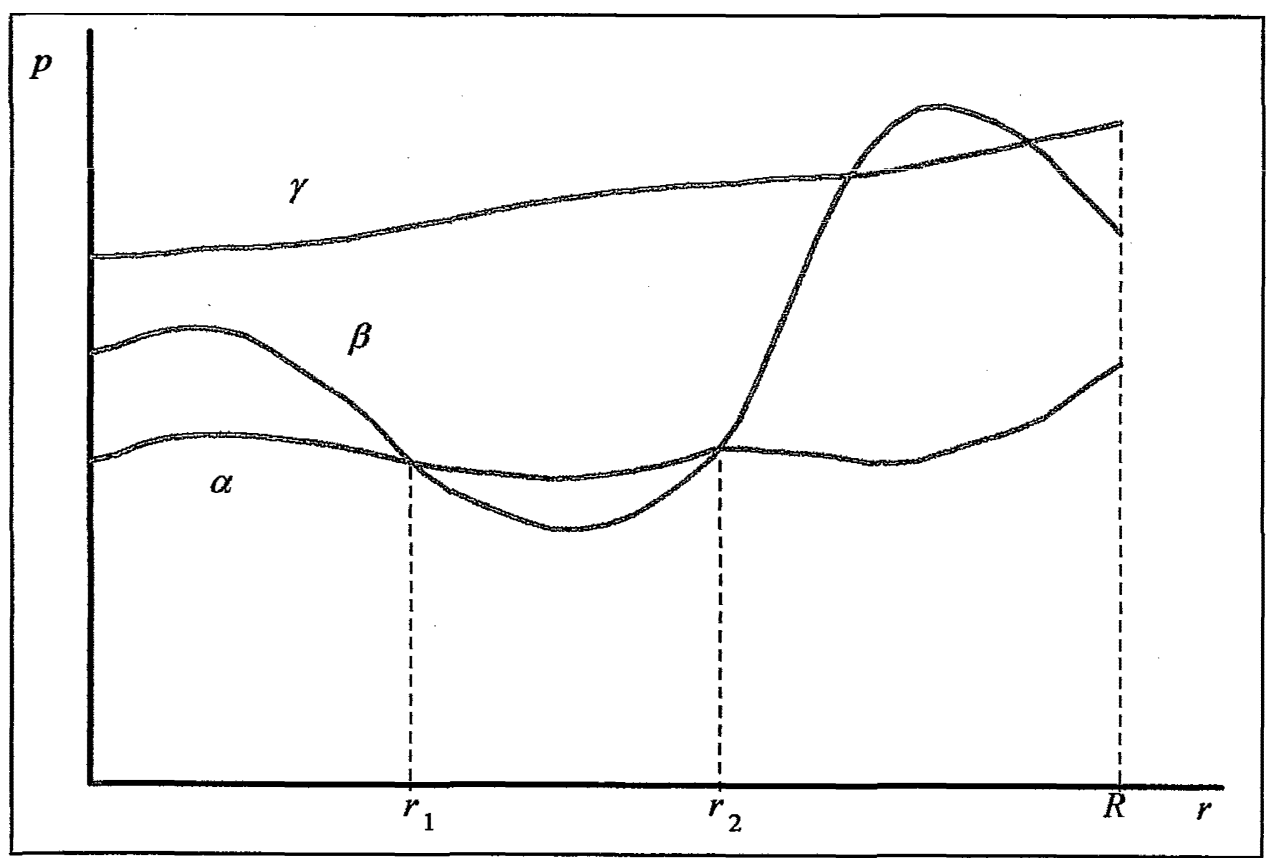

Figura 3.1 A escolha da técnica para uma mercadoria não-básica

Uma mudança no numerário utilizado altera apenas a forma das curvas na figura 3.1, mas não muda a ordem de comparação dos preços (Pasinetti, 1977 e Wood, 1990).

\subsubsection{A escolha da técnica para uma mercadoria básica}

O caso da escolha da técnica para uma mercadoria básica é mais complexo e envolve o sistema como um todo para determinar o salário e os preços relativos, dada a taxa de lucro. Vamos supor que em determinado momento uma técnica $\varepsilon$ esteja sendo utilizada para produzir a mercadoria $f$. Seja $f$ uma mercadoria básica com um total de $n_{f}$ técnicas alternativas. Podemos, então, rescrever a tecnologia para este sistema, partindo da eq. (3.5), como:

$$
\mathbf{p A}_{j}(1+r)+\mathbf{b}_{j} w=\mathbf{p}
$$

onde $j=1, \ldots, n_{f}$. Neste caso, a mudança para uma técnica alternativa não pode ser avaliada considerando apenas a mudança no preço da mercadoria $f, p_{\varepsilon}$, como no caso anterior. Uma alteração da técnica de produção da mercadoria $f$ provoca uma mudança 
no seu preço de produção. Mas, $f$ é uma mercadoria básica, que interfere direta ou indiretamente no custo de produção das demais mercadorias do sistema. Esta mudança nos preços levará à uma nova mudança no preço da mercadoria $f$, que provocará uma segunda mudança em todos os preços. Segundo Pasinetti (1977), este processo é infinito mas convergente, levando a um novo sistema de preços. Assim, a solução para o problema da escolha da técnica só pode ser obtida com referência ao sistema econômico como um todo.

Voltando à eq. (3.29), podemos obter $\boldsymbol{n}_{f}$ diferentes sistemas econômicos, cada qual com uma técnica diferente para a produção da mercadoria $f$.

Escolhendo uma mercadoria qualquer como numerário, exceto a mercadoria $f$, e dada a taxa de lucro, podemos obter o salário em termos da mercadoria numerário, para cada técnica alternativa. Assim, chegamos a $n_{f}$ relações entre o salário, em termos da mercadoria numerário, e a taxa de lucro, que são comparáveis.

Vamos supor, para simplificar, que existem quatro técnicas alternativas para a produção da mercadoria $f$, indicadas por $\alpha, \beta, \gamma$ e $\varepsilon$. Observando a eq. (3.29), podemos, então, obter quatro subsistemas, dos quais obtêm-se quatro relações entre $w$ e $r$, que podem ser representadas pela figura 3.2. Deve-se notar que nestes subsistemas as matrizes $\mathbf{A}_{\alpha}, \mathbf{A}_{\beta}, \mathbf{A}_{\gamma}$ e $\mathbf{A}_{\varepsilon}$ são idênticas, exceto pela coluna referente à mercadoria $f$, que é diferente em cada uma das quatro matrizes. $\mathrm{O}$ mesmo ocorre para os vetores $\mathbf{b}_{\alpha}, \mathbf{b}_{\beta}, \mathbf{b}_{\gamma} \mathbf{e}$ $\mathbf{b}_{\varepsilon}$, os quais diferem apenas no componente referente à mercadoria $f$.

Neste caso, o critério de mínimo custo leva à escolha da técnica que, para uma dada taxa de lucro, possui o maior salário, ou, para um dado salário, possui a maior taxa de lucro (Pasinetti, 1977). Dizendo de outra forma, dada uma taxa de lucro, a técnica que minimiza o custo será aquela que suporta o maior salário (Wood, 1990). Ou, ainda, este critério implica em uma minimização de custos em cada indústria, e obtenção de uma maior taxa de lucro, para um dado salário, no sistema como um todo. 


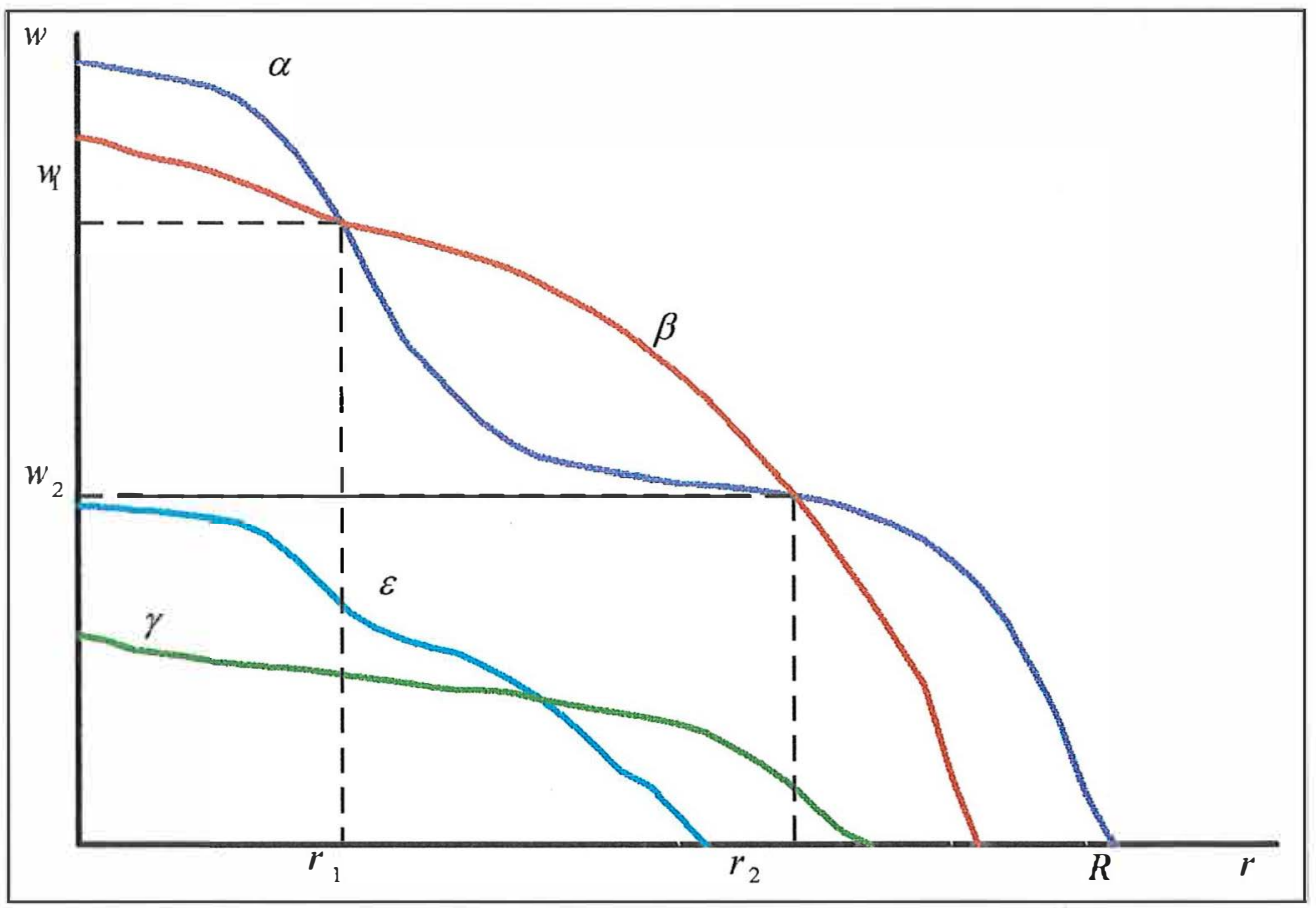

Figura 3.2 A escolha de técnicas de produção para uma mercadoria básica

Voltando ao exemplo da figura 3.2, as técnicas $\gamma$ e $\varepsilon$ são claramente obsoletas, uma vez que, para qualquer taxa de lucro, fornecem um salário menor que as outras duas técnicas. Verifica-se que quando $r$ está entre 0 e $r_{1}$ e entre $r_{2}$ e $R$ a técnica $\alpha$ é a adotada, enquanto que, para $r_{1}<r<r_{2}$ a técnica $\beta$ passa a ser a de mínimo custo. Nos pontos de mudança de técnica, tanto uma das técnicas $\alpha$ ou $\beta$, isoladamente, quanto uma combinação das mesmas, são igualmente lucrativas.

Considerando todas as possíveis escolhas de técnicas no intervalo de variação da taxa de lucro, $0<r<R$, as curvas $w$-r mais externas formam uma curva envolvente. Pasinetti (1977) denomina esta curva de fronteira tecnológica de possibilidades de distribuição de renda entre lucros e salários, fronteira tecnológica de possibilidade de distribuição de renda, ou, simplesmente, fronteira tecnológica. Pode-se obter quatro propriedades desta curva: 
(i) em um ponto de mudança entre duas técnicas quaisquer, $\alpha$ e $\beta$, a técnica $\alpha$ ou a técnica $\beta$ (ou uma combinação linear das mesmas) produzirá o mesmo vetor de preços de produção, $\mathbf{p}_{\alpha}=\mathbf{p}_{\beta}$.

(ii) se, para uma dada taxa de lucro, uma técnica é mais lucrativa, então os preços, dado o salário, serão estritamente menores que os produzidos por outra técnica.

(iii) uma alteração do numerário no sistema de preços provocará apenas mudanças na forma das curvas $w$ - $r$, mas os pontos de mudança ocorrerão para os mesmos valores da taxa de lucro, não alterando a ordem das várias técnicas.

(iv) a fronteira tecnológica é estritamente decrescente para valores crescentes da taxa de lucro.

\subsubsection{A escolha da técnica em geral}

Consideremos, agora, que tanto as mercadorias básicas quanto as mercadorias não-básicas possam ter técnicas alternativas de produção. Supondo que existam $n$ mercadorias no sistema econômico, o conjunto de todas as técnicas deste sistema pode ser representado por

$$
\mathbf{p A}_{j}(1+r)+\mathbf{b}_{j} w=\mathbf{p}
$$

onde $j=1, \ldots, N^{30}$

Escolhendo como numerário do sistema uma mercadoria comum a todas as técnicas alternativas, é possível fazer a comparação destas técnicas através da fronteira tecnológica. Em geral, apenas a técnica de produção de uma mercadoria muda entre curvas $w-r$ adjacentes, mesmo no caso especial em que mais de duas curvas se interceptam exatamente no mesmo ponto, produzindo o mesmo vetor de preços de produção, como ilustra a figura 3.3. Segundo Pasinetti (1977), neste caso especial podese ordenar as técnicas de produção, de maneira que a mudança é feita entre curvas

\footnotetext{
${ }^{30}$ Considerando um sistema com $n$ mercadorias, e que a primeira mercadoria tenha $n_{1}$ processos, a segunda mercadoria $n_{2}, \ldots$, a $n$-ésima mercadoria $n_{n}$; então existe um número máximo de $N=n_{1} \times n_{2} \times$ $\ldots \times n_{n}$ possiveis processos ou técnicas.
} 


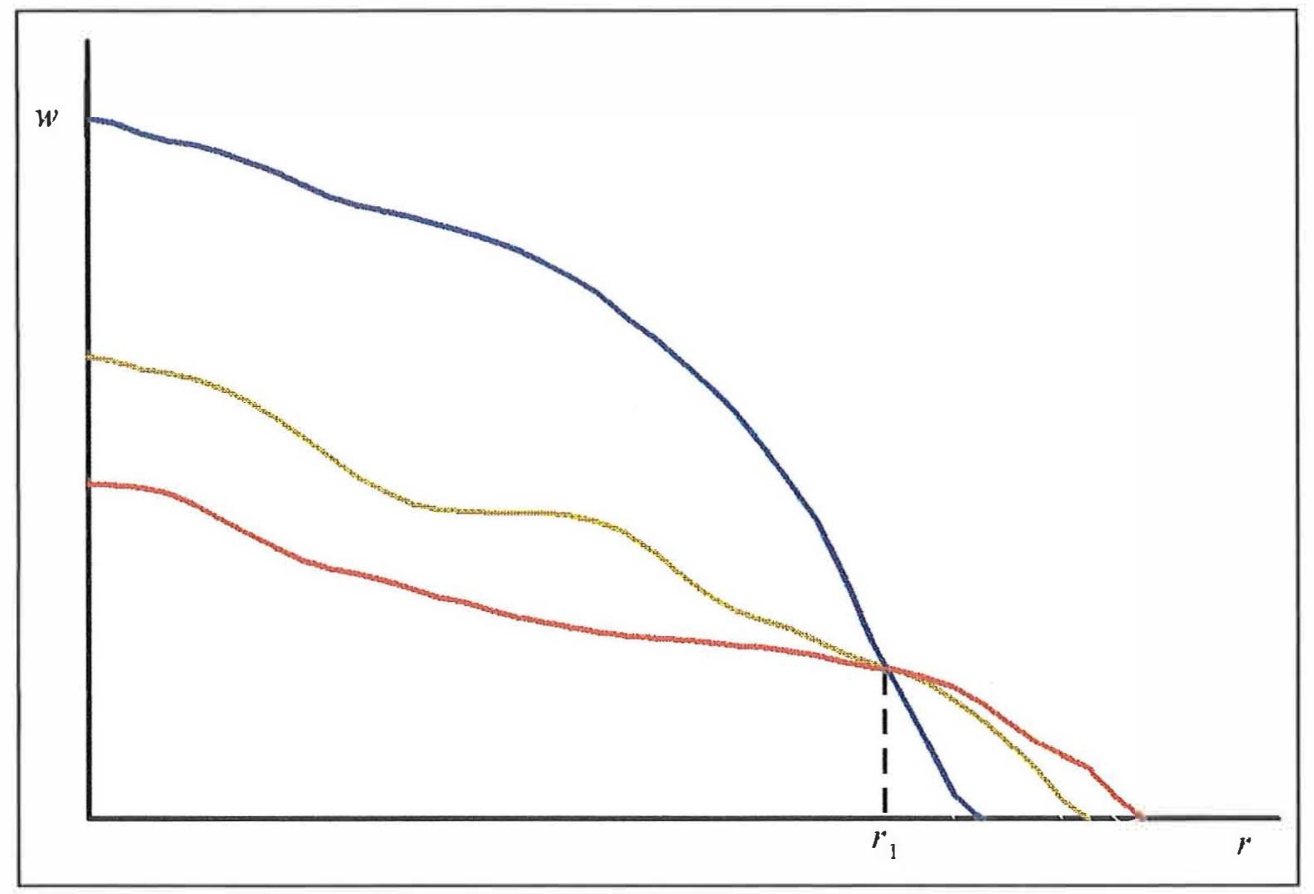

Figura 3.3 Caso especial em que três técnicas se interceptam em um mesmo valor da taxa de lucro.

adjacentes. Assim, como foi visto na seção 3.3.1.2, a comparação pode ser feita entre matrizes e vetores, respectivamente, com apenas uma coluna e um elemento diferente. Consequentemente, as quatro proposições descritas no item anterior se mantêm para o caso mais geral.

\subsubsection{A reversão de técnicas}

O fenômeno da reversão de técnicas decorre do simples fato que as curvas $w-r$ correspondentes às técnicas alternativas podem se interceptar mais que uma vez. Considerando um sistema econômico com $k$ mercadorias básicas, as relações entre $w$ e $r$ constituem-se de equações polinomiais de grau $k$. Analisando, separadamente, duas destas relações, elas podem se interceptarem $k$ vezes. Assim, depois que uma determinada técnica tenha sido descartada há a possibilidade da mesma retornar à fronteira tecnológica quando a taxa de lucro aumentar. 
Podemos discutir este tema utilizando a figura 3.2. Para simplificar, vamos supor que a economia está em um estado estacionário. O produto líquido por trabalhador para cada técnica $(\alpha, \beta, \gamma$ e $\varepsilon)$, considerando $r=0$, pode ser interpretado como sendo o intercepto no eixo vertical. Assim, quando $r=r_{1}$, a diferença entre o intercepto e $w_{1}$ para as técnicas $\alpha$ e $\beta$, pode ser interpretado como o lucro por trabalhador. Então, segundo Pasinetti (1977), a técnica $\alpha$, que possui o maior lucro por trabalhador, deve possuir o maior capital por trabalhador. Nos pontos de mudança de técnica, $r=r_{1}$ e $r=r_{2}$, a taxa de lucro é igual nas técnicas $\alpha$ e $\beta$. No ponto $r=r_{1}$, um aumento da taxa de lucro, está ligado à substituição da técnica $\alpha$ por uma técnica com um menor montante de capital por trabalhador (com menor produto líquido por trabalhador). Por outro lado, no ponto $r=r_{2}$, um aumento da taxa de lucro corresponde à substituição da técnica $\beta$ por uma técnica com maior montante de capital (com maior produto líquido por trabalhador).

Para a teoria econômica este resultado é relevante, uma vez que contraria o que se espera de sua função de produção neoclássica, ou seja, que exista uma relação monotônica entre a taxa de lucro e a quantidade de capital por trabalhador e entre a taxa de lucro e o produto líquido por trabalhador.

Este fenômeno constituiu-se em um dos temas discutidos durante as Controvérsias de Cambridge, e teve origem em um artigo de Samuelson de 1962. ${ }^{31}$

\subsubsection{Modelos marxistas}

Tendo em vista a importância do capital fixo no sistema capitalista, a teoria do valor-trabalho tornou-se mais geral, buscando incorporar este tema.

Morishima (1973 e 1974) propôs a teoria do valor ótimo, que representou uma formulação alternativa à teoria do valor efetivo, este determinado em um sistema de equações simultâneas. Os valores ótimos correspondem aos preços sombra determinados

\footnotetext{
${ }^{31}$ Samuelson, P. A. Parable and realism in capital theory: the surrogate production function. Review of economic studies, v. 39 p. 193-206, 1962. Reproduzido em Harcourt e Laing (1971). Alguns dos resultados deste artigo foram questionados originalmente em um artigo de Pasinetti de 1965 e em outro de Garegnani de 1966, realizados independentemente.
} 
em um problema de programação linear de minimização que é dual de outro problema de programação linear de maximização, em que os valores ótimos $\left(\mathbf{v}_{o}\right)$ são as variáveis de escolha.

Vamos supor que o trabalho seja homogêneo e vamos indicar as matrizes de coeficientes técnicos e de produções totais, respectivamente, por A e B. No item 3.2 estas matrizes foram consideradas como sendo quadradas e a matriz $\mathbf{B}$ como uma matriz identidade. A $i$-ésima coluna de $\mathbf{A}$ é formada pelos insumos utilizados na produção do conjunto de produtos da $i$-ésima coluna de $\mathbf{B}$, utilizando determinada técnica. Assim, com a análise de produtos conjuntos e técnicas alternativas podemos obter matrizes $\mathbf{A}$ e $\mathbf{B}$ retangulares.

Seja $\mathbf{y}_{\boldsymbol{w}}$ a cesta de mercadorias ou a parcela do produto líquido, em unidades fisicas, consumida por todos os trabalhadores do sistema econômico. $\mathrm{O}$ trabalho necessário é definido como o tempo de trabalho mínimo, em horas, utilizado para produzir $\mathbf{y}_{w}$. A mais-valia é a diferença entre o tempo total de trabalho empregado e o trabalho necessário.

O trabalho necessário, $v_{w}$, é obtido resolvendo o seguinte problema de programação linear:

Minimizar

$$
v_{w}=\mathbf{b q}
$$

com

$$
\begin{array}{rl}
\mathbf{B q} & \geq \mathbf{A q}+\mathbf{y}_{w} \quad \text { ou } \quad(\mathbf{B}-\mathbf{A}) \mathbf{q} \geq \mathbf{y}_{w} \\
\mathbf{e} & \mathbf{q} \geq \mathbf{0}
\end{array}
$$

A última restrição implica que a solução possui significado econômico. Considerando $v_{w}^{\prime}$, a solução do problema anterior, então, a taxa de mais-valia é dada pela razão entre o trabalho excedente e o trabalho necessário:

$$
\sigma=\frac{T N-v^{\prime}{ }_{w}}{v^{\prime}{ }_{w}}
$$


onde $T$ é o total de horas trabalhadas por cada trabalhador e $N$ é o total de trabalhadores, de maneira que $T N$ é o total de horas trabalhadas por todos os trabalhadores no sistema.

O dual do problema de programação linear anterior é dado por:

Maximizar

$$
\mathbf{v}_{o} \mathbf{y}_{w}
$$

com

$$
\begin{aligned}
\mathbf{v}_{o} \mathbf{B} & \leq \mathbf{v}_{o} \mathbf{A}+\mathbf{b} \text { ou } \quad \mathbf{v}_{o}(\mathbf{B}-\mathbf{A}) \mathbf{q} \geq \mathbf{b} \\
\mathrm{e} & \mathbf{v}_{o} \geq \mathbf{0}
\end{aligned}
$$

Supondo que bq' é a solução do problema de minimização, e $\mathbf{v}^{\prime}{ }_{o} \mathbf{y}_{w}$ é a solução do problema de maximização, então, pelo teorema da dualidade ${ }^{32}$

$$
\mathbf{b q}^{\prime}=\mathbf{v}_{o}^{\prime} \mathbf{y}_{w}
$$

Por fim, Morishima (1973) faz uma extensão do teorema marxista fundamental para o caso em que há produtos conjuntos e técnicas alternativas, denominando-o de Teorema Marxista Fundamental Generalizado (TMFG).

No artigo Positive profits with negative surplus value, de 1975, Steedman formula um exemplo numérico em termos dos valores efetivos, em que verifica que na presença de produção conjunta e técnicas alternativas podem coexistir uma taxa de maisvalia negativa com uma taxa de lucro positiva. Consequentemente, em seu modelo, a possibilidade de produção conjunta refuta o TMFG.

Considerando o exemplo numérico de Steedman (1975) com duas mercadorias, produção conjunta e a presença de duas técnicas alternativas, temos as seguintes equações

$$
\begin{aligned}
& (1+r) 25 p_{1}+5 w=30 p_{1}+5 p_{2} \\
& (1+r) 10 p_{2}+w=3 p_{1}+12 p_{2}
\end{aligned}
$$

\footnotetext{
${ }^{32}$ Sobre o teorema da dualidade ver Ravindran et al. (1987).
} 


$$
3 p_{1}+5 p_{2}=6 w
$$

A eq. (3.41) diz que o salário real para 6 unidades de trabalho contém 3 unidades da mercadoria um e 5 unidades da mercadoria dois. Tomando a mercadoria dois como numerário e resolvendo este sistema obtemos $p=\frac{p_{1}}{p_{2}}=\frac{1}{3}$, uma taxa de lucro positiva $(r=0,2)$ e um salário $w=1$. Este sistema é economicamente viável, uma vez que tanto os preços quanto os lucros são positivos.

Em contraste, em termos formais o sistema de valores fica,

$$
\mathbf{v A}+\mathbf{b}=\mathbf{v B}
$$

onde A e B são matrizes quadradas. No caso do exemplo numérico acima, temos

$$
\mathbf{A}=\left[\begin{array}{cc}
25 & 0 \\
0 & 10
\end{array}\right]
$$

e

$$
\mathbf{B}=\left[\begin{array}{cc}
30 & 3 \\
5 & 12
\end{array}\right]
$$

Obtendo-se

$$
\begin{aligned}
& 25 v_{1}+5=30 v_{1}+5 v_{2} \\
& 10 v_{2}+1=3 v_{1}+12 v_{2}
\end{aligned}
$$

Resolvendo, obtemos $v_{1}=-1$ e $v_{2}=2$. Retirando do produto líquido total do sistema, composto por 8 unidades da mercadoria um e 7 unidades da mercadoria dois, as unidades das duas mercadorias que compõem o salário real referente às 6 unidades de trabalho, restam, respectivamente, 5 e 2 unidades.

Então,

$$
M=5 v_{1}+2 v_{2}=-1
$$

O valor-trabalho do consumo dos trabalhadores, ou capital variável, seria 


$$
\begin{aligned}
& 3(-1)+(5) \cdot(2)=7 \\
& \text { e } \quad \sigma=-\frac{1}{7}
\end{aligned}
$$

Portanto, a mais-valia total $(M)$ e a taxa de mais-valia $(\sigma)$ são ambas negativas. Então, segundo Steedman (1975), em modelos em termos de valores efetivos com produção conjunta e técnicas alternativas podemos ter uma taxa de lucro positiva ao lado de uma taxa de mais-valia negativa.

Em um comentário ao artigo de Steedman (1975), Morishima (1976) propõe uma maneira de calcular os valores-trabalho, denominados valores verdadeiros, utilizando programação linear. Seja y o vetor-coluna com o produto líquido do sistema, com componentes $y_{i}, i=1, \ldots, n$ e $\mathbf{A}$ e $\mathbf{B}$ matrizes retangulares. Considerando $\mathbf{y}$ uma mercadoria composta, o seu valor verdadeiro $\left(v_{y}\right)$ é calculado como segue:

$$
v_{y}=\mathbf{b q}
$$

onde q minimiza bq, sujeito a

$$
\begin{aligned}
\mathbf{B q} & \geq \mathbf{A q}+\mathbf{y} \text { ou }(\mathbf{B}-\mathbf{A}) \mathbf{q} \geq \mathbf{y} \\
\mathbf{q} \geq \mathbf{0} &
\end{aligned}
$$

Como Morishima (1976) salienta, a definição do valor verdadeiro está relacionada com os valores ótimos, uma vez que os valores ótimos são as variáveis de escolha do problema dual, associado ao problema acima. Assim,

$$
\mathbf{v}_{o} \mathbf{y}
$$

onde $\mathbf{v}_{o}$ maximiza $\mathbf{v}_{o} \mathbf{y}$, sujeito a

$$
\begin{aligned}
\mathbf{v}_{o} \mathbf{B} & \leq \mathbf{v}_{o} \mathbf{A}+\mathbf{b} \quad \text { ou } \quad \mathbf{v}_{o}(\mathbf{B}-\mathbf{A}) \geq \mathbf{b} \\
\mathbf{v}_{o} & \geq \mathbf{0}
\end{aligned}
$$


Assim, também neste caso, os valores ótimos do problema de maximização correspondem aos preços sombra do problema de minimização.

Considerando o exemplo numérico utilizado por Steedman (1975), o valor verdadeiro do produto líquido $\mathbf{y}^{\prime}=\left[\begin{array}{l}8 \\ 8\end{array}\right]$ é

$$
v_{y}=5 q_{1}+q_{2}
$$

onde $q_{1}$ e $q_{2}$ minimizam $v_{y}$ sujeitos a

$$
\begin{aligned}
& 5 q_{1}+3 q_{2} \geq 8 \\
& 5 q_{1}+2 q_{2} \geq 7 \\
& q_{1} \geq 0 \text { e } q_{2} \geq 0
\end{aligned}
$$

Com isto, obtém-se que a quantidade total de trabalho que é necessária para produzir um produto líquido com 8 unidades da mercadoria um e 7 unidades da mercadoria dois, é minimizada para $q_{1}=0$ e $q_{2}=3,5$. $O$ valor verdadeiro da mercadoria composta é 3,5 unidades de trabalho.

O tempo de trabalho necessário é agora definido como a quantidade mínima de tempo de trabalho que os trabalhadores devem trabalhar para produzir uma cesta de produto líquido que é pelo menos tão grande quanto os meios de subsistência, isto é, a quantidade da $j$-ésima mercadoria produzida como um produto líquido é igual ou maior que a quantidade da j-ésima mercadoria contida na cesta de mercadorias que representa o salário real.

Assumindo, como Steedman, que o salário real corresponde a 3 unidades da mercadoria um e 5 unidades da mercadoria dois para cada 6 unidades de trabalho, Morishima calcula o valor do trabalho necessário $\left(v_{w}\right)$ resolvendo o seguinte problema de minimização.

$$
v_{w}=5 q_{1}+q_{2}
$$

onde $q_{1}$ e $q_{2}$, minimizam $v_{w}$ sujeitos a

$$
5 q_{1}+3 q_{2} \geq 3
$$




$$
\begin{aligned}
& 5 q_{1}+2 q_{2} \geq 5 \\
& q_{1} \geq 0 \text { e } q_{2} \geq 0
\end{aligned}
$$

Como resultado, o trabalho necessário foi calculado em 2,5 unidades de trabalho. Daí a taxa de mais-valia é

$$
\sigma=\frac{T N-v_{w}}{v_{w}}=\frac{6-2,5}{2,5}=1,4
$$

Assim, temos uma taxa de mais-valia de $140 \%$, que corresponde a uma taxa de lucro de $20 \%$. Consequentemente, segundo Morishima (1976), a presença de produção conjunta e técnicas alternativas não provoca nenhuma contradição no TMFG.

Em geral, a principal crítica ao trabalho de Steedman (1975) é que este não respeita a definição marxista de valor como tempo de trabalho, que não pode ser negativo. Portanto, seu método de valoração não possui nenhum significado (Morishima, 1976; Swanson, 1986 e Gontijo, 1994).

Por outro lado, a principal crítica aos trabalhos de Morishima refere-se à utilização do conceito de valor mínimo, ao invés de tempo de trabalho socialmente necessário, ou "trabalho médio" presente em O Capital (Steedman, 1976 e Gontijo 1994). Salienta-se que Morishima foi buscar esta definição em $A$ miséria da filosofia, onde Marx afirma: “(iii) é importante enfatizar que o que determina o valor não é o tempo levado para produzir um objeto, mas o tempo mínimo no qual ele possivelmente seria produzido e esse mínimo é determinado pela concorrência." (Marx citado por Morishima \& Catephores, 1980).

Os valores efetivos de Steedman são aditivos mas podem ser negativos. Por outro lado, os valores verdadeiros de Morishima são positivos mas não são aditivos. Segundo Steedman (1976, p.607) em sua réplica ao comentário de Morishima: “...both Morishima and I suggest that marxist economists should abandon actual, additive values and that we 
both accept the GFMT, with its "true" values, as one sensible way of formulantig such an abandonment. $" 33$

Rankin (1988) propôs a inclusão de restrições de capacidade ao método de Morishima. Estas restrições, no caso do exemplo do Steedman (1975), referem-se à quantidade máxima de tempo de trabalho que os trabalhadores dispõem, na tecnologia existente, para produzir a parte do produto líquido que compõe a cesta de mercadorias dos trabalhadores. Rescrevendo o problema de minimização descrito nas eqs. (3.60) a (3.63), temos

$$
v_{w}=5 q_{1}+q_{2}
$$

onde $q_{1}$ e $q_{2}$ minimizam $v_{w}$ sujeito a

$$
\begin{aligned}
& 5 q_{1}+3 q_{2} \geq 3 \\
& 5 q_{1}+2 q_{2} \geq 5 \\
& q_{1} \leq 5 \\
& q_{2} \leq 1 \\
& q_{1} \geq 0 \text { e } q_{2} \geq 0
\end{aligned}
$$

Segundo Rankin (1988) as eqs. (3.68) e (3.69) representam restrições de capacidade que asseguram que o problema está limitado à estrutura disponível de meios de produção, ou seja, 5 unidades de trabalho no processo um e 1 unidade no processo dois.

As quantidades produzidas, $q_{1}$ e $q_{2}$, que minimizam este problema, são 0,6 e 1 , respectivamente. Com isto, o valor do trabalho necessário $\left(v_{w}\right)$ é igual a 4 unidades de trabalho. Consequentemente, a mais-valia passa a ser

$$
M=6-4=2
$$

\footnotetext{
${ }^{33} \mathrm{O}$ termo GFMT refere-se à Generalised Fundamental Marxian Theorem.
} 
e a taxa de mais-valia

$$
\sigma=\frac{M}{v_{w}}=0,5
$$

Dessa maneira, obtém-se um resultado diferente do encontrado por Morishima $(1,4)$, em que obteve $q_{2}$ igual a 2,5 , ver eq. (3.64), sendo que só havia disponibilidade de 1 unidade de tempo de trabalho no processo 2 . Contudo, uma crítica que pode ser feita à este artigo é que se o trabalho é homogêneo, então, pode fluir de um processo para outro, pois estamos considerando apenas uma indústria.

Assim, o método proposto por Morishima é empregado na análise do sistema de valores, gerando resultados com significado econômico, inclusive no caso de um sistema com o setor agrícola, que será analisado no próximo capítulo. 


\section{MODELOS SRAFFIANOS COM O SETOR AGRÍCOLA}

\subsection{Introdução: sistemas econômicos sraffianos}

A utilização da terra como insumo em um sistema econômico foi analisada por Sraffa em um capítulo de seu conciso livro, considerando dois tipos de renda, a extensiva e a intensiva. Nas palavras de Sraffa (1985, p.238): “Enquanto o caso das terras de qualidades diferentes será facilmente reconhecido como o resultado de um processo de rendimentos decrescentes 'extensivos', pode ser menos óbvio que existe uma conexão similar entre o emprego de dois métodos de produzir cereal na terra de uma só qualidade e um processo de rendimentos decrescentes 'intensivos' ".

Assim, a renda da terra extensiva é obtida quando consideram-se diferentes qualidades de terra, e a renda da terra intensiva aparece quando métodos ou técnicas de produção estão sendo utilizados em uma terra de qualidade homogênea.

Este trabalho gerou críticas às teorias da renda da terra anteriores. A principal refere-se à constatação de que a determinação da renda da terra e dos preços das mercadorias está condicionada à distribuição do excedente econômico entre lucros e salários, dada a demanda por cereal. Consequentemente, as ordens de eficiência e rentabilidade das terras podem ser modificadas com as variáveis distributivas $(w$ e $r) .^{35}$ Pode-se acrescentar que a definição da terra marginal, bem como da escassez de uma

\footnotetext{
${ }^{35}$ Seguindo Quadrio-Curzio (1980), optamos por utilizar o termo eficiência, e não fertilidade, que possui uma conotação ligada às características naturais do solo. Assim, tomando a taxa de lucro como um dado exógeno, o método mais eficiente corresponderá àquele com um maior salário, ou o contrário, dado o valor do salário, o método mais eficiente é aquele que proporciona a maior taxa de lucro. Além disso, a ordem de rentabilidade da terra é definida de acordo com o valor da renda paga pela sua utilização.
} 
única qualidade de terra, também estão condicionadas à distribuição de renda (Kurz, 1980).

Após a publicação do livro de Sraffa vários autores passaram a estudar e desenvolver sua teoria sobre a renda da terra, nos dois casos por ele analisados. ${ }^{36}$ Segundo Salvadori (1986), estes casos podem ser caracterizados pelo seguinte conjunto de suposições:

(i) a demanda final é definida como um dado vetor de produto líquido;

(ii) existe uma mercadoria que utiliza em sua produção a terra como insumo, como por exemplo, o cereal;

(iii) existe um processo de produção para cada mercadoria diferente do cereal;

(iv1) existe um processo de produção do cereal para cada qualidade de terra (renda extensiva); e

(iv2) existe uma única qualidade de terra (renda intensiva).

Outros dois tipos de renda da terra foram desenvolvidos a partir do modelo sraffiano. O primeiro chamado de renda extensiva intensiva, segundo Salvadori (1986), ocorre quando a suposição (iii) é abandonada. ${ }^{37}$ Neste caso, pode ocorrer renda intensiva quando apenas um processo de produção é utilizado para produzir o cereal e dois processos são utilizados para produzir a mercadoria industrial, os quais utilizam o cereal como insumo em diferentes proporções.

O segundo foi denominado de renda singular e pode ser introduzido quando é abandonada a suposição (i). ${ }^{38}$ Pode surgir apenas quando uma qualidade de terra e um método de produção do cereal é utilizado e, ainda, assumindo que toda a terra disponível é cultivada.

\footnotetext{
${ }^{36}$ Para Sraffa (1985) os casos mais complexos podem ser examinados como uma combinação dos modelos para renda extensiva e intensiva, como, por exemplo, quando vários produtos agrícolas estão sendo cultivados em uma mesma qualidade de terra.

${ }^{37}$ A renda extensiva intensiva foi desenvolvida inicialmente no seguinte trabalho: Abram-Frois G., Berrebi, E. Rentes rareté superprofit. Paris, Econômica, 1980, e posteriomente no trabalho de Saucier P. Le choix des techcniques en situation de limitations de ressources. Paris: University Press, 1981. (mimeo).
} 
A seguir vamos apresentar, resumidamente, o modelo sraffiano para o caso de terras de qualidades diferentes e para o caso de várias técnicas em uma terra de mesma qualidade.

\section{OMODELO SRAFFIANO COM TERRAS DE QUALIDADES DIFERENTES}

Supomos que a economia está dividida em 2 setores, o setor industrial e o setor agrícola. $\mathrm{O}$ setor industrial produz $n_{a}$ mercadorias, com ausência de técnicas alternativas e produção conjunta, ou seja, cada mercadoria é produzida por uma única técnica e esta produz apenas uma mercadoria. Na agricultura, uma mercadoria homogênea, denominada cereal, é produzida em $n_{z}$ diferentes qualidades de terra. Assim, a produção da mercadoria agrícola admite técnicas alternativas, ou seja, existe uma técnica específica associada com cada qualidade de terra $m$ (com $\left.m=1, \ldots, n_{z}\right)$. $\mathrm{O}$ excedente econômico passa a ser distribuído entre salários, lucros e, eventualmente, renda da terra. Há $n_{a}+n_{z}$ atividades: $\boldsymbol{n}_{a}$ indústrias e $\boldsymbol{n}_{z}$ maneiras de produzir a mercadoria agrícola. ${ }^{39}$

Sejam A e B matrizes retangulares $\left(n_{a}+1\right) \times\left(n_{a}+n_{z}\right)$, com elementos $a_{i j}$ e $b_{h j}$ $\left(i=1, \ldots, n_{a}+1\right.$ e $\left.j=1, \ldots, n_{a}+n_{z}\right)$, respectivamente. Similarmente ao modelo sraffiano apresentado no capítulo anterior, $a_{i j}$ indica a quantidade da mercadoria $i$ que entra como insumo na produção de uma unidade da mercadoria indicada na $j$-ésima coluna de $\mathbf{B}$ (quantidades $b_{h j}, \operatorname{com} h=1, \ldots, n_{a}+1$ ).

Seja $\mathbf{H}$ uma matriz diagonal, $n_{z} \times n_{z}$, onde os $n_{z}$ elementos da diagonal principal representam as áreas das diferentes qualidades de terra, $h_{m} \operatorname{com} m=1, \ldots, n_{z}$, em hectares, utilizadas para produzir os volumes da mercadoria agrícola dados em B. Seja $\mathbf{t}$ um vetor-linha com $n_{z}$ elementos $t_{m}$, que representam a renda da terra por unidade de área na terra de tipo $m, \operatorname{com} m=1, \ldots, n_{z}$.

As quantidades de trabalho empregadas nas $n_{a}+n_{z}$ atividades estão representadas no vetor-linha $\mathbf{b}$, com elementos $b_{j}$, e os preços de produção estão representados por um

\footnotetext{
${ }^{38}$ Este novo tipo de renda foi originalmente apresentada por Salvadori (1983).

${ }^{39}$ Adotamos, ainda, as suposições $\left.i\right)-i v$ ) e vi) do início da seção 3.2 .
} 
vetor-linha $\mathbf{p}$ com $n_{a}+1$ elementos: os $n_{a}$ preços das mercadorias industriais e o preço da mercadoria agrícola.

Assim, o sistema econômico sraffiano com terras de diferentes qualidades, seguindo a eq. (3.5), pode ser descrito, como segue:

$$
\mathbf{p A}(1+r)+\mathbf{b} w+\left[\begin{array}{ll}
\mathbf{0} & \mathbf{t H}
\end{array}\right]=\mathbf{p B}
$$

onde 0 é um vetor-linha com $n_{a}$ elementos iguais a zero.

Este sistema de preços de produção possui $n_{a}+n_{z}+3$ incógnitas (os $n_{a}$ preços das mercadorias industriais, as $n_{z}$ rendas da terra, a taxa de lucro, o salário e o preço de produção da mercadoria agrícola) com apenas $\boldsymbol{n}_{a}+\boldsymbol{n}_{z}$ equações.

Uma vez que teremos sempre uma qualidade de terra como marginal, com uma determinada técnica, com renda igual a zero, adicionamos uma equação ao sistema, indicada por

$$
\prod_{m=1}^{n_{z}} t_{m}=0
$$

com $t_{m} \geq 0$. Vamos admitir que a terra marginal é a $k$-ésima, isto é, $t_{k}=0$, tal que $k \in$ $(1, \ldots, m)$. Além disso, escolhendo uma mercadoria como numerário, o sistema fica com $n_{a}+n_{z}+2$ incógnitas e $n_{a}+n_{z}+1$ equações. Há ainda "um grau de liberdade" e seguindo a tradição sraffiana escolhe-se o salário ou a taxa de lucro como variável exógena para obter uma solução única para o sistema.

\section{OMODELO SRAFFIANO COM TERRA HOMOGENEA}

Supomos, como no caso da renda extensiva, que existam $\boldsymbol{n}_{a}$ mercadorias industriais, com ausência de técnicas alternativas e produção conjunta. Existe apenas uma mercadoria agrícola, denominada cereal, produzida em apenas uma qualidade de terra, $\operatorname{com} n_{z}$ diferentes técnicas ou métodos de produção. Admitimos que apenas duas técnicas de produção são utilizados a cada vez. ${ }^{40}$

\footnotetext{
${ }^{40}$ Esta suposição deve-se ao fato que a mesma possibilita que o número de incógnitas seja igual ao número de equações do sistema (Montani, 1972).
} 
Seja $\mathbf{h}$ um vetor-linha com as áreas, em hectares, utilizadas com cada uma das duas técnicas alternativas empregadas na produçãor de uma unidade da mercadoria agrícola, com elementos $h_{m}$.

O modelo econômico sraffiano com terra de mesma qualidade pode ser definido pelo sistema abaixo:

$$
\mathbf{p A}(1+r)+\mathbf{b} w+\left[\begin{array}{ll}
\mathbf{0} & \mathbf{t h}
\end{array}\right]=\mathbf{p B}
$$

Os $n_{z}$ elementos do vetor $\mathbf{t}$ passam a representar a renda da terra por unidade de área, que é uniforme, pois a terra é homogênea.

Neste sistema temos $n_{a}+4$ incógnitas (os $n_{a}$ preços das mercadorias industriais, a renda da terra, a taxa de lucro, o salário e o preço da mercadoria agrícola) com $n_{a}+2$ equações, se dois métodos de cultivo do cereal estiverem sendo utilizados na mesma qualidade de terra. Considerando uma das mercadorias como numerário, o sistema continua com 1 grau de liberdade e, como anteriormente, podemos fixar exogenamente $w$ ou $r$, para obter uma solução única para o sistema.

\subsection{Sistemas econômicos sraffiano-marxistas}

Esta seção será dedicada ao desenvolvimento e à análise dos sistemas econômicos sraffiano-marxistas com dois setores: o industrial e o agrícola. De início vamos analisar o caso de sistemas com terras com diferentes qualidades (seção 4.2.1) e, posteriormente, com terras homogêneas (seção 4.2.2). Em cada um desses casos vamos discutir o sistema econômico em termos dos valores-trabalho e dos preços de produção, bem como a relação entre os mesmos.

Devemos ressaltar que estamos adotando os mesmos supostos adotados para o modelo sraffiano, ou seja, na produção da mercadoria industrial temos ausência de técnicas alternativas e produção conjunta e as suposições $i$ )-iv) e vi) do início da seção 3.2 . 


\subsubsection{Terras com diferentes qualidades ${ }^{41}$}

\subsubsection{Os valores-trabalho}

A seguir vamos analisar três abordagens para o cálculo dos valores-trabalho no caso de um modelo que inclui uma mercadoria agrícola, o cereal, produzida em $\boldsymbol{n}_{z}$ qualidades de terra. Posteriormente, será discutido um modelo para uma economia hipotética, a fim de ressaltar as principais características de cada abordagem e, assim, optar pela mais coerente.

\subsection{Primeira abordagem}

Primeiro, vamos analisar o caso em que o valor da mercadoria agrícola é mensurado pelo tempo de trabalho médio utilizado em sua produção. Seja v o vetor-linha com os valores-trabalho por unidade de cada mercadoria, $\operatorname{com} n_{a}+1$ elementos, ou seja, os $n_{a}$ valores-trabalho das mercadorias industriais e o valor-trabalho da mercadoria agrícola. Partindo do sistema econômico representado por (3.15), podemos indicar o modelo sraffiano-marxista em termos de valores-trabalho, incluindo o setor agrícola, como segue:

$$
\mathbf{v A}+\mathbf{b}=\mathbf{v B}
$$

onde A, B e b estão definidos como na eq. (4.1).

O sistema acima possui $n_{a}+1$ incógnitas (os $n_{a}$ valores-trabalho das mercadorias industriais e o valor-trabalho da mercadoria agrícola) e $n_{a}+n_{z}$ equações. Há, portanto, um excesso de equações. De maneira geral será impossível achar uma solução que satisfaça as $n_{a}+n_{z}$ equações.

Separando, nas matrizes A, B e b, as colunas correspondentes ao setor industrial e ao setor agrícola, obtemos

\footnotetext{
${ }^{41}$ Os exemplos númericos utilizados nesta seção e na próxima foram desenvolvidos por Montani (1975), Venter (1990), Hoffmann \& Venter (1990) e Venter \& Hoffmann (1991). Salienta-se, que os mesmos foram aplicados apenas aos modelos sraffianos e não aos modelos sraffiano-marxistas, aqui desenvolvidos.
} 


$$
\begin{aligned}
& \mathbf{A}=\left[\begin{array}{ll}
\mathbf{A}_{a} & \mathbf{A}_{z}
\end{array}\right] \\
& \mathbf{B}=\left[\begin{array}{ll}
\mathbf{B}_{a} & \mathbf{B}_{z}
\end{array}\right] \\
& \mathbf{b}=\left[\begin{array}{ll}
\mathbf{b}_{a} & \mathbf{b}_{z}
\end{array}\right]
\end{aligned}
$$

As $n_{a}$ equações relativas ao setor industrial são

$$
\mathbf{v} \mathbf{A}_{a}+\mathbf{b}_{a}=\mathbf{v B}_{a}
$$

e as $n_{z}$ equações relativas ao setor agrícola são

$$
\mathbf{v} \mathbf{A}_{z}+\mathbf{b}_{z}=\mathbf{v B}_{z}
$$

Note-se que $\mathbf{A}_{a}, \mathbf{B}_{a}$ e $\mathbf{b}_{a}$ têm $\boldsymbol{n}_{a}$ colunas e $\mathbf{A}_{z}, \mathbf{B}_{z}$ e $\mathbf{b}_{z}$ têm $\boldsymbol{n}_{z}$ colunas.

O último elemento de $\mathbf{v}$ é o escalar $v_{z}$, o valor-trabalho por unidade da mercadoria agrícola.

Se na produção agrícola o produto for sempre apenas o cereal, a matriz $\mathbf{B}_{z}$ só tem elementos diferentes de zero na sua última linha. Se admitirmos, ainda, que os coeficientes em $\mathbf{A}_{z}$ e $\mathbf{b}_{z}$ se referem à produção de uma unidade do cereal em cada tipo de terra, a última linha de $\mathbf{B}_{z}$ é um vetor-linha $\operatorname{com} n_{z}$ elementos iguais a 1 , que vamos representar por $\mathbf{l}_{z}$. Então as $\boldsymbol{n}_{z}$ equações relativas ao setor agrícola ficam

$$
\mathbf{v} \mathbf{A}_{z}+\mathbf{b}_{z}=v_{z} \mathbf{l}_{z}
$$

Inicialmente, vamos considerar o caso de uma mercadoria agrícola não-básica. Neste caso, os valores-trabalho das outras mercadorias podem ser determinados independentemente das $n_{z}$ equações referentes ao cereal.

Para determinar o valor médio da mercadoria agrícola, vamos considerar apenas o subsistema agrícola. Primeiro agregamos as várias equações referentes às várias qualidades de terras pós-multiplicando a eq.(4.9) por um vetor-coluna $\mathbf{q}_{z}$ com $\boldsymbol{n}_{z}$ elementos que são as quantidades totais da mercadoria agrícola produzidas em cada qualidade de terra, de forma a obter uma 'soma ponderada', chegando a uma única equação, descrita por

$$
\mathbf{v} \mathbf{A}_{z} \mathbf{q}_{z}+\mathbf{b}_{z} \mathbf{q}_{z}=v_{z} \mathbf{l}_{z} \mathbf{q}_{z}
$$


Nesta equação a única incógnita é o valor-trabalho da mercadoria agrícola, que pode ser facilmente obtido, pois os valores-trabalho das demais mercadorias podem ser previamente determinados utilizando a eq.(4.8).

No caso em que a mercadoria agrícola é básica, determinamos primeiro seu valor médio agregando as várias equações do subsistema agrícola (como realizado na eq.(4.11)) e, posteriormente, adicionando esta equação ao sistema (4.8), obtemos um sistema com $n_{a}+1$ incógnitas e $n_{a}+1$ equações que, em geral, fornecerá uma solução única para o sistema, que indicaremos por $\overline{\mathbf{v}}$.

A taxa de mais-valia do sistema é determinada neste subsistema, através da eq. (3.19). Se não há renda da terra, a taxa de lucro de Marx, em valores-trabalho, é

$$
\pi=\frac{M}{C+V}
$$

onde $M, C$ e $V$ representam, respectivamente, a mais-valia total, o capital constante total e o capital variável total do sistema.

Havendo produção agrícola com renda da terra, esta deverá ser subtraída da maisvalia total. Uma idéia seria determinar a taxa de lucro na terra marginal. Veremos, no exemplo numérico (seção 4.2.1.1.4), os problemas que essa abordagem pode originar.

\subsection{Segunda abordagem}

O valor-trabalho de uma mercadoria agrícola pode, também, ser mensurado seguindo a interpretação da teoria da renda de Marx realizado por Fine (1979, p.250): “...For DRI, the market value is not formed from de average or normal values, but by the worst method of production. This is not because the worst method is predominant, but because the intervention of landed property modifies the social formation of value in agriculture..." ${ }^{42}$ Os valores-trabalho calculados por esta metodologia serão denominados valores marginais.

${ }^{42} \mathrm{O}$ significado de DRI é renda diferencial I. 
Os valores marginais podem ser obtidos considerando, também, o sistema econômico sraffiano-marxista dado na eq. (4.4). Como vimos, este sistema possui $\boldsymbol{n}_{a}+\boldsymbol{n}_{z}$ equações e apenas $\boldsymbol{n}_{a}+1$ incógnitas. No caso em que a mercadoria agrícola é não-básica a determinação dos valores-trabalho das mercadorias industriais básicas é realizada de maneira idêntica ao caso anterior, ou seja, através do subsistema representado pela eq. (4.8). A diferença está na determinação do valor-trabalho da mercadoria agrícola. Dados os valores-trabalho das mercadorias industriais, podemos determinar o valor-trabalho em cada qualidade de terra $m$, como segue

$$
\dot{\mathbf{v}} \mathbf{a}_{m}+\mathbf{b}_{m}=v_{m}
$$

$m=1, \ldots, n_{z}$. O valor marginal do cereal é obtido no subsistema que apresentar a menor taxa de lucro em valores-trabalho ( $\pi$ ), definida na eq. (4.12), possibilitando, dessa forma, que todas as terras sejam cultivadas.

Por outro lado, considerando uma mercadoria agrícola básica, obtemos os valores marginais considerando o sistema econômico sraffiano-marxista definido na eq. (4.4). Como vimos, este sistema possui $n_{a}+n_{z}$ equações e apenas $n_{a}+1$ incógnitas. Obtemos os valores marginais agregando às $n_{a}$ equações referentes as mercadorias industriais apenas a equação correspondente à terra marginal. Como não sabemos, a priori, qual é a terra marginal, inicialmente obtemos tantos subsistemas para a determinação do vetor de valores marginais quantas forem as técnicas alternativas ou tipos de terra, como segue:

$$
\mathbf{v}_{m} \mathbf{A}_{m}+\mathbf{b}_{m}=\mathbf{v}_{m}
$$

com $m=1, \ldots, n_{z . .}$ Neste caso a matriz $\mathbf{A}_{m}$ tem dimensão $\left(n_{a}+1\right) \times\left(n_{a}+1\right)$ e os vetores $\mathbf{v}_{m}$ e $\mathbf{b}_{m}$ têm $\boldsymbol{n}_{a}+1$ elementos. Analogamente ao caso analisado antes, os valores marginais, também, são os obtidos no subsistema que apresentar a menor taxa de lucro em valorestrabalho $(\pi)$. 


\subsection{Terceira abordagem}

Finalmente, o valor-trabalho em um modelo que inclui uma mercadoria agrícola pode ser mensurado em termos dos valores verdadeiros, seguindo a contribuição de Morishima (1974; 1976 e 1980). Neste caso o valor-trabalho de qualquer cesta de mercadorias (ou de uma mercadoria) é obtido resolvendo um problema de programação linear. Adaptando a proposta de Morishima ao caso de um sistema com setor agrícola, seja $\mathbf{s}$ um vetor-coluna com $n_{z}$ elementos $\left(s_{m}, \operatorname{com} m=1, \ldots, n_{z}\right)$ que são as quantidades disponíveis de cada tipo de terra. Indica-se por $\mathbf{q}$ um vetor-coluna com $n_{a}+n_{z}$ elementos que são os multiplicadores das atividades, de maneira que Bq seja o vetor-coluna das quantidades totais produzidas e Aq seja o vetor-coluna das quantidades de cada mercadoria usadas como insumos. Os últimos $n_{z}$ elementos de $\mathbf{q}$ constituem o vetorcoluna $\mathbf{q}_{\mathbf{z}}$. $\mathrm{O}$ produto líquido é representado por um vetor-coluna $\mathbf{y}$, com $\boldsymbol{n}_{a}+1$ elementos. Com isto, podemos obter o seguinte problema de programação linear:

$$
\text { Minimizar } \quad v_{y}=\mathbf{b q}
$$

com

$$
\begin{aligned}
\mathbf{B q} & \geq \mathrm{Aq}+\mathrm{y} \\
\mathbf{H q}_{z} & \leq \mathrm{s} \\
\mathbf{q} & \geq \mathbf{0}
\end{aligned}
$$

Na equação (4.16) as matrizes $\mathbf{B}$ e $\mathbf{A}$ são as mesmas já utilizadas na eq. (4.1). A eq. (4.16) indica que o produto total de cada mercadoria básica no sistema têm que ser, no mínimo, igual ao que é gasto dessas mercadorias como insumo mais o seu produto líquido. A segunda restrição, eq. (4.17), está relacionada ao fato de que a área de cada qualidade de terra cultivada para produzir o cereal não pode ultrapassar o total dessa mesma qualidade disponível no sistema econômico. Por fim, a eq. (4.18) implica que a solução do sistema possui significado econômico, ou seja, não existe produção negativa. 


\subsection{Os valores individuais}

Para Morishima \& Catephores (1980) os valores individuais das mercadorias podem ser obtidos de duas formas. Primeiro, o valor verdadeiro de uma mercadoria $i$ é definido como o valor verdadeiro da mercadoria composta que contém apenas 1 unidade da mercadoria $i$, sendo todos os outros elementos no vetor y iguais a zero. Assim, para obter os valores individuais apenas o vetor y é modificado, na eq. (4.16). Indicando esses valores individuais por $v_{y i}$ e sendo $y_{i}$ os elementos de $\mathbf{y}$ no problema (4.15)-(4.18), Morishima \& Catephores (1980) assinalam que

$$
v_{y} \leq \sum v_{y i} y_{i}
$$

Essa desigualdade indica que a soma dos valores verdadeiros individuais das mercadorias multiplicados por suas respectivas quantidades contidas no vetor de produtos líquidos pode ser maior do que o valor verdadeiro do produto líquido. Em outros termos, “...o valor verdadeiro de uma mercadoria composta não é aditivo em relação a seus componentes, exceto em alguns casos especiais." ${ }^{43}$ (Morishima \& Catephores, 1980, p.45)

Veremos que com o setor agrícola, podemos obter, também:

$$
v_{y}>\sum v_{y i} y_{i}
$$

contrariando a eq. (4.19) de Morishima \& Catephores (1980).

Segundo, podemos relacionar os valores verdadeiros ao que Morishima (1974) denominou de valores ótimos. Os valores ótimos $\left(v_{o}\right)$ são as variáveis de escolha de um problema de maximização que é dual do problema de minimização. Para encontrar o problema dual daquele descrito nas eqs. (4.15)-(4.18), primeiro devemos multiplicar a restrição (4.17) por -1 , para que todas as desigualdades do problema de minimização fiquem com o mesmo sentido. Posteriormente, para cada linha e coluna deste problema de minimização devemos obter, correspondentemente, uma coluna e uma linha no problema dual. Seja $\mathbf{v}_{t}$ um vetor-linha com $n_{z}$ elementos, que são os valores-sombra dos

\footnotetext{
${ }^{43}$ Estes casos especiais correspondem aos sistemas sem produção conjunta e sem técnicas alternativas.
} 
vários tipos de terra, e seja $\mathbf{v}_{o}$ um vetor-linha com $n_{a}+1$ elementos com os valorestrabalho ótimos da mercadorias industriais e do cereal. Então os valores-trabalho ótimos em um sistema com uma mercadoria agrícola podem ser obtidos resolvendo o seguinte problema de programação linear:

$$
\text { Maximizar } Z=\left[\begin{array}{ll}
\mathbf{v}_{o} & -\mathbf{v}_{t}
\end{array}\right]\left[\begin{array}{l}
\mathbf{y} \\
\mathbf{s}
\end{array}\right]
$$

com

$$
\begin{aligned}
& \mathbf{v}_{o}(\mathbf{B}-\mathbf{A})-\left[\begin{array}{ll}
\mathbf{0} & \mathbf{v}_{t} \mathbf{H}
\end{array}\right] \leq \mathbf{b}, \\
& \mathbf{v}_{o} \geq \mathbf{0} \text { e } \quad \mathbf{v}_{t} \geq \mathbf{0}
\end{aligned}
$$

Se $Z^{0}$ é a solução do problema de maximização e $\mathbf{b q}^{0}$, na eq. (4.15), é a solução do problema de minimização correspondente, então pelo teorema da dualidade teremos ${ }^{44}$

$$
\mathbf{b q}^{0}=Z^{0}
$$

ou

$$
\mathbf{v}_{y}=\mathbf{v}_{o} \mathbf{y}-\mathbf{v}_{t} \mathbf{s}
$$

ou seja, quando temos um produto agrícola o total de tempo de trabalho é o valor ótimo de cada mercadoria multiplicada pelo respectivo produto líquido menos o valor-sombra das terras. Considerando apenas os valores-trabalho individuais ótimos das mercadorias (sem excluir o valor-sombra da terra), o valor-trabalho total do produto líquido do sistema econômico é superior ao valor-trabalho do produto líquido. Ou seja, neste caso, teremos

$$
v_{y} \leq \sum v_{o i} y_{i}
$$

Este resultado é diferente do que Morishima \& Catephores (1980) apresentam $\left(v_{y}=\sum v_{o i} y_{i}\right)$ e é relevante, uma vez que indica que os valores ótimos, como os valores verdadeiros individuais, não são aditivos na presença de técnicas alternativas, como é o

\footnotetext{
${ }^{44}$ Sobre o teorema da dualidade ver Ravindran et al. (1987).
} 
caso de um sistema econômico com um produto agrícola produzido em terras com diferentes qualidades. ${ }^{45}$

É interessante notar que $\mathbf{v}_{o} \mathbf{y}$ representa o valor-trabalho do produto líquido y se toda a produção ocorresse no pior tipo de terra [a terra marginal para o problema (4.21)(4.23)].

Vamos voltar a discutir os valores individuais quando estivermos analisando o exemplo numérico.

\subsection{A mensuração da exploração ${ }^{46}$}

No capítulo $X$, volume I, de $O$ Capital, Marx discutiu três maneiras de quantificar a exploração, que pressupunha serem equivalentes.

A primeira é dada pela razão entre o trabalho excedente e o trabalho necessário. Supomos que um assalariado trabalhe $T$ horas por período e receba uma cesta de bens, d, para sua manutenção. Consideremos, ainda, que existam $N$ trabalhadores homogêneos. Então, $N \mathbf{d}$ é o vetor com os montantes de bens consumidos por todos os trabalhadores do sistema. Podemos obter o valor-trabalho desse vetor, $v_{N d}$, ou seja, o valor do trabalho necessário, substituindo y por $N \mathbf{d}$ na eq. (4.16) do problema (4.15)-(4.18). Com isto, obtemos a seguinte relação entre trabalho excedente e trabalho necessário:

$$
e_{1}=\frac{T N-v_{N \mathrm{~d}}}{v_{N \mathrm{~d}}},
$$

Uma segunda maneira de mensurar a exploração, segundo Marx, consiste em tomar por base apenas um trabalhador. Seja $v_{\mathrm{d}} \mathbf{o}$ valor-trabalho da cesta de consumo de um trabalhador, obtido substituindo y por $\mathbf{d}$ na eq. (4.16) do problema (4.15)-(4.18). Então a razão entre o trabalho não-remunerado e o trabalho remunerado por trabalhador é

\footnotetext{
${ }^{45}$ Ver Morishima \& Catephores (1980), p.68, nota 29 (referida na p.46).

${ }^{46}$ Este item está baseado em Morishima \& Catephores (1980, p. 46-53).
} 


$$
e_{2}=\frac{T-v_{\mathrm{d}}}{v_{\mathrm{d}}}
$$

Por fim, segundo Morishima \& Catephores (1980), a terceira maneira de quantificar a exploração é a razão entre a mais-valia e o capital variável:

$$
e_{3}=\frac{v_{y}-v_{N \mathrm{~d}}}{v_{N \mathrm{~d}}}
$$

em que tanto $v_{y}$ como $v_{N \mathrm{~d}}$ são obtidos resolvendo problemas como (4.15)-(4.18).

Como foi dito acima, para Marx as três razões acima eram equivalentes, o que efetivamente ocorre na ausência de produção conjunta e técnicas alternativas. Para Morishima \& Catephores (1980), em geral tem-se $e_{1}=e_{2} \geq e_{3}$. Segundo estes, a desigualdade deve-se ao fato de que o vetor de produção, em uma economia capitalista maximizadora dos lucros, não corresponde, necessariamente, ao vetor que busca a 'utilização eficiente do trabalho', no problema de minimização acima. Neste caso podemos, então, ter $1 N \geq v_{y}$.

Mas, quando analisamos um sistema econômico com produção agrícola em terras com diferentes qualidades teremos $e_{2} \geq e_{1} \geq e_{3}$, porque o produto necessário para uma única unidade de trabalho pode ser obtido na terra mais produtiva em termos da quantidade de trabalho por unidade de produto. Em outras palavras, o produto necessário sendo menor, poderá ser produzido na terra mais produtiva, de maneira que $\frac{v_{N \mathrm{~d}}}{N} \geq v_{\mathrm{d}}$.

Seguindo Morishima (1974), vamos utilizar $e_{1}(=\sigma)$ como a medida do grau de exploração no sistema econômico ou como a taxa de mais-valia, uma vez que fazemos os cálculos da exploração sobre o tempo total de trabalho utilizado na economia. ${ }^{47}$ 


\subsection{Um exemplo numérico}

Nesta seção, será apresentado um sistema supondo uma economia com duas mercadorias: uma industrial e uma agrícola. Vamos considerar dois tipos de terra, indicados por $\alpha$ e $\beta$, cada um com sua técnica própria de cultivo. Admite-se que a utilização de apenas um dos dois tipos de terra é insuficiente para atender toda a demanda da economia por cereal, mas não há necessidade de usar toda a área disponível das duas qualidades de terra. Consideremos, ainda, que a mercadoria agrícola é básica.

Sejam $q_{i j}$ e $L_{j}$, respectivamente, a quantidade da mercadoria $i$ e a quantidade de trabalho utilizadas na atividade $j$, e $H_{m}$ a área de terra do tipo $m$ que é cultivada, com $m=\alpha$ ou $\beta$. Então, os processos de produção para as duas mercadorias são completamente descritos pelas seguintes expressões:

$q_{11}$ merc. $1 \oplus q_{21}$ merc. $\oplus \oplus L_{1}$ trabalho $\rightarrow q_{1}$ merc. 1

$q_{12}$ merc. $1 \oplus q_{22}$ merc. $2 \oplus L_{2}$ trabalho $\oplus H_{1}$ terra $\alpha \rightarrow q_{2}$ merc. 2

$q_{13}$ merc. $1 \oplus q_{23}$ merc. $2 \oplus L_{3}$ trabalho $\oplus H_{2}$ terra $\beta \rightarrow q_{3}$ merc. 2 onde “ $\oplus$ " significa "combinado com" $\mathrm{e}$ " $\rightarrow$ " significa "para produzir".

$$
\begin{aligned}
\text { Considerando } a_{i j}=\frac{q_{i j}}{q_{j}}, b_{i}=\frac{L_{i}}{q_{i}} \text { e } h_{i}=\frac{H_{i}}{q_{i}}, \text { temos } \\
\mathbf{A}=\left[\begin{array}{lll}
a_{11} & a_{12} & a_{13} \\
a_{21} & a_{22} & a_{23}
\end{array}\right], \\
\mathbf{b}=\left[\begin{array}{lll}
b_{1} & b_{2} & b_{3}
\end{array}\right] \\
\mathrm{e} \quad \mathbf{H}=\left[\begin{array}{cc}
h_{\alpha} & 0 \\
0 & h_{\beta}
\end{array}\right]
\end{aligned}
$$

Sejam, ainda, o vetor $\mathbf{d}$ e a matriz $\mathbf{B}$ dados como segue

${ }^{47}$ Esta conclusão pode ser aplicada também ao caso de terras de mesma qualidade, mas escassas. 


$$
\mathbf{d}=\left[\begin{array}{l}
d_{1} \\
d_{2}
\end{array}\right]
$$

e $\quad \mathbf{B}=\left[\begin{array}{lll}1 & 0 & 0 \\ 0 & 1 & 1\end{array}\right]$

O vetor com os valores-trabalho é descrito por

$$
\mathbf{v}=\left[\begin{array}{ll}
v_{a} & v_{z}
\end{array}\right]
$$

Então, em termos gerais, o sistema econômico sraffiano-marxista em termos de valores-trabalho pode ser indicado através da eq. (4.4):

$$
\mathbf{v A}+\mathbf{b}=\mathbf{v B}
$$

Inicialmente, vamos analisar a determinação dos valores médios. Sejam,

$$
\begin{aligned}
\mathbf{A}_{z} & =\left[\begin{array}{ll}
a_{12} & a_{13} \\
a_{22} & a_{23}
\end{array}\right], \\
\mathbf{b}_{z} & =\left[\begin{array}{ll}
b_{2} & b_{3}
\end{array}\right] \\
\mathbf{l}_{z} & =\left[\begin{array}{ll}
1 & 1
\end{array}\right]
\end{aligned}
$$

Assim, obtemos o subsistema agrícola representado pela eq. (4.9). Considerando

$$
\mathbf{q}_{z}=\left[\begin{array}{l}
q_{2} \\
q_{3}
\end{array}\right],
$$

obtemos a eq. (4.11). Podemos, então, agregar esta equação ao restante do sistema original e teremos um novo sistema com duas equações e duas incógnitas e uma solução única.

A seguir, vamos considerar o primeiro exemplo numérico:

4 merc. $1 \oplus 1 \quad$ merc. $2 \oplus 0,5$ trabalho $\rightarrow 10$ merc. 1

0,5 merc. $1 \oplus 2$ merc. $2 \oplus 0,15$ trabalho $\oplus 1$ terra $\alpha \rightarrow 4,2$ merc. 2 
2,5 merc. $1 \oplus 0,4$ merc. $2 \oplus 0,4$ trabalho $\oplus 1$ terra $\beta \rightarrow 5,4$ merc. 2

Podemos ler a eq. (4.44), por exemplo, como: 0,5 unidades da mercadoria industrial combinadas com 2 unidades da mercadoria agrícola, 0,15 unidades de trabalho e 1 unidade de área da terra de qualidade $\alpha$ produzem 4,2 unidades do produto agrícola.

Considerando o que foi discutido anteriormente, e admitindo que seja cultivada uma unidade de cada tipo de terra, com produção de 9,6 unidades do cereal, obtemos

$$
\overline{\mathbf{v}}=\left[\begin{array}{ll}
0,10323 & 0,11940
\end{array}\right]
$$

Para o caso em que d é definido como

$$
\mathbf{d}=\left[\begin{array}{r}
2,2 \\
5,5
\end{array}\right]
$$

segue-se que $\bar{\omega}=0,88383$ e a taxa de mais-valia é $\sigma=0,13144$. A tabela 4.1 mostra os valores de $C, V \mathrm{e} M$ nos setores industrial e agrícola.

Tabela 4.1 Capital constante, capital variável, valor do produto e mais-valia para as mercadorias industrial e agrícola.

\begin{tabular}{lcccccc}
\hline Mercadoria & $\begin{array}{c}\text { Capital } \\
\text { constante }\left(C_{j}\right)\end{array}$ & $\begin{array}{c}\text { Capital } \\
\text { variável }\left(V_{j}\right)\end{array}$ & $C_{j}+V_{j}$ & $\begin{array}{c}\text { Valor do } \\
\text { produto }\end{array}$ & $M_{j}$ & $\sigma_{j}$ \\
\hline Industrial & 0,53234 & 0,44192 & 0,97426 & 1,03234 & 0,05808 & 0,1314 \\
Agrícola & 0,59627 & 0,48611 & 1,08238 & 1,14627 & 0,06390 & 0,1314 \\
\hline Total & 1,12861 & 0,92802 & 2,05663 & 2,17861 & 0,12198 & 0,1314 \\
\hline
\end{tabular}

Pode-se verificar que com os valores médios é obedecida a igualdade

$$
\overline{\mathbf{v}} \mathbf{y}=1,05=\mathbf{b q},
$$

Voltando ao sistema original podemos calcular $C, V$ e $M$ para cada técnica ou tipo de terra, como mostra a tabela 4.2. 
Tabela 4.2 Capital constante, capital variável, valor do produto e mais-valia, nas terras $\alpha$ e $\beta$.

\begin{tabular}{lcccccc}
\hline Terra & $\begin{array}{c}\text { Capital } \\
\text { constante }\left(C_{j}\right)\end{array}$ & $\begin{array}{c}\text { Capital } \\
\text { variável }\left(V_{j}\right)\end{array}$ & $C_{j}+V_{j}$ & Valor do & $M_{j}$ & $\sigma_{j}$ \\
& 0,29042 & 0,13257 & 0,42299 & 0,50149 & 0,07850 & 0,08881 \\
\hline$\alpha$ & 0,29042 & 0,35353 & 0,65938 & 0,64478 & $-0,01460$ & $-0,01460$ \\
$\beta$ & 0,30584 & 0,48611 & 1,08237 & 1,14627 & 0,06389 & 0,13144 \\
\hline Total & 0,59627 & 0 &
\end{tabular}

Observamos que na terra $\beta$, para o nível de consumo dos trabalhadores estabelecido por d, definido na eq. (4.47), a mais-valia é negativa. Assim, este método de valoração é passível da mesma crítica aplicada ao trabalho de 1975 de Steedman, ou seja, a mais-valia é definida como tempo de trabalho, portanto, não pode ser negativa. Mas, devemos ressaltar que esta crítica não se aplica ao sistema com valores médios, definido nas eqs. (4.8) e (4.11), onde foram obtidos os valores-trabalho e a taxa de mais-valia do sistema, e onde temos produção simples.

Como a tentativa de calcular a mais-valia na terra $\beta$ leva a um absurdo, não podemos determinar a taxa de lucro com base na terra marginal e, consequentemente, não temos como separar as parcelas da mais-valia que correspondem a renda da terra $\mathrm{e}$ lucros.

Passemos, agora, à determinação dos valores marginais para o mesmo modelo com duas mercadorias, descrito anteriormente. Considerando o sistema econômico indicado na eq.(4.4), podemos determinar os valores-trabalho agregando apenas a equação referente à terra marginal ao subsistema industrial. Supondo que a terra de qualidade $\alpha$ é a marginal, temos,

$$
\begin{aligned}
& \mathbf{A}_{\alpha}=\left[\begin{array}{ll}
a_{11} & a_{12} \\
a_{21} & a_{22}
\end{array}\right] \\
& \mathbf{b}_{\alpha}=\left[\begin{array}{ll}
b_{1} & b_{2}
\end{array}\right]
\end{aligned}
$$


Então, podemos escrever

$$
\mathbf{v}_{\alpha} \mathbf{A}_{\alpha}+\mathbf{b}=\mathbf{v}_{\alpha}
$$

Para o exemplo numérico descrito nas equações (4.43), (4.44) e (4.45), temos

$$
\mathbf{v}_{\alpha}=\left[\begin{array}{ll}
0,09842 & 0,09055
\end{array}\right]
$$

Dado o vetor d, eq. (4.47), segue-se que $\omega_{\alpha}=0,71457$. Para obter a taxa de lucro de Marx devemos primeiro calcular o capital constante, o capital variável e a mais-valia neste subsistema. Este cálculo está apresentado na tabela 4.3.

Assim, obtemos $\pi_{\alpha}=0,15735$.

Tabela 4.3 Capital constante, capital variável, valor do produto e mais-valia, para as mercadorias industrial e agrícola, considerando apenas a terra $\alpha$.

\begin{tabular}{lcccccc}
\hline Mercadoria & $\begin{array}{c}\text { Capital } \\
\text { constante }\left(C_{j}\right)\end{array}$ & $\begin{array}{c}\text { Capital } \\
\text { variável }\left(V_{j}\right)\end{array}$ & $C_{j}+V_{j}$ & $\begin{array}{c}\text { Valor do } \\
\text { produto }\end{array}$ & $M_{j}$ & $\sigma_{j}$ \\
\hline Industrial & 0,48425 & 0,35728 & 0,84153 & 0,98425 & 0,14272 & 0,39945 \\
Agrícola & 0,23031 & 0,10718 & 0,33750 & 0,38031 & 0,04281 & 0,39945 \\
\hline Total & 0,71457 & 0,46447 & 1,17904 & 1,36457 & 0,18553 & 0,39945
\end{tabular}

Por outro lado, tomando a terra de qualidade $\beta$ como a marginal, temos, analogamente,

$$
\begin{aligned}
& \mathbf{A}_{\beta}=\left[\begin{array}{ll}
a_{11} & a_{13} \\
a_{21} & a_{23}
\end{array}\right] \\
& \mathbf{b}_{\beta}=\left[\begin{array}{ll}
b_{1} & b_{3}
\end{array}\right]
\end{aligned}
$$

Segue-se que,

$$
\mathbf{v}_{\beta} \mathbf{A}_{\beta}+\mathbf{b}_{\beta}=\mathbf{v}_{\beta}
$$

Resolvendo este sistema para o exemplo numérico, temos 


$$
\mathbf{v}_{\beta}=\left[\begin{array}{ll}
0,10545 & 0,13273
\end{array}\right]
$$

e, similarmente, $\omega_{\beta}=0,96200$. E, ainda, a partir da tabela 4.4 obtemos $\pi_{\beta}=0,019688$.

Tabela 4.4 Capital constante, capital variável, valor do produto e mais-valia, para as mercadorias industrial e agrícola, considerando apenas a terra $\beta$.

\begin{tabular}{lcccccc}
\hline Mercadoria & $\begin{array}{c}\text { Capital } \\
\text { constante }\left(C_{j}\right)\end{array}$ & $\begin{array}{c}\text { Capital } \\
\text { variável }\left(V_{j}\right)\end{array}$ & $C_{j}+V_{j}$ & $\begin{array}{c}\text { Valor do } \\
\text { produto }\end{array}$ & $M_{j}$ & $\sigma_{j}$ \\
\hline Industrial & 0,55455 & 0,48100 & 1,03555 & 1,05455 & 0,01900 & 0,0395 \\
Agrícola & 0,31673 & 0,38480 & 0,70153 & 0,71673 & 0,01520 & 0,0395 \\
\hline Total & 0,87127 & 0,86580 & 1,73707 & 1,77127 & 0,03420 & 0,0395 \\
\hline
\end{tabular}

Verifica-se que

$$
\pi_{\alpha}>\pi_{\beta}
$$

e, então, a terra $\beta$ é a marginal. Com isto, podemos calcular a renda da terra $\alpha$.

Seja $\rho_{\alpha}$ a renda por unidade da terra $\alpha$, em valor-trabalho. Considerando que $\pi$ é determinado no subsistema com a terra marginal, obtemos a renda da terra como um resíduo, dada por

$$
\rho_{\alpha}=\frac{M_{\alpha}-\pi_{\beta}\left(C_{\alpha}+V_{\alpha}\right)}{H_{\alpha}}
$$

ou seja, a renda da terra é a mais-valia menos o lucro, por unidade de área. Para o exemplo numérico, chegamos a $\rho_{\alpha}=0,08587$.

Contudo, neste sistema o valor-trabalho do produto líquido é diferente do total de trabalho direto empregado.

$$
\mathbf{v y}=1,139 \neq 1,05=\mathbf{b q}
$$

Com isto, esta abordagem produz uma solução incompatível com a definição de valor. Se o valor-trabalho corresponde ao tempo de trabalho socialmente necessário à 
produção, não vemos como justificar, nesse caso, a diferença entre o valor-trabalho do produto líquido e o total de trabalho empregado no sistema econômico.

Finalmente, vamos examinar o cálculo dos valores verdadeiros. Vamos admitir que haja disponibilidade de apenas uma unidade de cada tipo de terra, ou seja,

$$
\mathbf{s}=\left[\begin{array}{l}
s_{\alpha} \\
s_{\beta}
\end{array}\right]=\left[\begin{array}{l}
1 \\
1
\end{array}\right]
$$

A eq. (4.16), pode ser reescrita como

$$
(\mathbf{B}-\mathbf{A}) \mathbf{q} \geq \mathbf{y}
$$

Considerando o mesmo sistema econômico com uma mercadoria industrial e uma agrícola analisado anteriormente, as eqs. (4.15), (4.16) e (4.17) ficam:

$$
\operatorname{Minimizar}\left[\begin{array}{lll}
b_{1} & b_{2} & b_{3}
\end{array}\right]\left[\begin{array}{l}
q_{1} \\
q_{2} \\
q_{3}
\end{array}\right]
$$

com

$$
\begin{array}{r}
{\left[\begin{array}{ccc}
1-a_{11} & -a_{12} & -a_{13} \\
-a_{21} & 1-a_{22} & 1-a_{23}
\end{array}\right]\left[\begin{array}{l}
q_{1} \\
q_{2} \\
q_{3}
\end{array}\right] \geq\left[\begin{array}{l}
y_{1} \\
y_{2}
\end{array}\right]} \\
{\left[\begin{array}{cc}
h_{\alpha} & 0 \\
0 & h_{\beta}
\end{array}\right]\left[\begin{array}{l}
q_{2} \\
q_{3}
\end{array}\right] \leq\left[\begin{array}{l}
s_{\alpha} \\
s_{\beta}
\end{array}\right]}
\end{array}
$$

com $q_{i} \geq 0$, para $i=1,2$ e 3 .

Para o exemplo numérico, o valor-trabalho verdadeiro da mercadoria composta é 1,05 , que é minimizado para 


$$
\mathbf{q}^{0}=\left[\begin{array}{c}
10 \\
4,2 \\
5,4
\end{array}\right]
$$

Nota-se que no caso desta definição o valor da mercadoria composta y é, por construção, igual ao total de trabalho empregado (bq), de acordo com a eq. (4.15).

Pode-se verificar que os valores individuais calculados pelo primeiro método sugerido por Morishima \& Catephores (1980) são iguais àqueles obtidos da eq.(4.52), ou seja, o valor da mercadoria composta formada por apenas 1 unidade da mercadoria industrial é 0,09842 e por apenas 1 unidade da mercadoria agrícola é 0,09055. Utilizando estes valores podemos verificar a validade da eq. (4.20), ou seja,

$$
v_{y}=1,05>\sum v_{y i} y_{i}=0,85669
$$

O total obtido utilizando os valores-trabalho verdadeiros individuais é menor porque estes são determinados considerando a produção de cereal na terra mais produtiva, ao passo que a obtenção de todo o produto líquido exige que parte do cereal seja produzida na terra menos produtiva.

Os valores-trabalho ótimos são obtidos através do seguinte problema de programação linear [ver eqs. (4.21)-(4.23)]:

$$
\text { Maximizar } Z=\left[\begin{array}{llll}
v_{o a} & v_{o z} & -v_{t \alpha} & -v_{t \beta}
\end{array}\right]\left[\begin{array}{c}
y_{a} \\
y_{z} \\
s_{\alpha} \\
s_{\beta}
\end{array}\right]
$$

com

$$
\begin{gathered}
{\left[\begin{array}{ll}
v_{o a} & v_{o z}
\end{array}\right]\left[\begin{array}{ccc}
1-a_{11} & -a_{12} & -a_{13} \\
-a_{21} & 1-a_{22} & 1-a_{23}
\end{array}\right]-\left[0 \quad\left[\begin{array}{ll}
v_{t \alpha} & v_{t \beta}
\end{array}\right]\left[\begin{array}{cc}
h_{\alpha} & 0 \\
0 & h_{\beta}
\end{array}\right]\right] \leq\left[\begin{array}{lll}
b_{1} & b_{2} & b_{3}
\end{array}\right]} \\
\mathrm{e} \quad \mathbf{v}_{o} \geq \mathbf{0} \mathrm{e} \quad \mathbf{v}_{t} \geq \mathbf{0}
\end{gathered}
$$


Pode-se verificar que os valores-trabalho ótimos para a mercadoria industrial e agrícola são os apresentados na eq. (4.56): 0,10545 e 0,13273, respectivamente. Além disso, o valor-sombra da terra $\alpha$ é igual a 0,08927 e da terra $\beta$ é igual a zero.

Assim, pelo teorema da dualidade teremos $\mathbf{b q ^ { 0 }}=Z^{0}$.

Além disso, podemos verificar que ocorre a desigualdade prevista na eq. (4.26):

$$
v_{y}=1,05<\sum v_{o i} y_{i}=1,13927
$$

Os valores individuais ótimos correspondem ao tempo de trabalho necessário para produzir uma unidade adicional de cada mercadoria. Como a terra $\alpha$, mais produtiva, já está totalmente utilizada, esses valores são condicionados pela produtividade menor obtida na terra $\beta$. Por isso o valor total do produto líquido calculado com base nos valores individuais ótimos é maior do que o valor verdadeiro do produto líquido, em cujo cálculo se leva em consideração que parte do cereal pode ser produzido na terra mais produtiva.

Tendo em vista calcular as taxas de exploração dadas pelas eqs. (4.27)-(4.29), vamos determinar o trabalho necessário para produzir o consumo dos trabalhadores. Com $N=1,05$ e d dado na eq. (4.47), o consumo total dos trabalhadores é

$$
N \mathbf{d}=\left[\begin{array}{c}
2,31 \\
5,775
\end{array}\right]
$$

Resolvendo o problema de programação linear (4.62)-(4.64) para um produto líquido igual a $N \mathbf{d}$, obtemos

$$
v_{N \mathrm{~d}}=0,92083
$$

Segue-se que

$$
e_{1}=\frac{T N-v_{N \mathrm{~d}}}{v_{N \mathrm{~d}}}=\frac{1,05-0,92083}{0,92083}=0,1403
$$

Uma vez que neste caso o trabalho empregado (TN) é igual ao valor verdadeiro do produto líquido da economia $\left(v_{y}\right)$, temos $e_{3}=e_{1}$. 
Resolvendo o problema de programação linear (4.62)-(4.64) considerando a obtenção de um produto líquido igual ao consumo de uma unidade de trabalho (d), obtemos

$$
v_{\mathrm{d}}=0,87273
$$

e, consequentemente,

$$
e_{2}=\frac{T-v_{\mathrm{d}}}{v_{\mathrm{d}}}=\frac{1-0,87273}{0,87273}=0,1458
$$

Esse resultado mostra a possibilidade de termos $e_{2}>e_{1}$, como já foi assinalado na seção 4.2.1.1.3.2. A medida mais adequada do grau de exploração é, certamente, o valor de $e_{1}$, onde se considera como mais-valia a diferença entre o tempo de trabalho efetivamente empregado e o tempo de trabalho (mínimo) necessário para produzir o consumo de todos os trabalhadores.

Note-se que a taxa de mais-valia obtida com a primeira abordagem $(\sigma=0,1314$, conforme tabela 4.1.) subestima o grau de exploração dado por $e_{1}=0,1403$. Isso ocorre porque naquela abordagem o valor-trabalho do consumo dos trabalhadores é calculado considerando valores médios obtidos na produção de um produto líquido maior $y_{1}=3$ e $y_{2}=6,2$ ). No cálculo de $v_{N \mathrm{~d}}$, por outro lado, admite-se que a economia seja restruturada para obter, como produto líquido, apenas o consumo dos trabalhadores, o que fará com que uma maior proporção do cereal possa ser produzido na terra mais produtiva, reduzindo o tempo médio de trabalho por unidade produzida.

Os resultados obtidos mostram que para uma economia com setor agrícola onde são cultivados vários tipos de terra, os valores-trabalho devem ser calculados como os valores verdadeiros de Morishima, apesar de surgirem desigualdades não previstas por Morishima \& Catephores (1980).

É interessante notar que o valor-sombra da terra $\alpha\left[v_{t \alpha}=0,08927\right.$ na solução do problema (4.67)-(4.69)], que pode ser associado à renda da terra, não aparece como parcela da mais-valia [o numerador da eq. (4.73), igual a 0,12917], mas como um valortrabalho hipotético acima do valor-trabalho do produto líquido $(1,05)$, que só existiria, 
efetivamente, se não houvesse a terra de tipo $\alpha$ e todo o cereal tivesse que ser produzido em terras do tipo $\beta$. Isso é perfeitamente coerente com a noção marxista de que a terra contribui para produzir os valores de uso mas não gera valor-trabalho. A renda da terra, como uma parcela do valor monetário do excedente, só aparece no domínio dos preços de produção.

\subsubsection{Os preços de produção}

Considerando o sistema econômico descrito na eq. (3.11) e seguindo o modelo sraffiano, eq. (4.1), o modelo sraffiano-marxista em termos de preços de produção com terras de diferentes qualidades pode ser representado como segue

$$
(\mathbf{p A}+\mathbf{b} w)(1+r)+\left[\begin{array}{ll}
\mathbf{0} & \mathbf{t H}
\end{array}\right]=\mathbf{p B}
$$

Como visto anteriormente, no modelo marxista o salário é previamente determinado por aspectos históricos, econômicos e institucionais. Lembrando que as quantidades fisicas da cesta de bens que constitui o salário real de subsistência por trabalhador formam um vetor-coluna d, $\operatorname{com} n_{a}+1$ elementos, rescrevemos a eq. (4.76) como segue:

$$
(\mathbf{p A}+\mathbf{p d b})(1+r)+\left[\begin{array}{ll}
\mathbf{0} & \mathbf{t H}
\end{array}\right]=\mathbf{p B}
$$

Acrescentamos, como no modelo sraffiano, mais uma equação ao sistema, referente à terra marginal $k$, dada por

$$
\prod_{m=1}^{n_{z}} t_{m}=0
$$

com $t_{m} \geq 0$, tal que $k \in(1, \ldots, m)$.

O sistema acima possui $n_{a}+n_{z}+2$ incógnitas (os $n_{a}$ preços das mercadorias industriais, as $\boldsymbol{n}_{z}$ rendas da terra, a taxa de lucro e o preço da mercadoria agrícola) e $\boldsymbol{n}_{a}+$ $n_{z}+1$ equações. Escolhendo uma mercadoria como numerário, obtém-se uma solução única para o sistema. 
A renda é uma decorrência da escassez. Neste sistema supomos que existe uma demanda na economia por cereal que só pode ser atendida cultivando todas as qualidades de terra. As diferentes qualidades de terra recebem renda porque são escassas, com exceção da terra de pior qualidade, que é abundante e, portanto, não recebe renda.

A determinação da margem extensiva ou da terra marginal pode ser analisada de maneira análoga à questão da escolha da técnica, vista no capítulo anterior. A terra marginal é aquela que possui a técnica menos eficiente ou de máximo custo, ou ainda, de mínima taxa de lucro, para um dado salário real (d). Assim, a determinação da terra marginal no modelo sraffiano-marxista em termos de preços de produção corresponde à questão da escolha da técnica (menos eficiente).

Admitindo que existam técnicas alternativas apenas para a mercadoria agrícola, podemos considerar a mercadoria agrícola como sendo uma mercadoria não-básica ou básica. A seguir, cada caso será tratado separadamente.

A DETERMINAÇÃO DA TERRA MARGINAL PARA UMA MERCADORIA AGRÍCOLA $N \tilde{A O}-B \dot{A} S I C A$

Vamos supor um sistema econômico com uma mercadoria agrícola não-básica e $n_{a}$ mercadorias industriais básicas, e, ainda, que os meios de produção para a mercadoria agrícola são mercadorias básicas.

Como a mercadoria agrícola é não-básica, dado o vetor $\mathbf{d}$ e a taxa de lucro uniforme do sistema os preços relativos das mercadorias básicas são determinados independentemente da mercadoria agrícola, em um subsistema preços de produção-taxa de lucro formado por $n_{a}$ equações referentes às mercadorias industriais. ${ }^{48}$ Este subsistema coincide com um sistema de produção simples de Sraffa e, portanto, possui solução

\footnotetext{
${ }^{48}$ Para preservar esta independência está implícito que o vetor $\mathbf{d}$ é formado por mercadorias básicas. No caso em que o mesmo possuir mercadorias não-básicas, a determinação dos preços relativos e da taxa de lucro nesse subsistema dependerá da equação referente à mercadoria não-básica incluída no salário real. A pressuposição de que a única mercadoria agrícola do sistema não faz parte da cesta de consumo dos trabalhadores é, certamente, irreal. Essa pressuposição é temporariamente adotada apenas para facilitar a exposição do problema de determinação da renda da terra.
} 
economicamente significativa ( $\mathbf{p}_{a}>\mathbf{0}$ e $r_{a} \geq 0$ ), como visto no capítulo anterior. Assim, temos

$$
\left(\mathbf{p}_{a} \mathbf{A}_{a}+\mathbf{p}_{a} \mathbf{d b}_{a}\right)\left(1+r_{a}\right)=\mathbf{p}_{a}
$$

$\mathrm{O}$ índice inferior $(a)$ é a indicação de que estão sendo consideradas apenas as $\boldsymbol{n}_{a}$ primeiras equações correspondentes às mercadorias industriais.

As $n_{z}$ equações restantes compõem um outro subsistema denominado subsistema renda. Indiquemos por $\mathbf{a}_{m}$ o vetor-coluna de coeficientes técnicos da mercadoria agrícola produzida na terra $m$ e por $b_{j}$ o elemento de b referente à quantidade de trabalho empregado na produção de cereal na terra de tipo $m$. A quantidade de trabalho gasta na produção de uma unidade de cereal na terra $m$ e o seu correspondente preço de produção são representados, respectivamente, por $b_{m}$ e $p_{m}$. Então, é possível determinar $p_{m}$ ou o custo de produção para cada técnica, considerando $t_{m}=0$, através da seguinte equação

$$
\left(\mathbf{p}_{a} \mathbf{a}_{m}+\mathbf{p}_{a} \mathbf{d} b_{j}\right)\left(1+r_{a}\right)=p_{m}
$$

com $m=1, \ldots, n_{z}$. Assim, existirão tantos preços de produção para a mercadoria agrícola, quantas forem as técnicas alternativas.

Comparando os $n_{z}$ preços $p_{m}$, com $m=1, \ldots, n_{z}$, determina-se o maior deles, isto é, determina-se $p_{k}$, tal que

$$
p_{k} \geq p_{m}
$$

com $m=1, \ldots, n_{z}$. Então a terra do tipo $k$, com o maior preço de produção, é a terra marginal e o preço do cereal é $p_{z}=p_{k}$.

A partir da determinação do preço da mercadoria agrícola na terra marginal é possível determinar a renda nos outros tipos de terra, como segue:

$$
t_{m}=\frac{p_{z}-\left(\mathbf{p}_{a} \mathbf{a}_{m}+\mathbf{p}_{a} \mathbf{d} b_{j}\right)\left(1+r_{a}\right)}{h_{m}}
$$

onde $\boldsymbol{m}$ indica as diferentes qualidades de terra utilizadas na produção do cereal. 


\section{A DETERMINAÇÃO DA TERRA MARGINAL PARA UMA MERCADORIA AGRÍCOLA $B \dot{S} S I C A$}

No caso em que a mercadoria agrícola é básica, obtemos os preços de produção e a taxa de lucro, para um dado vetor $\mathbf{d}$, através de um subsistema preços de produçãotaxa de lucro. ${ }^{49}$ Como no caso anterior, este subsistema coincide com um sistema de produção simples e possui solução economicamente significativa. Este subsistema é formado por $\boldsymbol{n}_{a}$ equações referentes ao sistema industrial mais uma equação referente à mercadoria agrícola, onde supomos que $t_{m}=0$. Admitindo que não há produção conjunta e os coeficientes em $\mathbf{A}$ e b se referem à produção de uma unidade de cada mercadoria, temos,

$$
\left(\mathbf{p}_{m} \mathbf{A}_{m}+\mathbf{p}_{m} \mathbf{d} \mathbf{b}_{m}\right)\left(1+r_{m}\right)=\mathbf{p}_{m}
$$

onde $m=1, \ldots, n_{z}$. Neste caso, a matriz quadrada $\mathbf{A}_{m}$ passa a ser $\left(n_{a}+1\right) \times\left(n_{a}+1\right)$ e os vetores $\mathbf{p}_{m}, \mathbf{b}_{m}$ e $\mathbf{d}$ têm $\boldsymbol{n}_{a}+1$ elementos.

Assim, considerando a mercadoria agrícola como básica, dado um vetor $\mathbf{d}$, a solução para o sistema muda para cada $t_{m}$ igual a zero, daí, haverá $n_{z}$ soluções. Para encontrar estas $n_{z}$ soluções devemos substituir $t_{m}=0$ no subsistema descrito na eq. (4.83). Sendo que apenas uma substituição deve ser feita de cada vez.

Dado o vetor $\mathbf{d}$, a terra com a técnica mais eficiente será aquela que proporcionar uma maior taxa de lucro ao sistema representado na eq. (4.83). Por outro lado, a terra $k$ menos eficiente, denominada terra marginal, será aquela que para o mesmo vetor $\mathbf{d}$ gerar uma menor taxa de lucro. Então,

$$
r_{k} \leq r_{m}
$$

\footnotetext{
${ }^{49}$ Neste caso, como só existem mercadorias básicas no sistema, os elementos do vetor $\mathbf{d}$ correspondem, necessariamente, à mercadorias básicas.
} 
com $k \in(1, \ldots, m)$. Retirando a terra marginal $(k)$, as $n_{z}-1$ equações restantes do setor agrícola formam um outro subsistema, denominado subsistema renda. Cada equação deste subsistema possui apenas uma incógnita: a renda. Obtidos $\mathbf{p}_{k}$ e $r_{k}$, temos

$$
t_{m}=\frac{p_{z}-\left(\mathbf{p}_{k} \mathbf{a}_{m}+\mathbf{p}_{k} \mathbf{d} b_{j}\right)\left(1+r_{k}\right)}{h_{m}}
$$

ou seja, obtemos $t_{m}$ que representa a renda na terra de tipo $m$, após determinada a terra marginal.

\subsection{A determinação da terra marginal}

Nesta seção, vamos analisar o mesmo modelo discutido no item 4.2.4, com duas mercadorias, uma industrial e uma agrícola, considerando os preços de produção e os valores-trabalho.

O sistema sraffiano-marxista em termos de preços de produção segue a eq. (77), ou seja,

$$
(\mathbf{p A}+\mathbf{p d b})(1+r)+\left[\begin{array}{ll}
\mathbf{0} & \mathbf{t H}
\end{array}\right]=\mathbf{p B}
$$

Os preços de produção estão representados por

$$
\mathbf{p}=\left[\begin{array}{ll}
p_{a} & p_{z}
\end{array}\right]
$$

e as rendas da terra por

$$
\mathbf{t}=\left[\begin{array}{ll}
t_{\alpha} & t_{\beta}
\end{array}\right]
$$

As matrizes e vetores $\mathbf{A}, \mathbf{b}, \mathbf{H}, \mathbf{d}$ e $\mathbf{B}$, foram descritas nas eqs. (4.33) a (4.37).

As incógnitas deste sistema são a taxa de lucro $(r)$, os preços de produção $\left(p_{a} \mathrm{e}\right.$ $\left.p_{z}\right)$ e as rendas da terra $\left(t_{\alpha}\right.$ e $\left.t_{\beta}\right)$.

Admitindo que a terra $\alpha$ seja a marginal, temos $t_{\alpha}=0$. Neste caso, o subsistema preços de produção-taxa de lucro, pode ser representado por 


$$
\left(\mathbf{p}_{\alpha} \mathbf{A}_{\alpha}+\mathbf{p}_{\alpha} \mathbf{d} \mathbf{b}_{\alpha}\right)\left(1+r_{\alpha}\right)=\mathbf{p}_{\alpha}
$$

onde $\mathbf{A}_{\alpha}$ está definida em (4.49) e $\mathbf{b}_{\alpha}$ em (4.50).

Este sistema possui como incógnitas $p_{a}, p_{z}$ e $r_{\alpha}$, e apenas duas equações. Tomando a mercadoria agrícola como numerário, temos $p_{z}=1 \mathrm{e}$

$$
\mathbf{p}=\left[\begin{array}{ll}
p_{a} & 1
\end{array}\right]
$$

Vamos considerar a matriz de coeficientes técnicos aumentada:

$$
\mathbf{A}_{\alpha}^{+}=\mathbf{A}_{\alpha}+\mathbf{d b}_{\alpha}
$$

A taxa de lucro deste sistema pode ser obtida a partir da raiz característica máxima $\left(\lambda_{\alpha}\right)$ da seguinte equação característica:

$$
\left|\mathbf{A}_{\alpha}^{+}-\lambda_{\alpha} \mathbf{I}\right|=0
$$

Analogamente ao capítulo 3, temos que $\lambda_{\alpha}=\frac{1}{1+r_{\alpha}} \mathrm{e}$, com isto, obtemos a taxa de lucro.

Considerando o exemplo numérico descrito na seção 4.2.1.1.4, e lembrando eq. (4.91), obtemos as raízes 0,87542 e 0,30720 . Então, a raiz característica máxima é $\lambda_{\alpha}=0,87542$ e, consequentemente, $r_{\alpha}=0,14231$.

Se a terra $\beta$ for a menos eficiente, temos o seguinte subsistema preços de produção-taxa de lucro:

$$
\left(\mathbf{p}_{\beta} \mathbf{A}_{\beta}+\mathbf{p}_{\beta} \mathbf{d} \mathbf{b}_{\beta}\right)\left(1+r_{\beta}\right)=\mathbf{p}_{\beta}
$$

onde $\mathbf{A}_{\beta}$ e $\mathbf{b}_{\beta}$ estão indicados nas eqs. (4.53) e (4.54), respectivamente.

Para o mesmo exemplo numérico, obtemos, similarmente, $\lambda_{\beta}=0,98043 \mathrm{e}$, correspondentemente, $r_{\beta}=0,01996$. Com isto, temos que

$$
r_{\alpha}>r_{\beta}
$$


$\mathrm{e}$, portanto, a terra de qualidade $\beta$ é a marginal.

$\mathrm{O}$ vetor-linha com os preços de produção é um vetor característico à esquerda de $\mathbf{A}_{\beta}^{+}$, correspondente à raiz característica máxima. Então,

$$
\mathbf{p}_{\beta} \mathbf{A}_{\beta}^{+}=\lambda_{\beta} \mathbf{p}_{\beta}
$$

ou

$$
\mathbf{p}_{\beta}\left(\mathbf{A}_{\beta}^{+}-\lambda_{\beta} \mathbf{I}\right)=\mathbf{0}
$$

Resolvendo a eq. (4.95) para o exemplo numérico, $\operatorname{com} p_{z}=1$, obtemos

$$
\mathbf{p}_{\beta}=\left[\begin{array}{ll}
0,79714 & 1
\end{array}\right]
$$

Dada a taxa de lucro e o vetor de preços de produção, determinamos o salário em unidades monetárias em termos da mercadoria agrícola, como segue

$$
w_{\beta}=\mathbf{p}_{\beta} \mathbf{d}=7,25371
$$

Podemos, ainda, obter a renda na terra de qualidade $\alpha$ com a técnica mais eficiente $\alpha$, considerando a eq. (4.89):

$$
t_{\alpha}=\frac{1-\left(\mathbf{p}_{\beta} \mathbf{a}_{\alpha}+b_{2} w_{\beta}\right)\left(1+r_{\beta}\right)}{h_{\alpha}}=0,6438
$$

Vamos, agora, estudar os efeitos de mudanças no vetor d. Para cada vetor d fixado exogenamente obtemos uma nova solução para o sistema acima. Podemos variar o salário real multiplicando o vetor $\mathbf{d}$ por uma constante $\theta$. Lembrando a eq. (4.47), temos:

$$
\mathbf{d}^{*}=\theta \mathbf{d}=\theta\left[\begin{array}{l}
2,2 \\
5,5
\end{array}\right]
$$

Dessa maneira, mantemos a proporcionalidade na cesta de mercadorias consumida por um trabalhador no sistema econômico. Quando $\theta=1$ temos o sistema original. A cesta de mercadorias, em termos físicos, que compõe o salário dos trabalhadores pode ser modificada, hipoteticamente, de um extremo em que é nula, quando a taxa de lucro 
alcança seu valor máximo, até o outro extremo, em que absorve todo o produto líquido de ao menos uma mercadoria do sistema.

Com isto, obtemos duas relações entre $\theta$ e a taxa de juros: uma para o caso em que consideramos a terra $\alpha$ como marginal e outra para o caso em que fazemos a mesma suposição para a terra $\beta$, como mostra a figura 4.1a. Estas relações são decrescentes, pois um aumento do salário real representa uma redução na taxa de lucro. A taxa de lucro máxima é obtida fazendo $\mathbf{d}^{*}=\mathbf{0}$, o que implica $w=0$, e é igual a 0,81 na terra $\alpha \mathrm{e}$ 0,97 na terra $\beta$. O valor mínimo para a taxa de lucro ( $r_{\alpha}$ ou $r_{\beta}$ igual a 0$)$ é alcançado quando a raiz característica máxima da matriz de coeficientes técnicos aumentada $\left(\mathbf{A}_{\alpha}^{+}\right.$ou $\mathbf{A}_{\beta}^{+}$) assume o valor 1 .

As duas relações se interceptam quando $r_{\alpha}=r_{\beta}=0,476$ e $\theta=0,375$. Quando $r$ está entre 0 e 0,476 a terra $\alpha$ é a mais eficiente e quando temos $0,476<r<0,81$ a terra $\beta$ passa a ser a mais eficiente. Isto ocorre porque na terra $\beta$ utiliza-se uma técnica que é mais intensiva em trabalho que a técnica empregada na terra $\alpha$. Assim, enquanto existe uma participação pequena do salário real no excedente, a técnica $\beta$ é mais "barata", mas quando esta participação vai aumentando (valores crescentes de $\theta$ ) esta técnica vai se tornando relativamente mais "cara". O contrário ocorre na terra $\alpha$, com uma técnica menos intensiva em trabalho. Assim, para uma baixa participação do salário real no excedente, esta técnica é menos eficiente. Quando esta participação aumenta a técnica $\alpha$ torna-se, paulatinamente, mais eficiente porque a trabalho ficou mais "caro" e ela utiliza menos deste insumo do que a técnica $\beta$.

A relação entre a taxa de lucro e o salário está apresentada na figura 4.1b. Como estamos assumindo que a demanda por cereal não pode ser atendida com o cultivo de uma única qualidade de terra, então, a máxima taxa de lucro desta economia será igual a 0,81 (ponto $C$ ), determinada na terra $\alpha$. Isto ocorre porque uma maior taxa de lucro inviabilizará a produção nesta terra. $\mathrm{O}$ ponto de mudança de eficiência das técnicas neste sistema ocorre quando $r=0,476$ (ponto $B$ ). Nos pontos $A, B C$ o salário assume, 


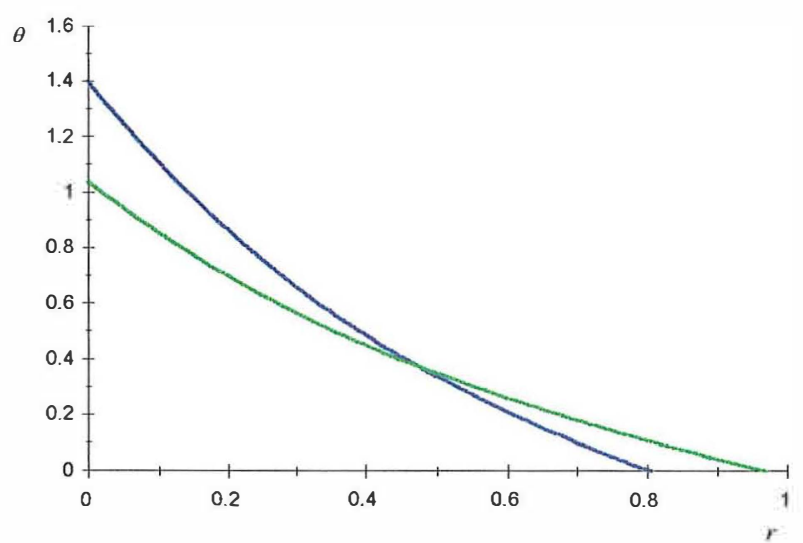

a)

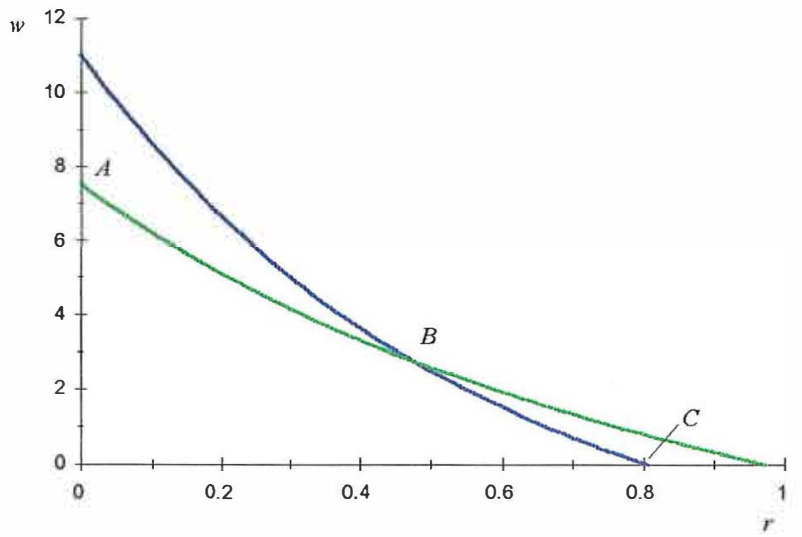

b)

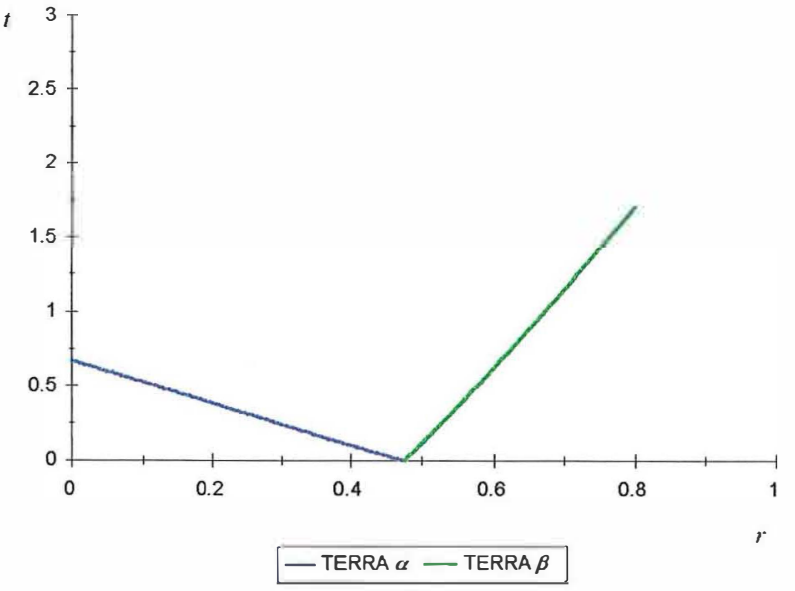

c)

Figura 4.1 Relações $\theta-r, w-r$ e $t-r$, modelo sraffiano-marxista em termos de preços de produção para terras de diferentes qualidades, primeiro exemplo numérico. 
respectivamente, os valores 7,53, 2,77 e zero. Com isto, a fronteira tecnológica para este sistema é representada pela curva $A B C$, como mostra a figura 4.1b.

$\mathrm{Na}$ figura 4.1a observa-se que o sistema econômico se torna inviável para $\theta \geq 1,04$, uma vez que não é possível cultivar as duas qualidades de terra. Para $\theta \geq 1,04$ o cultivo da terra $\beta$ deixa de ser lucrativo e, portanto, não é possível atender toda a demanda.

A figura 4.1c mostra que, para valores de $r$ entre 0 e 0,476 a terra $\alpha$, mais eficiente, tem uma renda positiva, e para valores de $r$ entre 0,476 e 0,81 a terra $\beta$, que passa a ser a mais eficiente, é que tem renda positiva. Quando $r=0,476$ não existe renda da terra, pois os dois tipos de terra são igualmente eficientes.

Se, ao contrário, admitirmos que a quantidade de cereal que deve ser produrida é pequena, de maneira que cultivando apenas parte de uma das qualidades de terra possamos satisfazer as necessidades da sociedade, então, será cultivada apenas a terra com a técnica mais eficiente. Então, para $0<r<0,476$ será cultivada apenas a terra $\alpha$ e quando $0,476<r<0,81$, apenas a terra $\beta$. Assim, a fronteira tecnológica seria dada pela parte externa da figura $4.1 \mathrm{~b}$, ao contrário do que foi visto acima, em que a fronteira é composta pelas partes internas dessa figura. Uma consequência desta suposição sobre a demanda é que como nenhuma terra é escassa, não existe renda da terra em nenhum ponto da relação $w$-r.

Podemos concluir que a ordem de eficiência das terras não é naturalmente estabelecida, mas depende da distribuição da renda entre salários e taxa de lucro, além da demanda total por cereal. Até mesmo o fato de determinado tipo de terra ser ou não ser escasso depende da distribuição da renda entre salários e lucros. Dadas as quantidades dos bens que devem ser produzidas, os diversos valores do salário e da taxa de lucro é que vão determinar se uma qualidade de terra específica é escassa ou abundante.

Este fenômeno, discutido por Sraffa, não foi analisado por Ricardo ou Marx. Ricardo acreditava que existia uma hierarquia das terras de acordo com a fertilidade naturalmente estabelecida e inalterada, dadas as quantidades de capital. Marx 
compartilhava da mesma opinião sobre a ordem de fertilidade das terras, para iguais aplicações de capital nas diferentes qualidades de terra.

Caso se considere que nas diferentes qualidades de terra se utilize a mesma quantidade dos mesmos meios de produção e de trabalho, por unidade de área, as relações $w$-r passam a ser linhas paralelas. Portanto, não existiria mudança na ordem de eficiência das terras em decorrência de alterações na distribuição de renda, dada uma demanda por cereal.

Abandonando estas restrições, ou seja, considerando que terras diferentes são exploradas utilizando diferentes quantidades dos meios de produção e de trabalho, como faz Sraffa, estas conclusões de Ricardo e Marx não se aplicam.

Vamos continuar analisando o mesmo exemplo numérico, verificando como alterações no vetor $\mathbf{d}$ afetam o capital variável e a taxa de mais-valia. Os valores-trabalho são calculados de acordo com o método de Morishima e as alterações no consumo dos trabalhadores são feitas conforme a eq. (4.99), multiplicando o vetor $\mathbf{d}$ original por um escalar $\theta$.

A figura 4.2a mostra como o capital variável $(V)$ cresce com $\theta$. Note-se que ocorre uma mudança na inclinação dessa relação quando $\theta=0,34$. Isso ocorre porque para valores baixos de $\theta$ todo o cereal necessário pode ser produzido na terra $\alpha$, que é mais produtiva. A partir do ponto em que a quantidade necessária de cereal exige o uso da terra $\beta$ (passando a ser atuante, na resolução do problema de programação linear, a restrição relativa à disponibilidade da terra $\alpha$ ), a inclinação da relação $V-\theta$ aumenta.

$O$ valor mínimo de $V$ ocorre quando $\theta$ é igual a zero e o valor máximo quando todo o trabalho disponível é empregado na produção da cesta de consumo dos trabalhadores, neste caso para $\theta=1,087$ e $V=1,009$.

A figura $4.2 \mathrm{~b}$ apresenta a relação entre a taxa de mais-valia e o coeficiente $\theta$. A curva se aproxima do eixo das ordenadas como uma hipérbole retangular, pois se o vetor $\theta N \mathbf{d}$ assumisse seu valor mínimo (nulo) o capital variável seria, também, igual a zero e a taxa de mais-valia tenderia para infinito. 


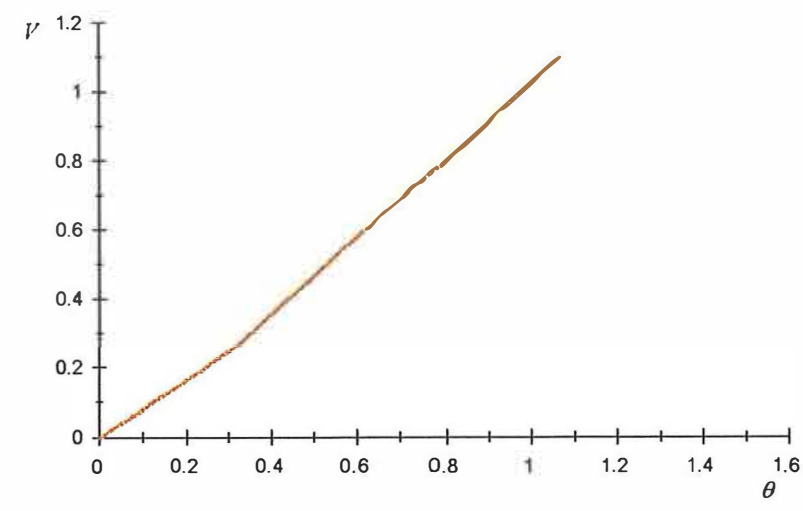

a)

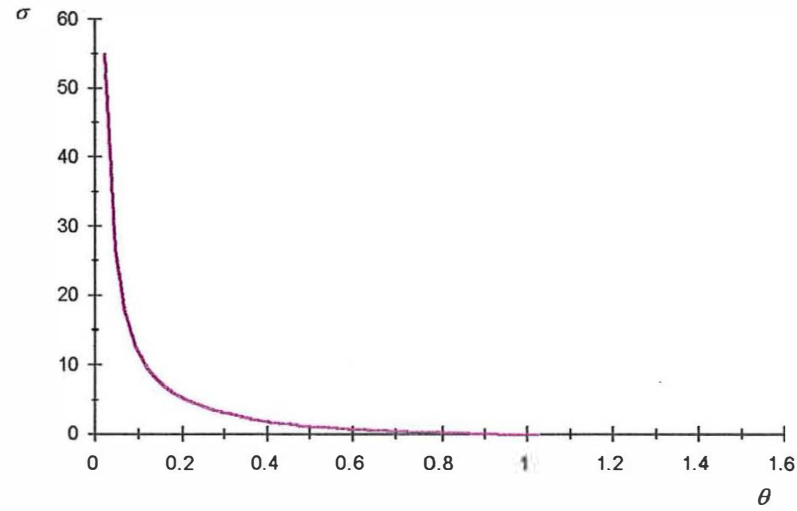

b)

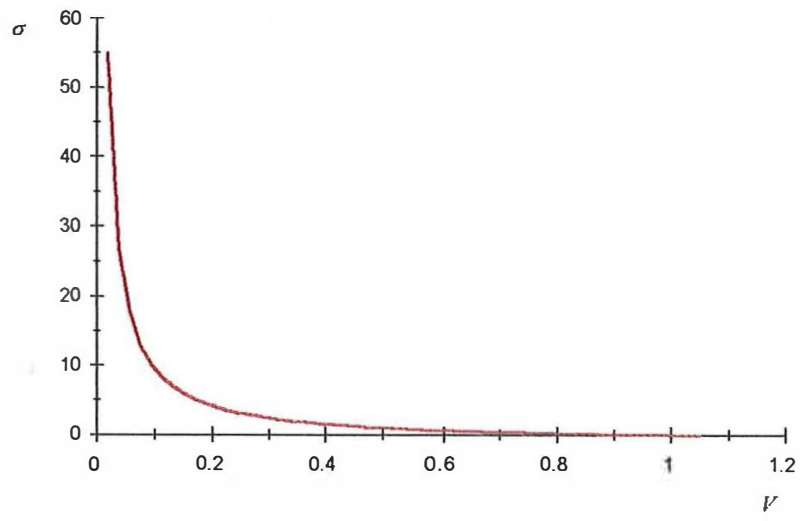

c)

Figura 4.2 Relações $V-\theta, \sigma-\theta$ e $\sigma-V$ para o modelo marxista com terras de diferentes qualidades, primeiro exemplo numérico. 
$\mathrm{O}$ valor mínimo da taxa de mais-valia ocorre quando $V$ atinge seu valor máximo. Este valor mínimo pode ser ou não igual a zero, dependendo da composição do vetor $\mathbf{d}$. Neste exemplo, para $\theta=1,087$ a taxa de mais-valia é igual a $4 \%(\sigma=0,04)$, mas para $\theta>1,087$ é impossível obter um produto líquido que seja suficiente para atender o consumo dos trabalhadores.

A figura $4.2 \mathrm{c}$ mostra a relação entre a taxa de mais-valia e o capital variável. Esta relação é similar àquela existente na figura $4.2 \mathrm{~b}$, uma vez que substituímos $\theta$ pelo valor da cesta de mercadorias consumida por todos os trabalhadores do sistema, que possuem uma relação crescente entre si, como vimos na figura 4.2a.

Para cada vetor d, fixado exogenamente, podemos determinar tanto o sistema em termos de preços de produção quanto o sistema em termos de valores-trabalho e, além disso, estabelecer relações entre os mesmos. Em outras palavras, partindo de um sistema em unidades fisicas podemos ir dos preços de produção aos valores-trabalho, ou o contrário, dos valores-trabalho aos preços de produção.

A figura 4.3 apresenta a relação entre a taxa de lucro vigente neste exemplo, ou seja, aquela referente à curva interna da figura 4.1a, e a taxa de mais-valia. Nota-se que esta relação é crescente e temos $\sigma>r$.

Ao examinar a figura 4.1 vimos que o cultivo da terra $\beta$ deixa de ser lucrativo para $\theta \geq 1,04$. Entretanto, a mais-valia é positiva para $\theta \leq 1,087$. Há, então, uma faixa de valores de $\theta$ para a qual a mais-valia é positiva mas já não é possível produção lucrativa. Isso corresponde, na figura 4.3, ao fato de $r$ só ser positivo para $\sigma$ maior do que 0,09 . Conclui-se, portanto, que em um sistema econômico onde há escassez de algum tipo de terra a mais-valia positiva não é condição suficiente para que haja taxa de lucro positiva.

\subsubsection{Ordem de eficiência e ordem de rentabilidade}

Vimos no exemplo anterior que, para três atividades, sendo duas relativas à 


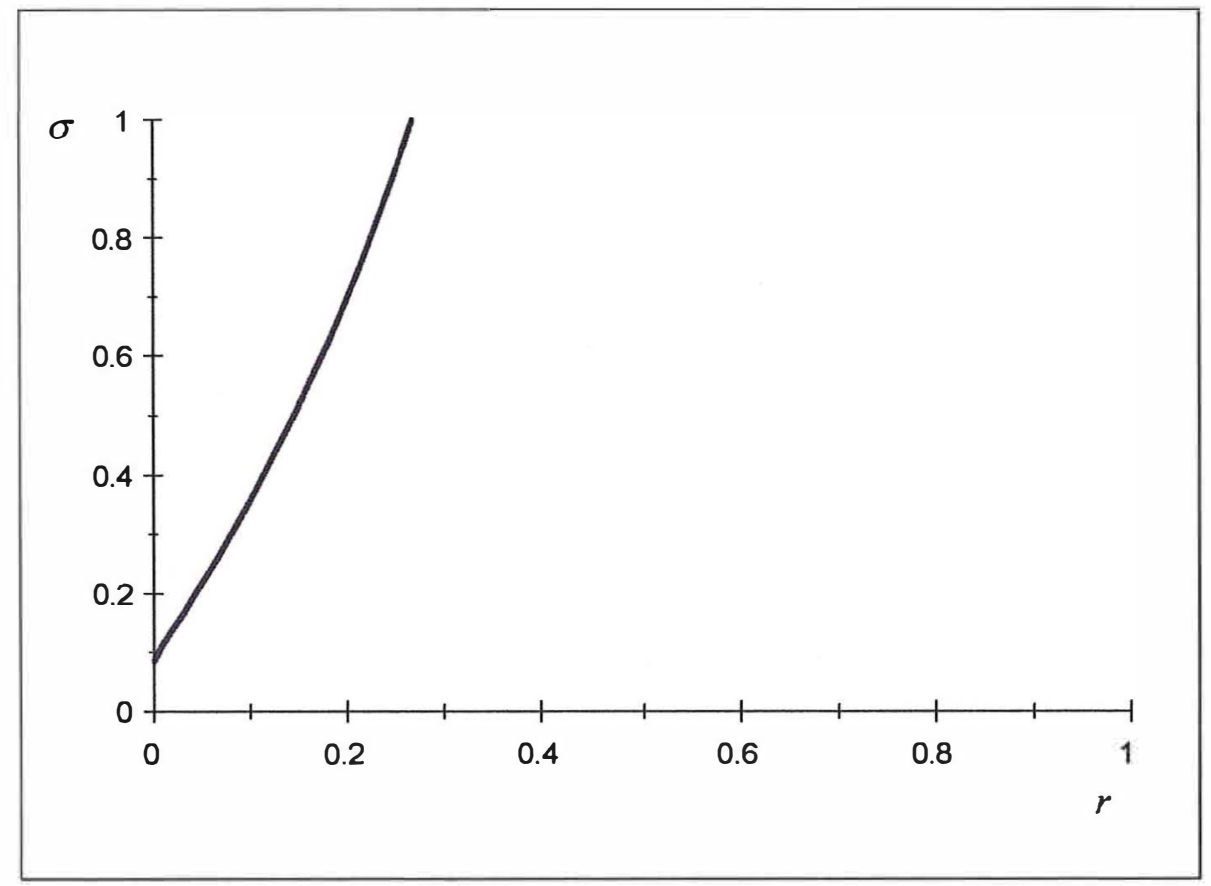

Figura 4.3 Relação $\sigma-r$ para os modelos com terras de diferentes qualidades, primeiro exemplo numérico.

produção da mercadoria agrícola, a ordem de eficiência depende da distribuição de renda. Se a demanda final é atendida utilizando-se dois tipos de terra no setor agrícola, a renda será paga somente em uma qualidade de terra. Assim, à ordenação das terras através da renda da terra corresponde a ordenação de terras pela eficiência. Isto é uma conclusão geral para sistemas com duas qualidades de terra utilizadas na produção da mercadoria agrícola. Resta, ainda, verificar se este resultado é válido para sistemas com três ou mais qualidades de terra no setor agrícola, no caso do modelo sraffiano-marxista.

Para analisar esta questão consideraremos, a seguir, um sistema com uma mercadoria industrial e uma mercadoria agrícola produzida em três diferentes qualidades de terra:

$q_{11}$ merc. $1 \oplus q_{21}$ merc. $2 \oplus L_{1}$ trabalho $\rightarrow q_{1}$ merc. 1

$q_{12}$ merc. $1 \oplus q_{22}$ merc. $2 \oplus L_{2}$ trabalho $\oplus H_{1}$ terra $\alpha \rightarrow q_{2}$ merc. 2 
$q_{13}$ merc. $1 \oplus q_{23}$ merc. $2 \oplus L_{3}$ trabalho $\oplus H_{2}$ terra $\beta \rightarrow q_{3}$ merc. 2

$q_{14}$ merc. $1 \oplus q_{24}$ merc. $2 \oplus L_{4}$ trabalho $\oplus H_{3}$ terra $\gamma \rightarrow q_{4}$ merc. 2

Como anteriormente, podemos obter o sistema econômico sraffiano-marxista na forma da eq. (4.77):

$$
(\mathbf{p A}+\mathbf{p d b})(1+r)+\left[\begin{array}{ll}
\mathbf{0} & \mathbf{t H}
\end{array}\right]=\mathbf{p B}
$$

Supomos que a demanda pelo produto agrícola é tal que não pode ser atendida com o cultivo de apenas dois tipos de terra, mas pode ser atendida utilizando os três tipos de terra. Contudo, não há a necessidade de se cultivar toda a área de terra disponivel. Com isto, procuraremos definir qual a terra marginal desse sistema para cada vetor $\mathbf{d}$.

Vamos indicar as qualidades de terra por $\alpha, \beta$ e $\gamma$. Podemos, então, obter três subsistemas preços de produção-taxa de lucro, descritos como segue:

$$
\left(\mathbf{p}_{m} \mathbf{A}_{m}+\mathbf{p}_{m} \mathbf{d} \mathbf{b}_{m}\right)\left(1+r_{m}\right)=\mathbf{p}_{m}
$$

onde $m=\alpha, \beta$ e $\gamma$. Em cada subsistema uma das terras é considerada a marginal, cuja técnica é a menos eficiente, e como esta terra não é escassa, podemos considerá-la livre e, consequentemente, não terá renda.

Fixando exogenamente um vetor $\mathbf{d}$, podemos determinar a taxa de lucro para cada técnica. Vamos analisar melhor este assunto através de um segundo exemplo numérico:

4 merc. $1 \oplus 1$ merc. $2 \oplus 0,5$ trabalho $\rightarrow 10$ merc. 1

0,5 merc. $1 \oplus 2$ merc. $2 \oplus 0,15$ trabalho $\oplus 1$ terra $\alpha \rightarrow 4,2$ merc. 2 (4.106)

2,5 merc. $1 \oplus 0,4$ merc. $2 \oplus 0,4$ trabalho $\oplus 1$ terra $\beta \rightarrow 5,4$ merc. 2 (4.107)

2 merc. $1 \oplus 1,5$ merc. $2 \oplus 0,1$ trabalho $\oplus 1$ terra $\gamma \rightarrow 3,8$ merc. 2 (4.108) 
Podemos, então, resolver os três subsistemas para o vetor $\mathbf{d}$ definido na eq. (4.47). Além disso, podemos obter as relações entre as variáveis distributivas do sistema, modificando este vetor proporcionalmente a uma constante $\theta$, como mostra a figura 4.4.

Apenas as três relações apresentadas na figura $4.4 \mathrm{~b}$ não são suficientes para determinar a terra marginal, mas lembrando a suposição sobre a demanda final pelo produto agrícola é possível determiná-la. Como há a necessidade de cultivar as três qualidades de terra, sendo que uma não é cultivada completamente, a terra marginal é a terra de qualidade $\gamma$, em toda extensão viável deste sistema. A esta região viável correspondem os valores da taxa de lucro entre 0 e 0,595 . Para a taxa de lucro entre 0 e 0,476 a terra $\alpha$ é mais eficiente e entre 0,476 e 0,595 a terra mais eficiente é a $\beta$. O ponto de mudança de eficiência ocorre quando $r=0,476$.

A fronteira tecnológica dessa economia é dada, exclusivamente, pela relação $w-r$ da terra $\gamma$, como mostra a figura 4.4b. Assim, tanto a taxa de lucro máxima quanto o salário máximo desse sistema são definidos pela terra $\gamma$, e são dados, respectivamente, por 0,595 e 7,375. Salientamos que o salário está mensurado em termos da mercadoria agrícola, numerário do sistema.

Observando a figura $4.4 \mathrm{c}$, verificamos que, a terra marginal não recebe renda, uma vez que não está sendo cultivada totalmente. Contudo, as terras $\alpha$ e $\beta$ possuem renda positiva. Observamos que para $r$ entre 0 e 0,11 a terra mais rentável é a de qualidade $\alpha$, e para $r$ entre 0,11 e 0,59 a terra mais rentável passa a ser a de qualidade $\beta$. Quando ambas as terras são igualmente rentáveis, a taxa de lucro é igual a 0,11.

Assim, a mudança na ordem de eficiência das terras ocorre quando o valor da taxa de lucro é maior ( $r=0,476$, na figura 4.4b) quando comparada ao valor da mesma no momento da mudança na ordem de rentabilidade ( $r=0,11$, na figura 4.4c). Para a taxa de lucro entre 0,476 e 0,11 , a terra mais eficiente é a terra de qualidade $\alpha$, sendo a terra mais rentável a de qualidade $\beta$.

Com isto, podemos concluir que, na presença de mais de duas qualidades de terra para a produção do cereal, a regra que garante que a ordem de eficiência das terras 


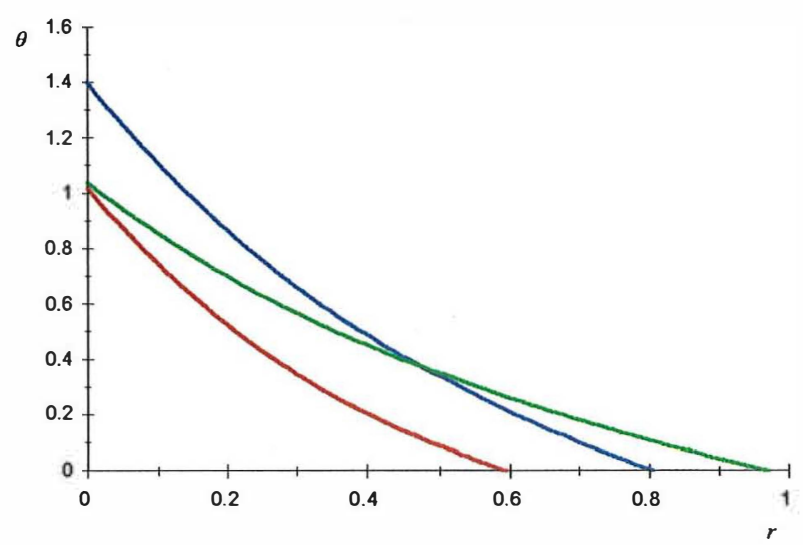

a)

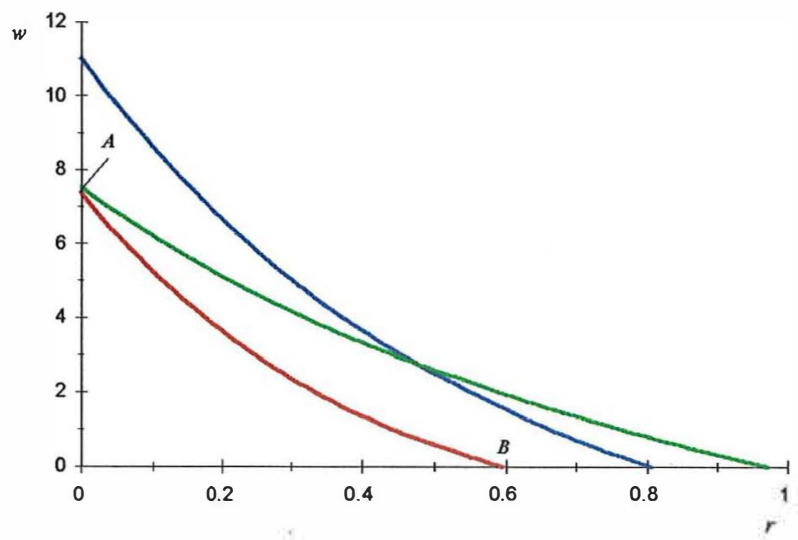

b)

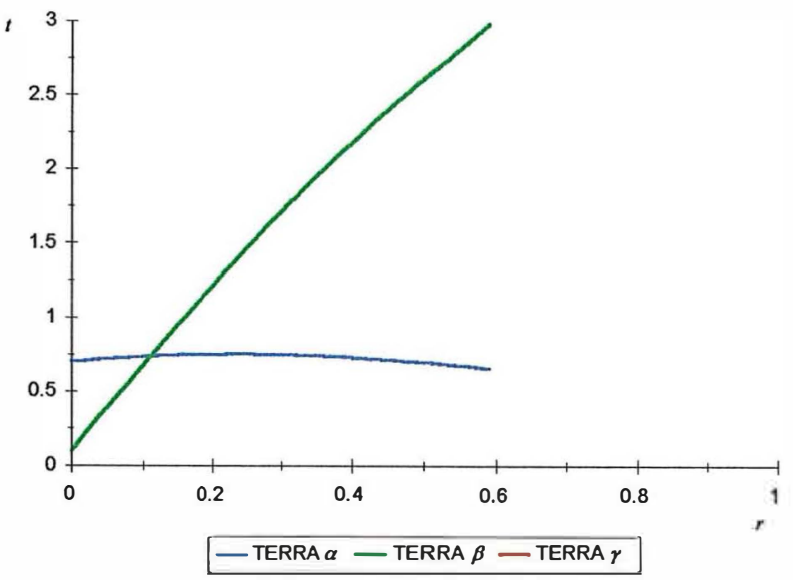

c)

Figura 4.4 Relações $\theta-r, w-r$ e $t-r$, modelo sraffiano-marxista em termos de preços de produção com terras de diferentes qualidades, segundo exemplo numérico. 
corresponde à ordem de rentabilidade das terras não se aplica. Tanto Ricardo quanto Marx pensavam que esta tese era geral, uma vez que assumiam, como anteriormente, que era empregada em cada qualidade de terra a mesma quantidade dos mesmos meios de produção e a mesma quantidade de trabalho por unidade de terra. Segundo Ricardo (1982, p.66-67): "Quando uma terra de terceira qualidade começa a ser cultivada, imediatamente aparece renda na de segunda, regulando-se, como no caso anterior, pela diferença entre as forças produtivas de uma e de outra. Ao mesmo tempo, aumenta a renda da terra de primeira qualidade, pois esta deve ser sempre superior à renda da segunda, de acordo com a diferença entre as produções obtidas numa e noutra, com uma dada quantidade de capital e de trabalho. A cada avanço do crescimento da população, que obrigará o país a recorrer à terra de pior qualidade para aumentar a oferta de alimentos, aumentará a renda de todas as terras mais férteis."

Marx mostrou um pensamento similar ao de Ricardo nos vários exemplos numéricos analisados no Livro III de O Capital (Kurz 1980).

Se assumimos, diferentemente do que fizeram Ricardo e Marx, e concordando com Sraffa, que diferentes qualidades de terra requerem diferentes técnicas de produção, o ponto de vista de Ricardo e Marx não é válido. Estas diferentes técnicas são caracterizadas por diferentes meios de produção ou diferentes quantidades dos mesmos meios de produção, ou diferentes quantidades de trabalho por unidade de área, ou, ainda, uma combinação destes.

No que se refere aos valores, temos que formular o problema de programação linear seguindo as eqs. (4.15),(4.16) e (4.17), como segue:

Minimizar $\quad\left[\begin{array}{llll}b_{1} & b_{2} & b_{3} & b_{4}\end{array}\right]\left[\begin{array}{l}q_{1} \\ q_{2} \\ q_{3} \\ q_{4}\end{array}\right]$

com 


$$
\begin{aligned}
& {\left[\begin{array}{cccc}
1-a_{11} & -a_{12} & -a_{13} & -a_{14} \\
-a_{21} & 1-a_{22} & 1-a_{23} & 1-a_{24}
\end{array}\right]\left[\begin{array}{l}
q_{1} \\
q_{2} \\
q_{3} \\
q_{4}
\end{array}\right] \geq\left[\begin{array}{l}
y_{1} \\
y_{2}
\end{array}\right]} \\
& {\left[\begin{array}{ccc}
h_{\alpha} & 0 & 0 \\
0 & h_{\beta} & 0 \\
0 & 0 & h_{\gamma}
\end{array}\right]\left[\begin{array}{l}
q_{2} \\
q_{3} \\
q_{4}
\end{array}\right] \leq\left[\begin{array}{l}
s_{\alpha} \\
s_{\beta} \\
s_{\gamma}
\end{array}\right]}
\end{aligned}
$$

com $q_{i} \geq 0$, para $i=1,2,3$ e 4 .

Resolvendo este problema para o segundo exemplo numérico chegamos ao valor verdadeiro da mercadoria composta igual a 1,15 unidades de trabalho, que é minimizado para

$$
\mathbf{q}^{0}=\left[\begin{array}{c}
10 \\
4,2 \\
5,4 \\
3,8
\end{array}\right]
$$

Então, também, neste caso verificamos que o valor do produto líquido é igual ao total de trabalho empregado.

Podemos obter o dual do problema descrito nas eqs. (4.109)-(4.111). Resolvendo este problema dual obtemos o valor-trabalho ótimo da mercadoria industrial igual a 0,10593 e do cereal igual a 0,13559 , e segue que:

$$
v_{y}=1,15<\sum v_{o i} y_{i}=1,2585
$$

Por outro lado, os valores-trabalho verdadeiros individuais das mercadorias industrial e agrícola são, respectivamente, 0,09842 e 0,09055. Temos, então

$$
v_{y}=1,15>\sum v_{y i} y_{i}=0,86811
$$

Modificando $\theta$, como anteriormente, obtemos as relações $V-\theta, \sigma-\theta$ e $\sigma-V$, mostradas na figura 4.5. Estas relações descrevem o mesmo comportamento daquele 
analisado no primeiro exemplo numérico, ou seja, a primeira apresenta uma relação crescente, e as restantes decrescentes. A relação entre a taxa de mais-valia e a taxa de lucro, apresentada na figura 4.6, é crescente como no exemplo anterior.

Deve-se salientar que a relação entre $V$ e $\theta$ possui três segmentos, não muito definidos em detrimento das dimensões da figura 4.5a. Isto ocorre devido ao fato de que temos três qualidades de terra neste exemplo. Os dois vértices desta poligonal ocorrem quando $\theta=0,315$ e $\theta=0,94$, aproximadamente.

A taxa de lucro se torna zero para $\theta=1,0216$. No entanto, a mais-valia é positiva para $\theta \leq 1,118$. Há, portanto, um intervalo de valores de $\theta$ para o qual a mais-valia é positiva mas a economia é inviável porque não há lucro positivo. Esse resultado mostra, novamente, que a existência de mais-valia positiva não é condição suficiente para lucro positivo.

\subsubsection{Reversão de técnicas}

Nesta seção vamos considerar um sistema com quatro processos, duas mercadorias industriais e uma agrícola. Admite-se que existam terras de qualidades $\alpha$ e $\beta$. Vamos assumir que apenas uma das duas qualidades de terra não é suficiente para suprir toda a demanda da economia, mas, por outro lado, não é necessário utilizar toda a área das duas qualidades de terra para atender esta demanda. Admitimos, ainda, que as três mercadorias são básicas.

Então, o sistema econômico pode ser representado como segue:

$q_{11}$ merc. $1 \oplus q_{21}$ merc. $2 \oplus q_{31}$ merc. $3 \oplus L_{1}$ trabalho $\rightarrow q_{1}$ merc. 1

$q_{12}$ merc. $1 \oplus q_{22}$ merc. $2 \oplus q_{32}$ merc. $3 \oplus L_{2}$ trabalho $\rightarrow q_{2}$ merc. 2

$q_{13}$ merc. $1 \oplus \dot{q}_{23}$ merc. $2 \oplus q_{33}$ merc. $3 \oplus L_{2}$ trabalho $\oplus H_{1}$ terra $\alpha \rightarrow q_{3}$ merc. 3

$q_{14}$ merc. $1 \oplus q_{24}$ merc. $2 \oplus q_{34}$ merc. $3 \oplus L_{4}$ trabalho $\oplus H_{2}$ terra $\beta \rightarrow q_{4}$ merc. 3 


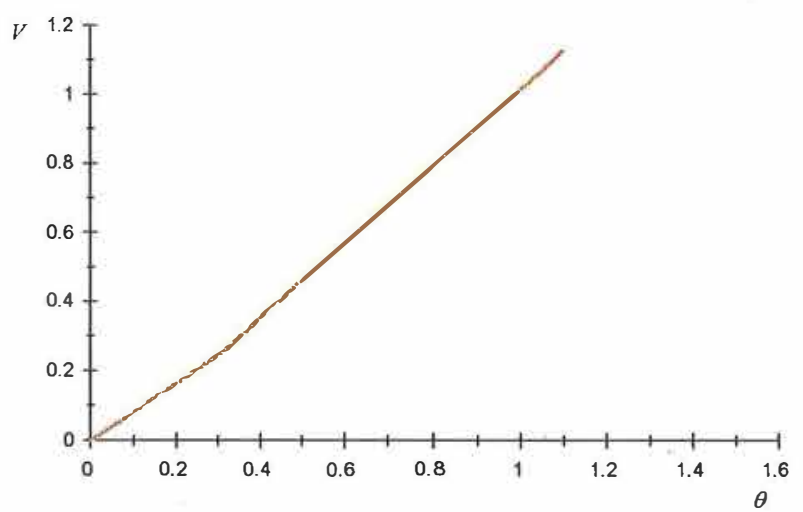

a)

$\sigma$

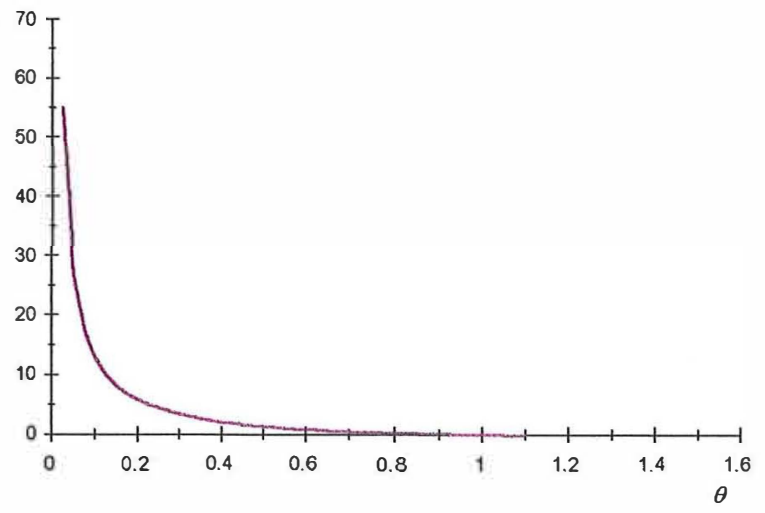

b)

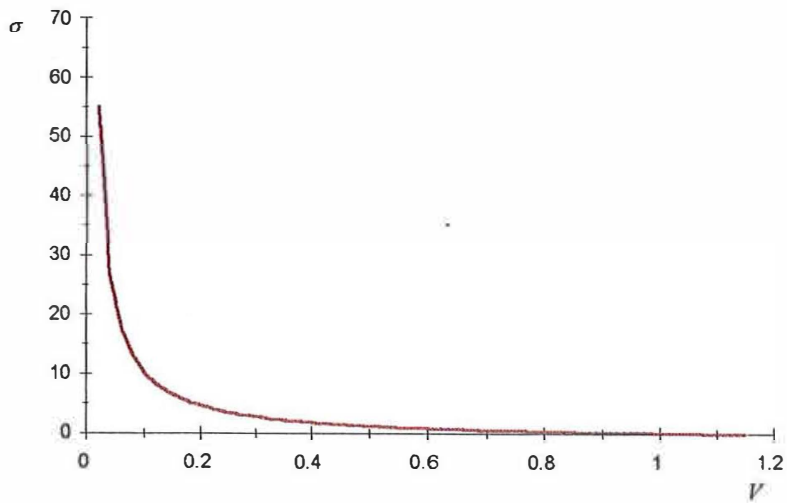

c)

Figura 4.5 Relações $V-\theta, \sigma-\theta$ e $\sigma-V$, para o modelo marxista com terras de diferentes qualidades, segundo exemplo numérico. 


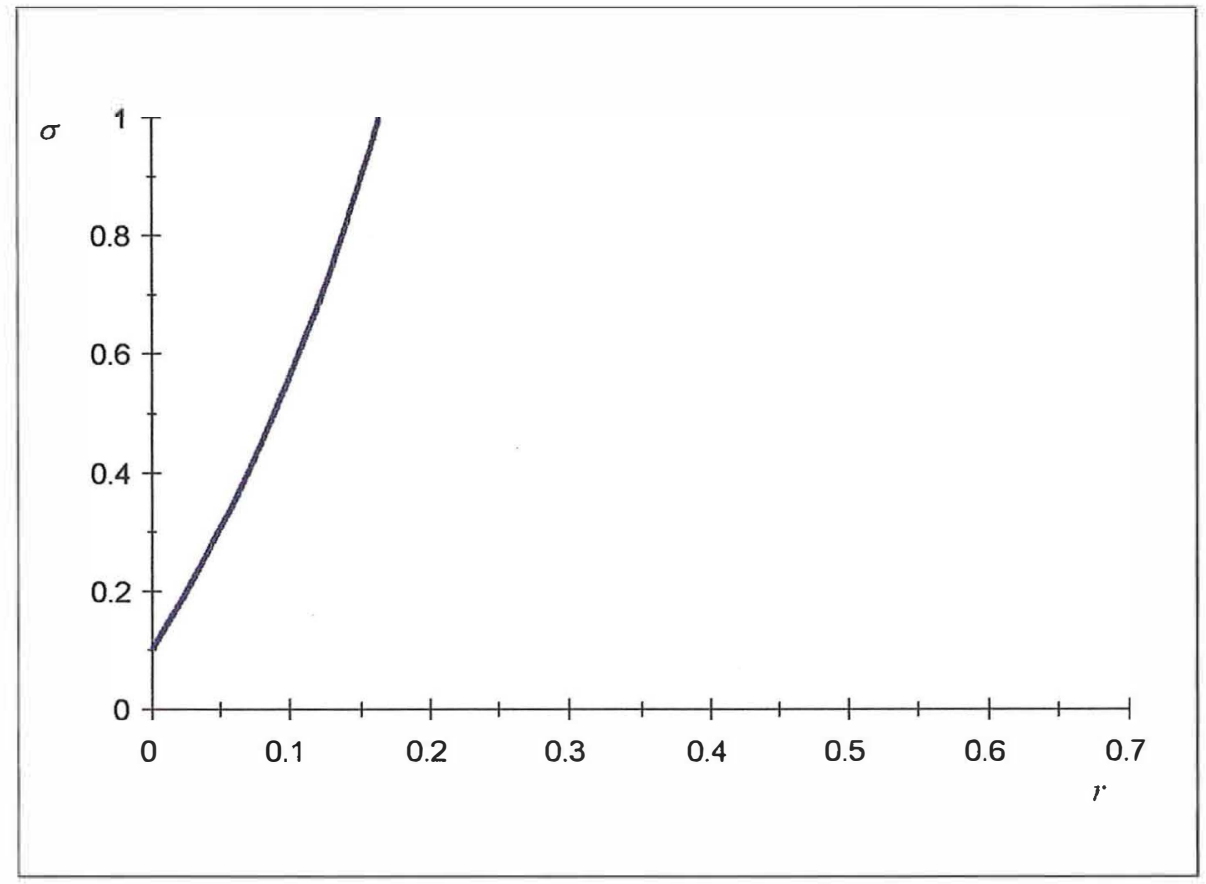

Figura 4.6 Relação $\sigma-r$ para modelos com terras de diferentes qualidades, Segundo o exemplo numérico

Podemos, facilmente, colocar este sistema na forma descrita na eq.(4.77), como visto anteriormente:

$$
(\mathbf{p A}+\mathbf{p d b})(1+r)+\left[\begin{array}{ll}
\mathbf{0} & \mathbf{t H}
\end{array}\right]=\mathbf{p B}
$$

Neste caso, obtemos dois subsistemas preços de produção-taxa de lucro: um considerando a terra de qualidade $\alpha$ como marginal, e o outro, posteriormente, supondo o mesmo para a terra de qualidade $\beta$. Fixando exogenamente o vetor $\mathbf{d}$, cada subsistema fornece uma determinada taxa de lucro e os respectivos preços relativos.

Comparando as taxas de lucro podemos estabelecer a terra menos eficiente, ou a terra marginal, e a mais eficiente, que possui uma renda positiva. Esta renda pode ser obtida através da eq. (4.78).

Vamos considerar o terceiro exemplo numérico: 
0,5 merc. $1 \oplus 0 \quad$ merc. $2 \oplus 1 \quad$ merc. $3 \oplus 1$ trabalho $\rightarrow 1,1$ merc. 1

$0 \quad$ merc. $1 \oplus 0,05$ merc. $2 \oplus 1 \quad$ merc. $3 \oplus 10$ trabalho $\rightarrow 1,1$ merc. 2

0,1 merc. $1 \oplus 0 \quad$ merc. $2 \oplus 0,2$ merc. $3 \oplus 10$ trabalho $\oplus 1$ terra $\alpha \rightarrow 2,2$ merc. 3

$0 \quad$ merc. $1 \oplus 1 \quad$ merc. $2 \oplus 0,2$ merc. $3 \oplus 0,4$ trabalho $\oplus 1$ terra $\beta \rightarrow 4$ merc. 3

Podemos observar que o produto líquido deste sistema econômico é constituído de 0,5 unidades da mercadoria um, 0,05 unidades da mercadoria dois e 3,8 unidades da mercadoria três.

Além disso, fixamos

$$
\mathbf{d}=\left[\begin{array}{c}
0,2 \\
0,03 \\
1,5
\end{array}\right]
$$

Podemos, então, estabelecer as relações entre as variáveis distributivas modificando o vetor $\mathbf{d}$, proporcionalmente, como anteriormente. Com isto, obtemos a figura 4.7, que será analisada a seguir.

Considerando a demanda por cereal, a ordem de eficiência das terras $\alpha$ e $\beta$ pode ser estabelecida, observando-se a relação entre $\theta r$ na figura 4.6a. A taxa de lucro máxima para a terra $\alpha$ é 0,83 e para a terra $\beta$ é 0,91 . Existem dois pontos de mudança de eficiência das terras: o ponto $B$, em que $r=0,35$ e $\theta=0,047$ e o ponto $C$, em que $r=0,78$ e $\theta=0,005$. Deve-se ressaltar que a região economicamente significativa para este sistema econômico é entre os pontos $A$ e $D$ ou $0<r<0,83$. Com isto, entre os pontos $A$ e $B$ e entre os pontos $C$ e $D$ a terra $\beta$ é a mais eficiente, e o contrário ocorre entre os ponto $B$ e $C$, em que a terra $\alpha$ é a mais eficiente. Verificamos, portanto, que é possível ocorrer uma reversão na ordem de eficiência também nos modelos que incluem o setor agrícola. 


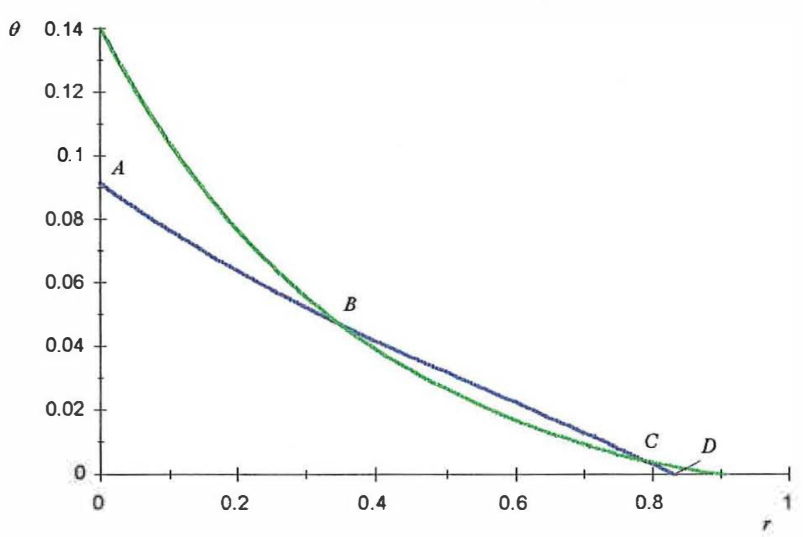

a)

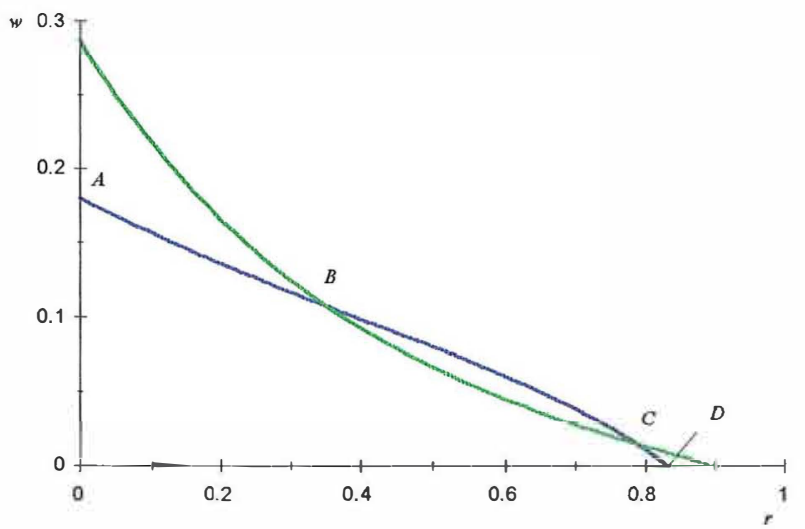

b)

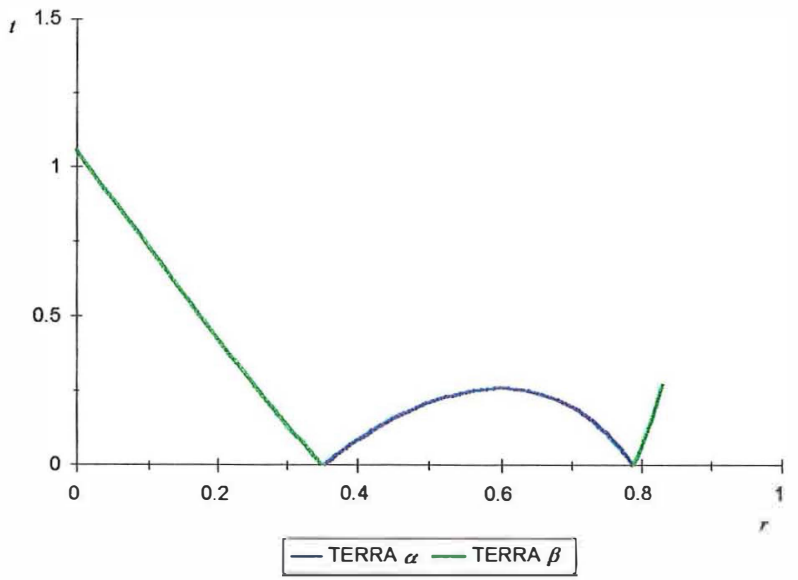

c)

Figura 4.7 Relações $\theta-r, w-r$ e $t-r$, modelo sraffiano-marxista em termos de preços de produção com terras de diferentes qualidades, terceiro exemplo numérico. 
De acordo com a suposição sobre a demanda, ambas as qualidades de terra devem ser cultivadas, mesmo que a terra marginal não seja totalmente cultivada. Assim, tanto o salário quanto a taxa de lucro devem ser determinados na terra marginal, para que $o$ sistema possa ser viável. Em outros termos, a fronteira tecnológica dessa economia é formada pela parte interna das relações $w-r$, na figura $4.7 \mathrm{~b}$. O salário máximo é 0,018 unidades monetárias em termos da mercadoria agrícola e a taxa de lucro máxima é 0,83. Em um primeiro momento, a fronteira tecnológica é formada com a relação $w-r$ da terra $\alpha$ (entre os pontos $A$ e $B$ ), posteriormente com a relação $w-r$ da terra $\beta$ (entre os pontos $B$ e $C$ ), e finalmente, volta a ser constituída com a relação $w-r$ da terra $\alpha$ (entre os pontos $C$ e $D)$.

Então, temos, correspondentemente, que a renda da terra primeiro é paga apenas na terra $\beta$, em seguida na terra $\alpha$, e por fim, novamente na terra $\beta$, como observamos na figura 4.6c. Assim, a renda da terra é paga na terra mais eficiente, enquanto, a fronteira tecnológica é definida naquela menos eficiente, dada a suposição sobre a demanda.

Formalmente, o valor verdadeiro da mercadoria composta para um modelo com duas mercadorias industriais sem processos alternativos e uma mercadoria agrícola com dois processos alternativos, pode ser obtido pelo seguinte problema de programação linear:

$$
\text { Minimizar } \quad\left[\begin{array}{llll}
b_{1} & b_{2} & b_{3} & b_{4}
\end{array}\right]\left[\begin{array}{l}
q_{1} \\
q_{2} \\
q_{3} \\
q_{4}
\end{array}\right]
$$

com

$$
\left[\begin{array}{cccc}
1-a_{11} & -a_{12} & -a_{13} & -a_{14} \\
-a_{21} & 1-a_{22} & -a_{23} & -a_{24} \\
-a_{31} & -a_{32} & 1-a_{33} & 1-a_{34}
\end{array}\right]\left[\begin{array}{l}
q_{1} \\
q_{2} \\
q_{3} \\
q_{4}
\end{array}\right] \geq\left[\begin{array}{l}
y_{1} \\
y_{2} \\
y_{3}
\end{array}\right]
$$




$$
\left[\begin{array}{cc}
h_{\alpha} & 0 \\
0 & h_{\beta}
\end{array}\right]\left[\begin{array}{l}
q_{3} \\
q_{4}
\end{array}\right] \leq\left[\begin{array}{l}
s_{\alpha} \\
s_{\beta}
\end{array}\right]
$$

com $q_{i} \geq 0$, para $i=1,2,3$ e 4 .

Considerando o terceiro exemplo numérico e fazendo os cálculos, obtemos 21,4 unidades de trabalho como o valor da mercadoria composta, que é minimizado para

$$
\mathbf{q}^{0}=\left[\begin{array}{c}
1,1 \\
1,1 \\
2,2 \\
4
\end{array}\right]
$$

Podemos verificar que ocorrem as desigualdades referentes aos valores-trabalho ótimos e aos valores verdadeiros individuais:

$$
\begin{aligned}
v_{y}=21,4<\sum v_{o i} y_{i} & =(10,9091)(0,5)+(14,8052)(0,05)+(5,54545)(3,8) \\
& =27,2675 \\
\text { e } \quad v_{y}=21,4>\sum v_{y i} y_{i} & =(7,47492)(0,5)+(12,84281)(0,05)+(3,48495)(3,8) \\
& =17,6224
\end{aligned}
$$

Vamos supor que os bens necessários à vida de um trabalhador sejam dados no vetor d, eq. (4.123), ou por uma proporção $(\theta)$ do mesmo. Além disso, temos que o total de trabalhadores empregados $(N)$ nesse sistema é igual a 21,4 unidades de trabalho. $\mathrm{O}$ valor do capital variável é obtido substituindo os elementos do vetor de produtos líquidos na eq. (4.125), pelos respectivos elementos do vetor $\theta N \mathbf{d}$. Além disso, já vimos que para cada valor da constante $\theta$ obtemos um valor para o capital variável e a correspondente taxa de mais-valia. Dessa forma, chegamos à figura 4.8 apresentada a seguir.

A relação entre o capital variável e a constante $\theta$ é descrita por uma poligonal com dois segmentos cujo vértice ocorre no ponto em que $\theta=0,071$. Esta mudança de inclinação ocorre devido ao fato de que as duas qualidades de terra não são igualmente produtivas, considerando o total de trabalho empregado. $\mathrm{O}$ valor da parcela do produto líquido que fica com os trabalhadores é calculado primeiro na terra $\beta$, mais produtiva em 


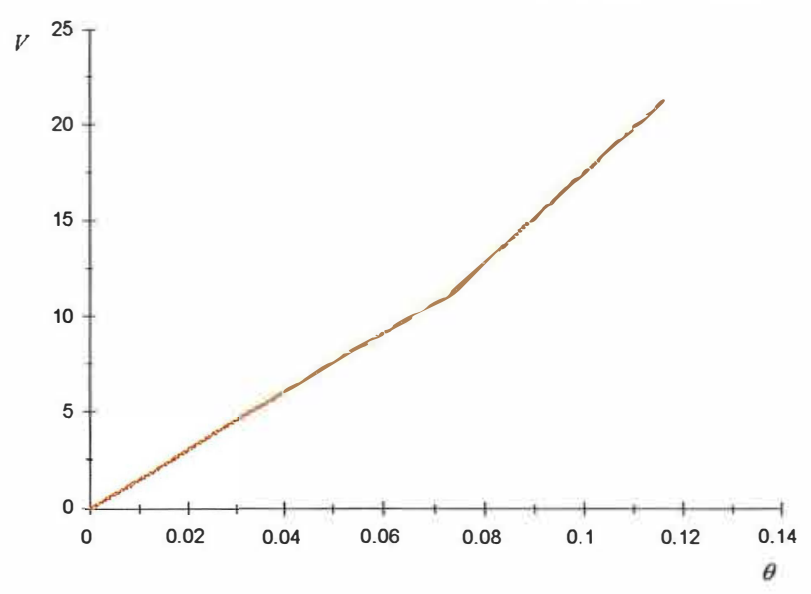

a)

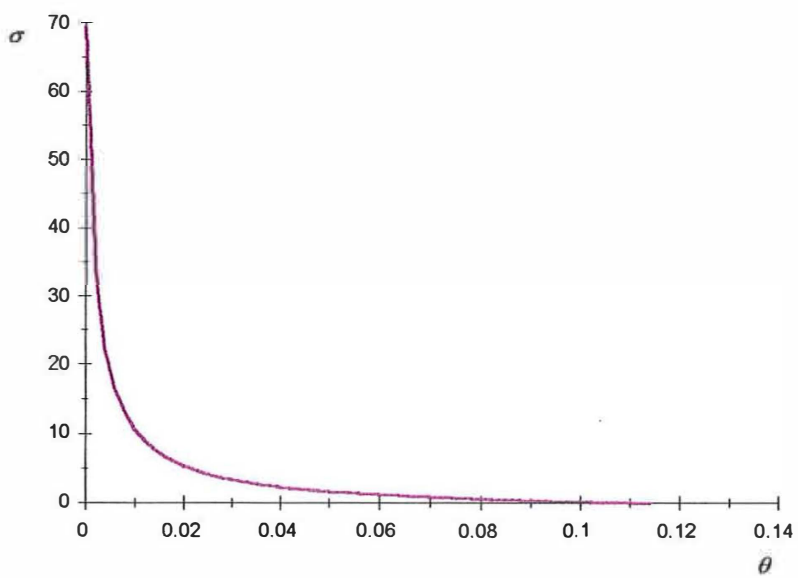

b)

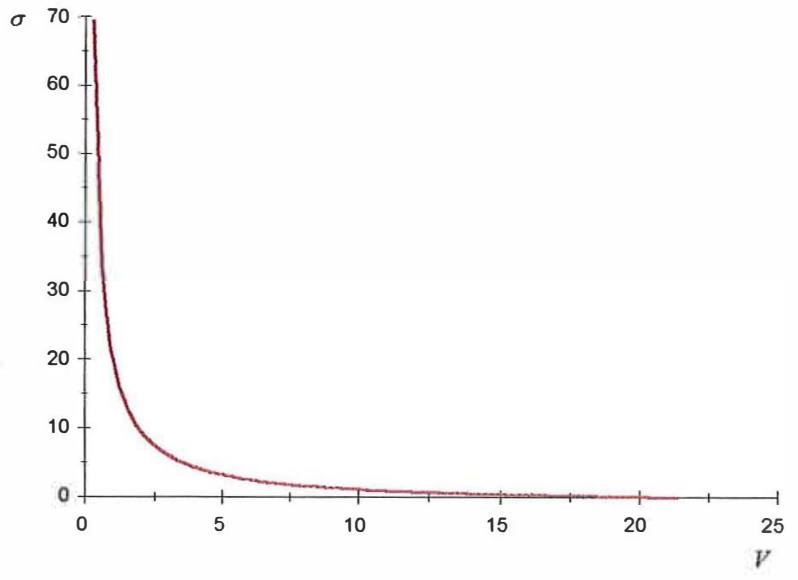

c)

Figura 4.8 Relações $V-\theta, \sigma-\theta$ e $\sigma-V$ para o modelo marxista com terras de diferentes qualidades, terceiro exemplo numérico. 


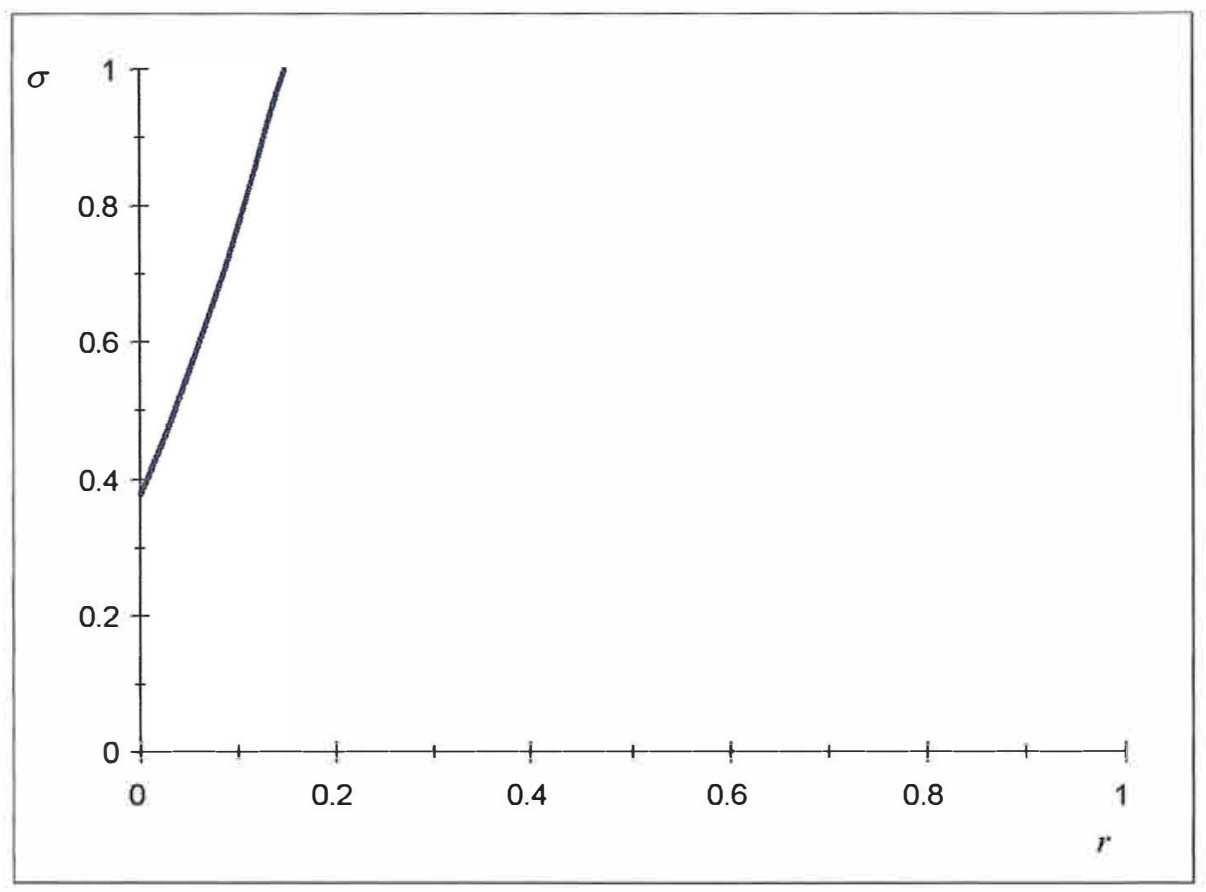

Figura 4.9 Relação $\sigma-r$ para modelos com terra de diferentes qualidades, segundo o exemplo numérico.

termos do trabalho empregado, e em seguida na terra $\alpha$. A partir daí temos, então, uma mudança de inclinação. As relações mostradas nas figuras 4.8b, 4.8c e 4.9 apresentam as mesmas características gerais descritas no primeiro exemplo numérico, como pode ser facilmente verificado.

\subsubsection{Terra Homogênea}

\subsubsection{Os valores-trabalho}

Nesta seção vamos considerar apenas uma abordagem para a determinação dos valores-trabalho, aquela que utiliza a sugestão de Morishima. Vamos considerar um sistema econômico que inclui uma mercadoria agrícola, produzida de maneira intensiva em uma terra de qualidade homogênea, com duas técnicas alternativas. Seja h um vetorlinha com as áreas, em hectares, utilizadas com cada uma das duas técnicas alternativas 
para produzir uma unidade da mercadoria agrícola, com elementos $h_{m}, \operatorname{com} m=\alpha$ e $\beta$. Seja $s$ a área de terra disponível. Então, o valor verdadeiro do vetor de produto líquido desse sistema pode ser obtido, em geral, utilizando o seguinte problema de programação linear:

$$
\text { Minimizar } \quad v_{y}=\mathbf{b q}
$$

com

$$
\begin{aligned}
\mathbf{B q} & \geq \mathbf{A q}+\mathbf{y} \text { ou }(\mathbf{B}-\mathbf{A}) \mathbf{q} \geq \mathbf{y} \\
\mathbf{h} \mathbf{q}_{z} & \leq s \\
\mathbf{q} & \geq \mathbf{0}
\end{aligned}
$$

Como foi realizado no item anterior, podemos obter os valores individuais através do dual do problema de programação linear acima, indicado por:

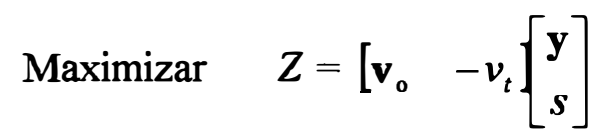

com

$$
\begin{aligned}
& \mathbf{v}_{o}(\mathbf{B}-\mathbf{A})-\left[\begin{array}{ll}
\mathbf{0} & v_{t} \mathbf{h}
\end{array}\right] \leq \mathbf{b} \\
& \mathrm{e} \quad \mathbf{v}_{o} \geq \mathbf{0} \text { e } v_{t} \geq \mathbf{0}
\end{aligned}
$$

O problema de minimização acima pode ser reformulado para fornecer os valores verdadeiros individuais, como visto anteriormente. Além disso, nas próximas seções vamos utilizar $e_{1}$, ver eq. (4.27), como medida da exploração ou como a taxa de maisvalia. 


\subsubsection{Os preços de produção}

Similarmente ao modelo sraffiano com terras de mesma qualidade, eq. (4.3), e considerando o modelo indicado na eq.(3.10), o modelo sraffiano-marxista em termos de preços de produção com terras homogêneas, pode ser descrito por

$$
(\mathbf{p A}+\mathbf{b} w)(1+r)+\left[\begin{array}{ll}
\mathbf{0} & \mathbf{t h}
\end{array}\right]=\mathbf{p B}
$$

Como no caso do modelo sraffiano, a matriz $\mathbf{H}$ e $\mathbf{o}$ vetor $\mathbf{t}$ são redefinidos considerando a existência de técnicas alternativas em uma terra de qualidade homogênea. Salienta-se, também, que neste modelo o salário em termos fisicos é previamente fixado, ou seja, temos $w=$ pd. Então, da eq. (4.137), temos

$$
(\mathbf{p A}+\mathbf{p d b})(1+r)+\left[\begin{array}{ll}
\mathbf{0} & \mathbf{t H}
\end{array}\right]=\mathbf{p B}
$$

O sistema econômico acima possui $\boldsymbol{n}_{a}+4$ incógnitas $\left(\boldsymbol{n}_{a}\right.$ preços das mercadorias industriais, a renda da terra, a taxa de lucro, o salário e o preço da mercadoria agrícola), com $n_{a}+2$ equações, considerando dois métodos de cultivo. Fixando o vetor d exogenamente e tomando uma das mercadorias como numerário, obtemos uma solução única para este sistema.

Veremos, a seguir, que tanto no caso da mercadoria agrícola ser considerada uma mercadoria não-básica quanto básica, é sempre possível dividir o sistema acima, eq. (4.138), em dois subsistemas: um denominado subsistema preços de produção-taxa de lucro e o outro subsistema renda. O subsistema preços de produção-taxa de lucro constitui-se em um sistema com produção simples e, portanto, produz soluções economicamente significativas, como visto no capítulo 3.

\section{A DETERMINAÇÃO DA RENDA INTENSIVA PARA UMA MERCADORIA AGRÍCOLA $N \tilde{A} O-B \dot{A} S I C A$}

Neste item vamos analisar o caso em que apenas a mercadoria agrícola é nãobásica, considerando o sistema econômico descrito na eq.(4.138). Supomos que as mercadorias que compõem o salário real dos trabalhadores são básicas. Neste caso os 
preços relativos e a taxa de lucro são determinados no subsistema preços de produçãotaxa de lucro, como visto para o caso de terras de diferentes qualidades. Este subsistema é formado pelas $\boldsymbol{n}_{a}$ primeiras equações referentes às mercadorias industriais, como segue:

$$
\left(\mathbf{p}_{a} \mathbf{A}_{a}+\mathbf{p}_{a} \mathbf{d b}_{a}\right)\left(1+\boldsymbol{r}_{a}\right)=\mathbf{p}_{a}
$$

A seguir, vamos analisar a determinação do preço da mercadoria agrícola e da renda da terra.

Inicialmente, existem duas técnicas que podem ser utilizadas na terra de qualidade homogênea. Vamos indicar por $\alpha$ e por $\beta$ estas técnicas de cultivo do cereal.

O preço da mercadoria agrícola pode ser determinado de três maneiras: cada técnica pode ser utilizada individualmente, ou ambas as técnicas podem ser empregadas lado a lado. No primeiro caso a terra não é escassa e, portanto, não existe o pagamento de renda. Assim, se apenas a técnica $\alpha$ está sendo utilizada, o preço da mercadoria agrícola $\left(p_{\alpha}\right)$ é determinado, em geral, como segue:

$$
\left(\mathbf{p}_{a} \mathbf{a}_{\alpha}+\mathbf{p}_{a} \mathbf{d} b_{\alpha}\right)\left(1+r_{a}\right)=p_{\alpha}
$$

Ou seja, conhecendo as condições técnicas ( $\mathbf{a}_{\alpha} \mathrm{e} b_{\alpha}$ ), o vetor $\mathbf{d}$, a taxa de lucro e os preços das mercadorias industriais (obtidos no subsistema preços de produção-taxa de lucro) determinamos o preço do cereal produzido com a técnica $\alpha\left(p_{\alpha}\right)$. Notemos que na equação acima temos $t=0$.

De maneira análoga, se apenas a técnica $\beta$ é utilizada, então o preço da mercadoria agrícola será $p_{\beta}$, determinado como segue:

$$
\left(\mathbf{p}_{a} \mathbf{a}_{\beta}+\mathbf{p}_{a} \mathbf{d} b_{\beta}\right)\left(1+r_{a}\right)=p_{\beta}
$$

Por fim, no segundo caso, como as duas técnicas estão sendo utilizadas, a terra é escassa e uma renda homogênea passa a ser paga. Então, estas duas técnicas são descritas por: 


$$
\begin{aligned}
& \left(\mathbf{p}_{a} \mathbf{a}_{\alpha}+\mathbf{p}_{a} \mathrm{~d} b_{\alpha}\right)\left(1+r_{a}\right)+t h_{\alpha}=p_{\alpha \beta} \\
& \left(\mathbf{p}_{a} \mathbf{a}_{\beta}+\mathbf{p}_{a} \mathbf{d} b_{\beta}\right)\left(1+r_{a}\right)+t h_{\beta}=p_{\alpha \beta}
\end{aligned}
$$

Assim, teremos duas incógnitas ( $p_{\alpha \beta}$, o preço da mercadoria agrícola e $t$, a renda da terra) e duas equações.

A técnica, ou a combinação de técnicas, mais eficiente será aquela que possuir o menor preço de produção: $p_{\alpha}$ ou $p_{\beta}$ ou, ainda, $p_{\alpha \beta}$.

Deve-se salientar que em primeira instância a determinação do preço da mercadoria agrícola dependerá da demanda final por cereal. Esta indicará a necessidade de se produzir apenas com a técnica mais eficiente, menos eficiente, ou com ambas as técnicas. Quando apenas uma técnica, utilizada em uma parte da terra homogênea, é suficiente para suprir a demanda, não existe renda, pois não há escassez. Por outro lado, quando é necessária a utilização de ambas as técnicas lado a lado, para suprir a demanda por cereal, surge a renda da terra devido à escassez de terra.

Quando ocorre o pagamento de renda, devemos satisfazer a condição econômica de uma renda não-negativa. Para tanto, o método que produz o maior retorno por unidade de área deverá apresentar o maior custo por unidade de produto (Sraffa, 1985). O custo unitário por unidade produzida de cereal $(\psi)$ inclui o lucro, o salário e o valor dos meios de produção, então, para as eqs. (4.142a) e (4.142b) teremos:

$$
\left(\mathbf{p}_{a} \mathbf{a}_{m}+\mathbf{p}_{a} \mathbf{d} b_{m}\right)\left(1+r_{a}\right)=\psi_{m}
$$

onde $m=\alpha$ e $\beta$.

Vamos indicar a produção por unidade de terra por $\frac{1}{h_{m}}, \operatorname{com} m=\alpha$ e $\beta$, ou seja, o inverso da intensidade do uso da terra.

Assim, podemos rescrever (4.142a) e (4.142b): 


$$
\begin{aligned}
& \psi_{\alpha}+t h_{\alpha}=p_{\alpha \beta} \\
& \psi_{\beta}+t h_{\beta}=p_{\alpha \beta}
\end{aligned}
$$

Resolvendo as eqs. (4.144a) e (4.144b) para $t$, obtemos

$$
t=\frac{\psi_{\alpha}-\psi_{\beta}}{h_{\beta}-h_{\alpha}}
$$

ou seja, a renda, e consequentemente o preço da mercadoria agrícola, são positivos se, e somente se, a técnica $i$ com o maior custo unitário $\left(\psi_{i}>\psi_{j}\right)$, corresponder à técnica com uma menor intensidade do uso da terra $\left(h_{j}>h_{i}\right)$ ou uma maior produtividade $\left(\frac{1}{h_{i}}>\frac{1}{h_{j}}\right)($ Kurz, 1980).

Ressalta-se que no caso em que o salário é composto apenas por mercadorias não-básicas ou básicas e não-básicas, a determinação da taxa de lucro e dos preços de produção das mercadorias básicas dependerá das equações referentes a estas mercadorias não-básicas. ${ }^{50}$ Além disso, como o cereal possui técnicas alternativas, a solução para o subsistema preços de produção-taxa de lucro dependerá de quais técnicas estarão sendo utilizadas (ou de qual técnica estará sendo utilizada).

\section{A DETERMINAÇÃO DA RENDA INTENSIVA PARA UMA MERCADORIA AGRÍCOLA $B \dot{A} S I C A$}

Quando a mercadoria agrícola é básica, como as demais mercadorias do sistema, o subsistema preços de produção-taxa de lucro é composto por $\boldsymbol{n}_{a}$ equações referentes às mercadorias industriais mais uma equação referente à mercadoria agrícola. ${ }^{51}$ Esta

\footnotetext{
${ }^{50}$ Salienta-se que neste item o cereal é a única mercadoria não-básica no sistema econômico.

${ }^{51}$ Neste caso, o salário real é composto por mercadorias básicas. No entanto, caso existam mercadorias industriais não-básicas, e estas façam parte do salário real, a solução do subsistema preços de produçãotaxa de lucro dependerá das equações referentes a estas mercadorias.
} 
equação referente à mercadoria agrícola pode ser estabelecida de três maneiras, consequentemente, podemos definir três subsistemas preços de produção-taxa de lucro.

Primeiro, podemos tomar cada técnica isoladamente, ou seja, uma equação referente ao setor agrícola é obtida quando apenas a técnica $\alpha$ está sendo empregada e a outra quando apenas a técnica $\beta$ está sendo utilizada, descritas respectivamente por:

$$
\begin{aligned}
& \left(\mathbf{p a} \mathbf{a}_{\alpha}+\mathbf{p d} b_{\alpha}\right)(1+r)=p_{\alpha} \\
& \left(\mathbf{p a}_{\beta}+\mathbf{p d} b_{\beta}\right)(1+r)=p_{\beta}
\end{aligned}
$$

Nestes dois primeiros casos não existe o pagamento da renda da terra.

Segundo, quando as duas técnicas estão sendo empregadas simultaneamente, teremos, então

$$
\begin{aligned}
& \left(\mathbf{p a} \mathbf{a}_{\alpha}+\mathbf{p d} b_{\alpha}\right)(1+r)+t h_{\alpha}=p_{\alpha \beta} \\
& \left(\mathbf{p a}_{\beta}+\mathbf{p d} b_{\beta}\right)(1+r)+t h_{\beta}=p_{\alpha \beta}
\end{aligned}
$$

Obtemos das equações acima uma única equação em que a única incógnita é o preço da mercadoria agrícola. Isto pode ser realizado facilmente, como segue: inicialmente, multiplicamos a eq. (4.148a) por $\frac{1}{h_{\alpha}}$ e a eq. (4.148b) por $\left(-\frac{1}{h_{\beta}}\right)$; e, posteriormente, somamos as duas equações resultantes. Desse modo, eliminamos $t \mathrm{e}$ obtemos uma única equação, que pode ser agregada às equações referentes ao setor industrial, formando o terceiro subsistema preços de produção-taxa de lucro. Apenas neste caso existe uma renda da terra positiva. Após obtermos a taxa de lucro e os preços de produção para um vetor $\mathbf{d}$ fixado exogenamente, obtemos a renda da terra utilizando a eq. (4.148a) ou a eq. (4.148b).

Em geral, podemos escrever estes três subsistemas como:

$$
\left(\mathbf{p}_{m} \mathbf{A}_{m}+\mathbf{p}_{m} \mathbf{d b}_{m}\right)\left(1+r_{m}\right)=\mathbf{p}_{m}
$$


onde $m=\alpha, \beta$ e $\alpha \beta$.

A análise dos custos realizada anteriormente para o caso de uma mercadoria agrícola não-básica pode ser empregada, também, neste caso. Das eqs. (4.148a) e (4.148b) redefinimos os custos $(\varphi)$, como segue

$$
\left(\mathbf{p} \mathbf{a}_{m}+\mathbf{p d} b_{m}\right)\left(1+r_{a}\right)=\varphi_{m}
$$

onde $m=\alpha$ e $\beta$. Similarmente, teremos de (4.148a), (4.148b) e (4.150):

$$
t=\frac{\varphi_{\alpha}-\varphi_{\beta}}{h_{\beta}-h_{\alpha}}
$$

Como anteriormente, a técnica que produzir com o maior custo por unidade de produto deverá possuir a maior produtividade, para garantir uma renda positiva.

\subsubsection{Mercadoria agrícola não-básica}

\subsection{A determinação do preço da mercadoria agrícola e da renda da terra}

Vamos tratar, primeiramente, de um sistema com três processos de produção, 0 primeiro referente a uma mercadoria industrial e os dois últimos referentes à mercadoria agrícola, com as técnicas $\alpha$ e $\beta$. Supomos que a terra é escassa, caso contrário, apenas o método mais barato seria utilizado $\mathrm{e}$, consequentemente, não haveria renda. Consideremos o primeiro exemplo numérico para o caso de uma terra homogênea:

5 merc. $1 \oplus 0,3$ trabalho $\rightarrow 10,5$ merc. 1

1 merc. $1 \oplus 0,04$ trabalho $\oplus 1$ terra $\rightarrow 2,1$ merc. $2 \quad$ (técnica $\alpha$ )

2 merc. $1 \oplus 0,5$ trabalho $\oplus 1$ terra $\rightarrow 3,2$ merc. $2 \quad$ (técnica $\beta$ )

Supomos que o salário real seja composto por 1,2 unidades da mercadoria industrial. Vamos considerar a mercadoria industrial como o numerário do sistema. 
Neste exemplo o subsistema preços de produção-taxa de lucro é formado por apenas uma equação, aquela referente à mercadoria industrial, única mercadoria básica do sistema, descrita na eq. (4.152). Neste caso, a fronteira tecnológica dessa economia é determinada, exclusivamente, a partir dessa equação.

Lembrando a eq. (4.139) e estabelecido o salário real, determinamos a taxa de lucro, igual a 0,959. A partir daí obtemos o preço do cereal para o caso em que consideramos que apenas a técnica $\alpha$ ou a técnica $\beta$, ou ainda, ambas as técnicas, estão sendo utilizadas, lembrando, respectivamente, as eqs. (4.140), (4.141) e (4.142). Podemos determinar a renda da terra no caso em que ambas as técnicas estão sendo utilizadas lado a lado. Além disso, sabemos que quando uma técnica está sendo empregada isoladamente a renda da terra é nula. Com isto, podemos estabelecer uma relação entre o preço da mercadoria agrícola e a renda da terra, apresentada na figura 4.10.

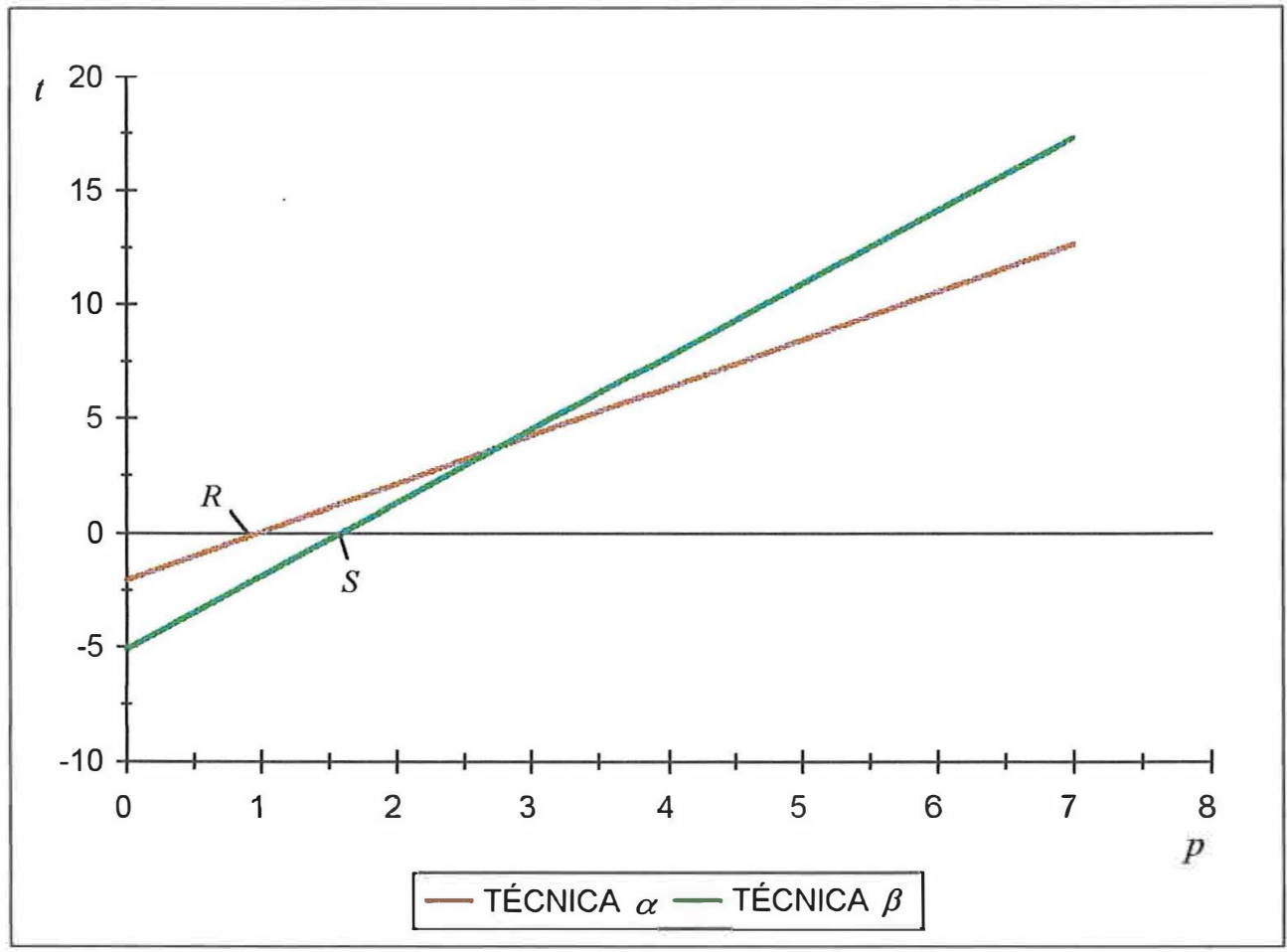

Figura 4.10 A determinação do preço de uma mercadoria agrícola nãobásica. 
As inclinações das duas linhas correspondem às produtividades fisicas das técnicas de produção e as distâncias $0 R$ e $O S$ aos preços ou custos por unidade de produto para as técnicas $\alpha$ e $\beta$, respectivamente. Então, a técnica $\beta$ possui a maior produtividade e o maior custo unitário.

Supomos, por um momento, que a demanda por cereal é pouco expressiva e pode ser atendida cultivando parte da terra com a técnica $\alpha$. Neste caso, a renda é igual a zero e o custo ou preço da mercadoria agrícola é igual a 0,978 unidades monetárias, mensurado em termos da mercadoria industrial, que é representado pela distância $0 R$. Esta técnica possui tanto uma produtividade menor quanto um custo menor.

Um aumento na demanda do produto agrícola levará à utilização da técnica $\beta$, uma vez que mesmo ocupando toda a área disponível, a técnica $\alpha$ não é capaz de satisfazer completamente a demanda. Consequentemente, o preço da mercadoria agrícola deverá subir até o ponto em que seja viável empregar a técnica $\beta$, ou seja, quando $p$ é igual a 2,763. Como as duas técnicas estão sendo utilizadas simultaneamente, a renda da terra é positiva, e neste caso igual a 3,751 unidades monetárias, mensuradas em termos da mercadoria industrial.

Isto reflete o fato que a terra tornou-se escassa, portanto, o aumento na produção do cereal será alcançado em detrimento de um aumento no custo por unidade produzida do cereal. Tanto a terra ainda cultivada com a técnica $\alpha$, quanto o restante da terra cultivada com a técnica $\beta$ terão a mesma renda por unidade de área, uma vez que a terra é homogênea.

Admitindo que novos crescimentos da demanda ocorram, teremos como consequência uma substituição gradativa da técnica $\alpha$ pela técnica $\beta$, uma vez que esta técnica é mais produtiva que a anterior, mantido o preço relativo e a renda da terra no mesmo patamar. 


\subsubsection{2 $O$ crescimento intensivo na produção da mercadoria agrícola}

Vimos no exemplo anterior que o crescimento da demanda impõe a substituição de uma técnica menos produtiva por outra mais produtiva, que levou, no caso analisado, à substituição crescente da técnica $\alpha$ pela técnica $\beta$. Mas, se a demanda por cereal continua aumentando, uma técnica mais produtiva deve ser empregada ao lado da técnica $\beta$. Isto pode ser visto acrescentando ao exemplo numérico anterior uma terceira técnica, como segue:

$$
2,5 \text { merc. } 1 \oplus 1,6 \text { trabalho } \oplus 1 \text { terra } \rightarrow 4 \text { merc. } 2 \quad \text { (técnica } \gamma \text { ) }
$$

De maneira análoga ao que foi realizado no item anterior, podemos obter a figura 4.11, que representa o crescimento da demanda e a substituição das técnicas de produção.

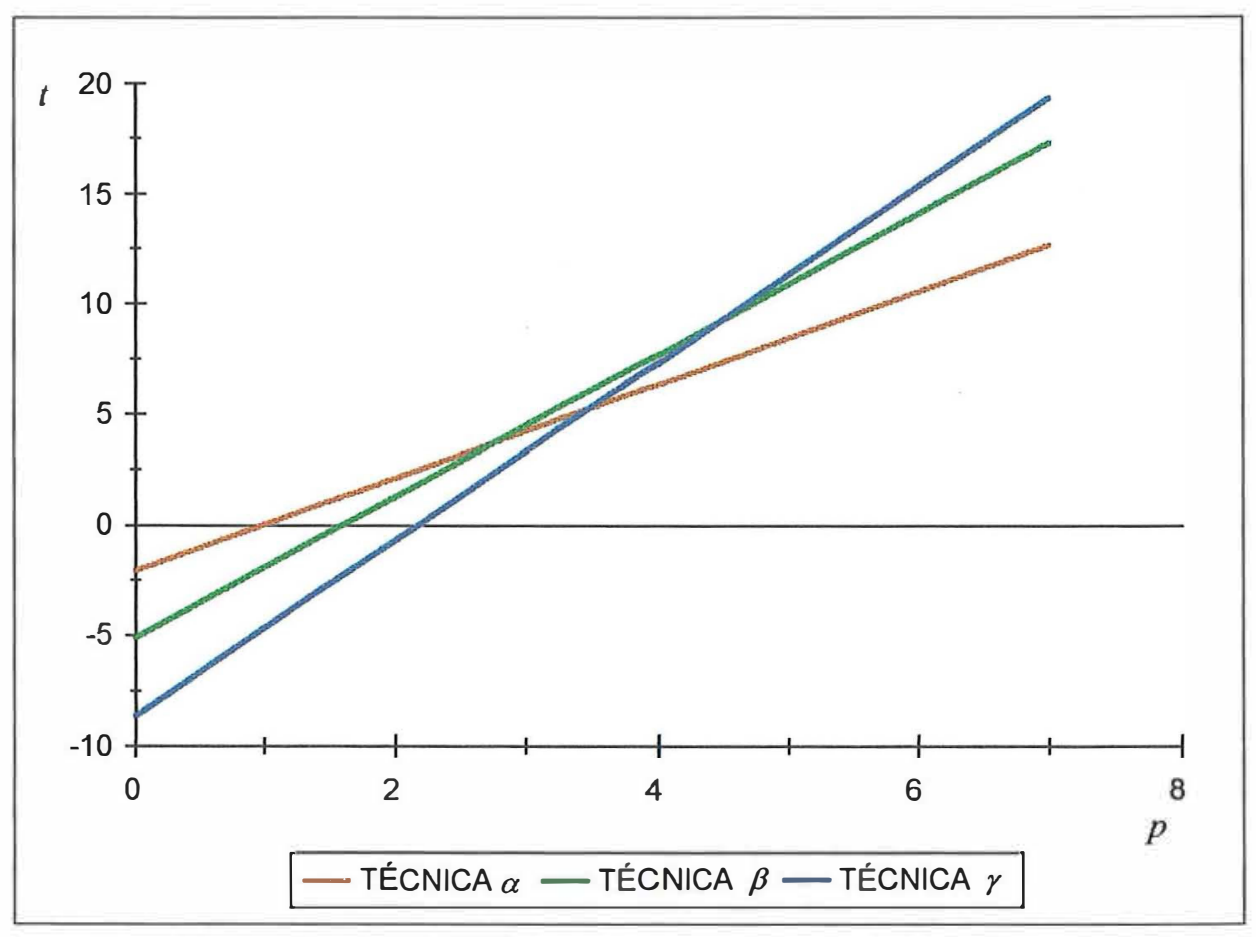

Figura 4.11 Crescimento da demanda por cereal. 
Uma terceira técnica caracterizada por um maior custo por unidade de produto pode ser empregada apenas se o preço do cereal aumentar. Considerando que a técnica $\gamma$ passa a ser empregada juntamente com a técnica $\beta$, a renda paga pelo uso da segunda técnica irá aumentar para 9,167 e ao mesmo tempo o preço relativo do cereal deverá subir para 4,456, sendo que, a renda por unidade de área será a mesma nas duas técnicas.

Este novo patamar para o preço e a renda irá permanecer constante enquanto estas duas técnicas coexistirem, ou seja, enquanto a técnica $\gamma$ não tenha substituído completamente a técnica $\beta$, em decorrência de um aumento na demanda por cereal.

\subsection{As relações entre as variáveis distributivas}

Voltando ao exemplo numérico apresentado nas eq. (4.152)-(4.154), serão analisadas as relações entre as variáveis distributivas no sistema em termos de preços de produção e de valores-trabalho. Neste item vamos considerar a mercadoria agrícola como numerário. Com isto, a solução do subsistema preços de produção-taxa de lucro dependerá das equações relacionadas à mercadoria agrícola.

Modificando a quantidade do produto industrial na cesta de consumo dos trabalhadores, proporcionalmente ao montante 1,2 , obtemos a figura 4.12 . Observamos na figura 4.12.a que a relação entre o salário real e a taxa de lucro é a mesma nas três possibilidades de utilização das técnicas, ou seja, quando apenas a técnica $\alpha$ ou a técnica $\beta$ está sendo utilizada isoladamente ou, ainda, quando as duas técnicas estão sendo utilizadas lado a lado. No entanto, a relação entre o salário em unidades monetárias e a taxa de lucro difere nos três casos, como podemos observar na figura 4.12.b. Isto ocorre porque o numerário do sistema é a mercadoria agrícola e a maneira de determinar o seu preço difere nestas três situações.

$\mathrm{Na}$ figura $4.12 \mathrm{~b}$ notamos que para valores de $r$ entre 0 e 1,09 a técnica mais eficiente é a $\alpha$. Mas, como a demanda não poderá ser atendida, será necessário que ambas as técnicas operem lado a lado, levando ao aparecimento da renda da terra, como 


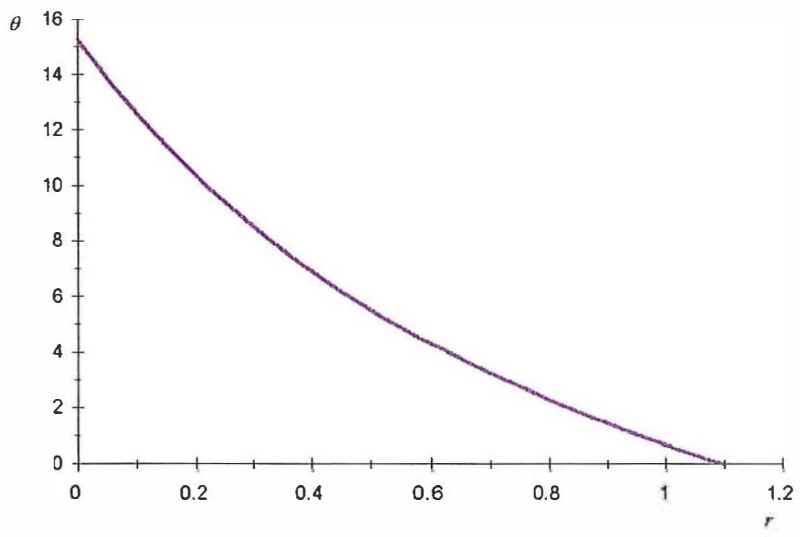

a)

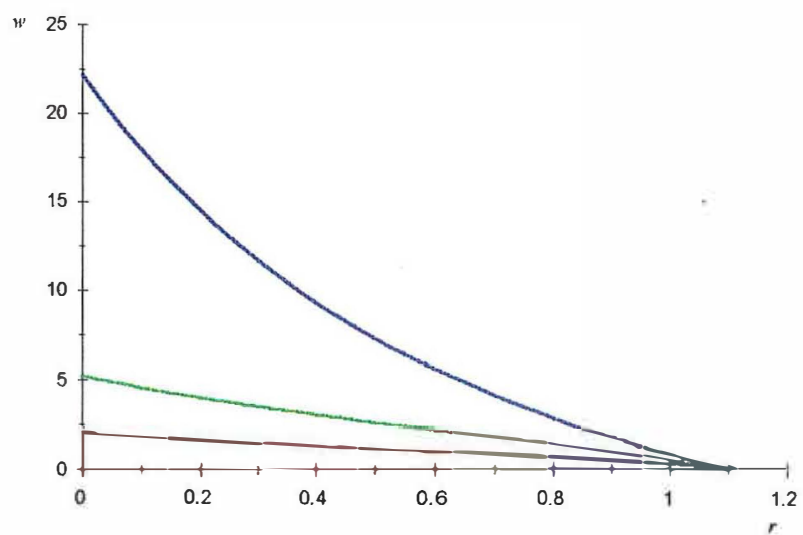

b)

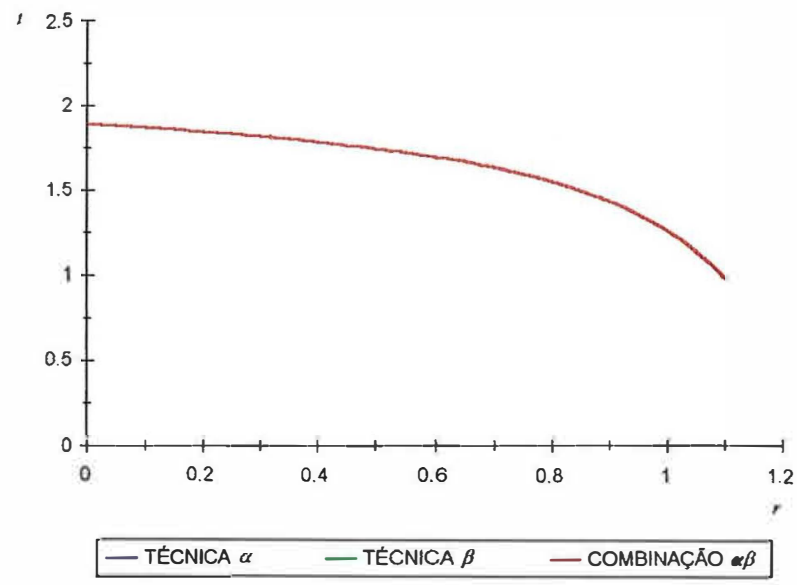

c)

Figura 4.12 Relações $\theta-r, w-r$ e $t-r$, modelo sraffiano-marxista em termos de preços de produção com terras homogêneas, primeiro exemplo numérico. 
mostra a figura 4.12c. Assim, a fronteira tecnológica desta economia corresponde à relação $w-r$ mais interna na figura $4.12 b$.

A seguir vamos tratar do sistema em termos dos valores-trabalho. No caso do sistema econômico analisado neste item teremos:

$$
\text { Minimizar } \quad\left[\begin{array}{lll}
b_{1} & b_{2} & b_{3}
\end{array}\right]\left[\begin{array}{l}
q_{1} \\
q_{2} \\
q_{3}
\end{array}\right]
$$

com

$$
\begin{array}{r}
{\left[\begin{array}{ccc}
1-a_{11} & -a_{12} & -a_{13} \\
-a_{21} & 1-a_{22} & 1-a_{23}
\end{array}\right]\left[\begin{array}{l}
q_{1} \\
q_{2} \\
q_{3}
\end{array}\right] \geq\left[\begin{array}{l}
y_{1} \\
y_{2}
\end{array}\right]} \\
{\left[\begin{array}{ll}
h_{\alpha} & h_{\beta}
\end{array}\right]\left[\begin{array}{l}
q_{1} \\
q_{2}
\end{array}\right] \leq s}
\end{array}
$$

com $q_{i} \geq 0$, para $i=1,2 \mathrm{e} 3$.

Utilizando este problema de programação linear obtemos o valor verdadeiro da mercadoria composta igual a 0,84 unidades de trabalho. Este valor é minimizado para $q_{1}$, $q_{2}$ e $q_{3}$ iguais, respectivamente, a 10,$5 ; 2,1$ e 3,2 unidades de cada mercadoria.

Modificando o valor do vetor $\mathbf{d}$, podemos traçar a figura 4.13. As relações mostradas nesta figura são similares àquelas obtidas no caso de terras de diferentes qualidades, ou seja, a relação $V-\theta$ é crescente, e as relações $\sigma-\theta$ e $\sigma-V$ são decrescentes. E, por fim, a relação entre os modelos em termos de preços de produção e de valores, descrita na figura 4.13, apresenta características similares às observadas no item 4.2.1. Esta relação é crescente, ou seja, um aumento da taxa de mais-valia no sistema de valores está relacionada a um aumento na taxa de lucro no sistema de preços de produção. Contudo, a relação entre a taxa de lucro e a taxa de mais-valia parte da origem dos eixos. Isto ocorre devido ao fato de que a determinação da taxa de lucro não depende da 


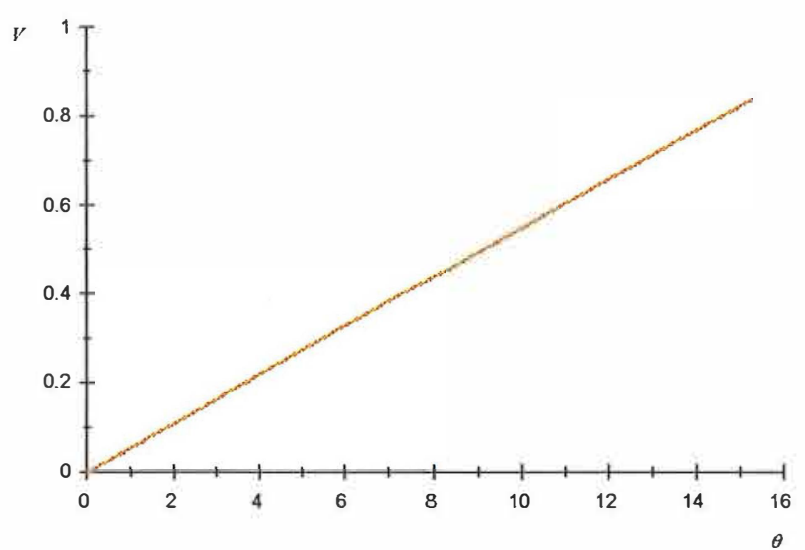

a)

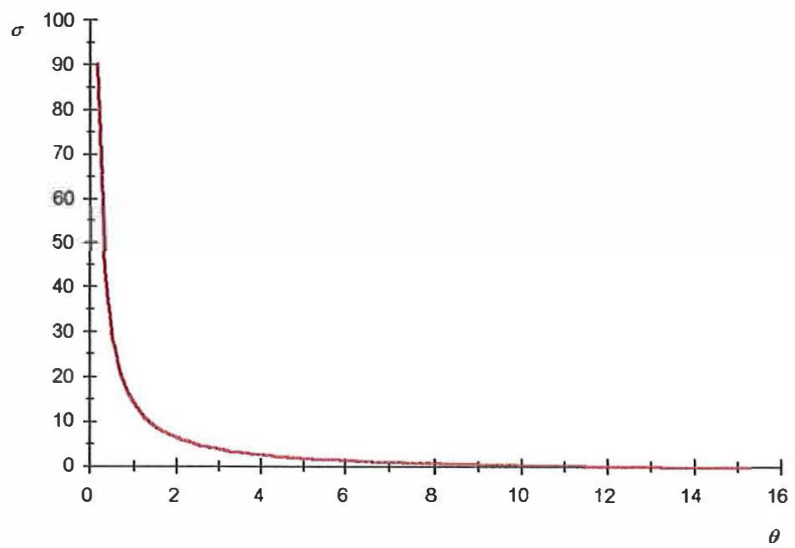

b)

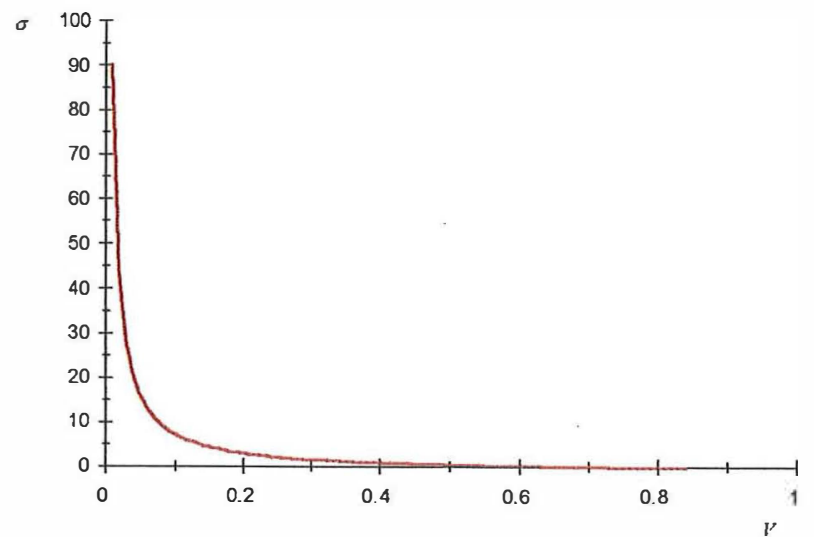

c)

Figura 4.13 Relações $V-\theta, \sigma-\theta$ e $\sigma-V$, para o modelo marxista com terras homogêneas, primeiro exemplo numérico. 


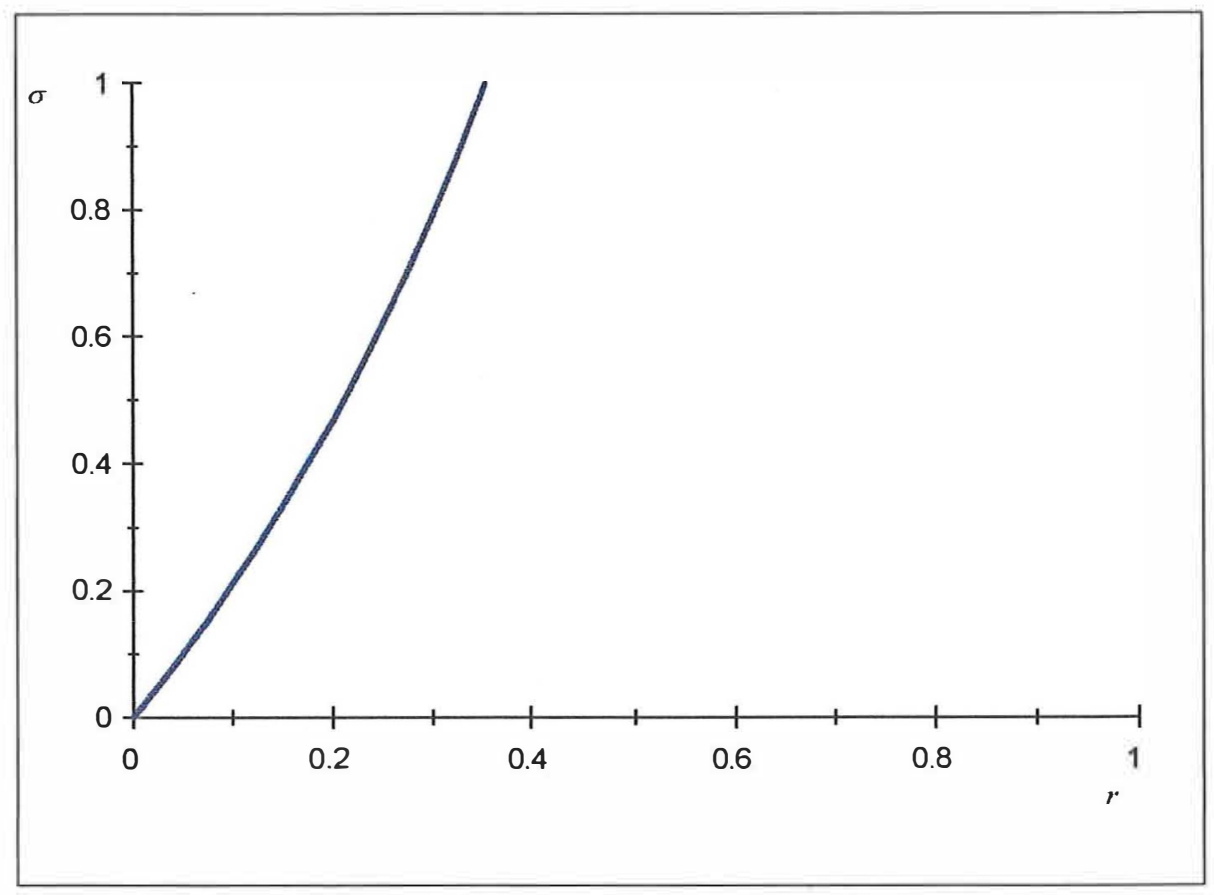

Figura 4.14 Relação $\sigma-r$ para modelos com terras homogêneas, segundo o exemplo numérico.

mercadoria agrícola, uma vez que esta é uma mercadoria não-básica e não participa do salário real (vetor $\mathbf{d})$.

Resolvendo o problema de maximização representado nas eqs. (4.134)-(4.136) para este exemplo numérico, obtemos o valor-trabalho ótimo da mercadoria industrial $(0,05454)$ e do cereal $(0,46777)$. De maneira similar aos casos com terras de diferentes qualidades, podemos verificar que:

$$
v_{y}=0,84<\sum v_{o i} y_{i}=2,61554
$$

O problema descrito nas eqs. (4.156)-(4.158) pode ser modificado a fim de obtermos os valores-trabalho verdadeiros individuais. Fazendo $y_{1}=1$ e $y_{2}=0$ na eq. (4.157) obtemos o valor-trabalho verdadeiro da mercadoria industrial $(0,05454)$ e fazendo o contrário, $y_{1}=0$ e $y_{2}=1$ na eq. (4.157) chegamos ao valor-trabalho verdadeiro da mercadoria agrícola $(0,045022)$, assim temos:

$$
v_{y}=0,84>\sum v_{y i} y_{i}=0,3751
$$




\subsubsection{Mercadoria agrícola básica}

Neste item, introduziremos algumas complicações no modelo. Vamos considerar uma mercadoria industrial e uma mercadoria agrícola, esta participando diretamente na produção da mercadoria industrial e na sua própria produção, ou seja, uma mercadoria básica. Este sistema possui três técnicas, a primeira referente à mercadoria industrial e as duas últimas, $\alpha$ e $\beta$, relacionadas à mercadoria agrícola, denominada cereal. Supomos que a demanda por cereal não poderá ser atendida apenas com o uso da técnica $\alpha$, mesmo utilizando toda a área disponível, mas poderá ser atendida utilizando apenas a técnica $\beta$, sem o cultivo de toda área disponível. Em adição, assumimos que a demanda por cereal poderá, ainda, ser atendida com o uso das técnica $\alpha$ e $\beta$, lado a lado. Para analisar esta questão vamos considerar um segundo exemplo numérico:

$$
\begin{aligned}
& 8 \text { merc. } 1 \oplus 1 \text { merc. } 2 \oplus 1 \text { trabalho } \rightarrow 16 \text { merc. } 1 \\
& 2 \text { merc. } 1 \oplus 2 \text { merc. } 2 \oplus 0,05 \text { trabalho } \oplus 1 \text { terra } \rightarrow 6 \text { merc. } 2 \\
& 1 \text { merc. } 1 \oplus 2 \text { merc. } 2 \oplus 1,5 \text { trabalho } \oplus 1 \text { terra } \rightarrow 8 \text { merc. } 2
\end{aligned}
$$

A partir desse sistema podemos formar três subsistemas preços de produção-taxa de lucro: o primeiro supondo que apenas a técnica $\alpha$ está sendo empregada, formado a partir das eqs. (4.161) e (4.162), o segundo supondo que apenas a técnica $\beta$ está sendo utilizada, com as eqs. (4.161) e (4.163), e o terceiro supondo que as duas técnicas estão sendo utilizadas lado a lado, formado por três equações, as eqs. (4.161)-(4.163). Nos dois primeiros subsistemas, fixando o salário em termos físicos, existem 3 incógnitas: o preço da mercadoria industrial, o preço do cereal e a taxa de lucro. Assim, tomando como numerário uma das mercadorias, podemos resolver estes subsistemas. No último existe, além das anteriores, uma incógnita a mais, a renda da terra.

Admitimos um salário real de:

$$
\mathbf{d}=\left[\begin{array}{c}
4 \\
1,5
\end{array}\right]
$$


ou seja, 4 unidades da mercadoria industrial e 1,5 unidades de cereal. Podemos, então, modificar esta cesta de mercadorias proporcionalmente a uma constante $\theta$. Neste caso obtemos a figura 4.15 , onde estão as três relações $\theta-r$ correspondentes aos três subsistemas acima mencionados. Sabemos que a técnica que possuir a maior taxa de lucro, para um dado $\theta$ será a mais efíciente. Para $r$ entre 0 e 0,5 a técnica $\beta$ é a mais eficiente; para $r$ entre 0,5 e 0,79 a combinação $\alpha \beta$ passa a ser a mais eficiente, e, por fim, entre 0,79 e 0,894 (aprox.) a técnica $\alpha$ torna-se mais eficiente. Isto deve-se, claramente, ao fato de que a técnica $\alpha$ é pouco intensiva em trabalho, desse modo, quando o salário real está elevado, passa a ter vantagens que a técnica $\beta$ ou, até mesmo, a combinação $\alpha \beta$ não possuem na mesma magnitude.

Mas, estamos mais interessados em obter a técnica (ou a combinação de técnicas) que determinará a taxa de lucro viável para esta economia para cada vetor $\theta \mathbf{d}$, de maneira que possa ser atendida a demanda por cereal, e esta técnica não necessariamente corresponderá à mais eficiente. Como apenas a técnica $\beta$ pode suprir, individualmente, a demanda por cereal, para $\theta$ entre 0 e 0,29 a taxa de lucro será determinada nesta técnica. Por outro lado, para $\theta$ entre 0,29 e 0,57 as técnicas $\alpha$ e $\beta$ determinarão, conjuntamente, a taxa de lucro. As taxas de lucro máximas para as técnicas $\alpha$ e $\beta$ são, respectivamente, 0,714 e 0,894 aproximadamente.

De acordo com a demanda por cereal a fronteira tecnológica desse sistema é dada pela curva formada com os pontos $A B C$ na figura $4.15 \mathrm{~b}$. No ponto de mudança de técnica temos $r=0,5$ e $w=1,57$ unidades monetárias em termos da mercadoria agrícola.

Ampliando um pouco mais a figura 4.15.b, na região próxima à origem dos eixos, como mostra a figura 4.16, podemos verificar que entre os pontos $A$ e $B$ a fronteira tecnológica é crescente neste sistema econômico sraffiano-marxista, como ocorre nos modelos sraffianos com renda intensiva. ${ }^{52}$ Isto só é possível porque neste intervalo existe uma renda positiva e decrescente, o que possibilita uma relação entre o salário e a taxa de lucro crescente, considerando o produto agrícola como o numerário do sistema. Por

\footnotetext{
52 Ver Montani (1975).
} 


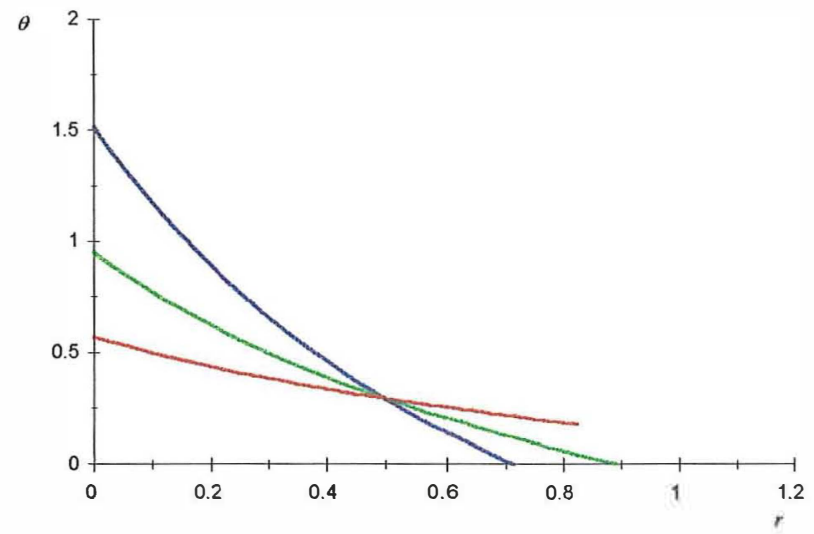

a)

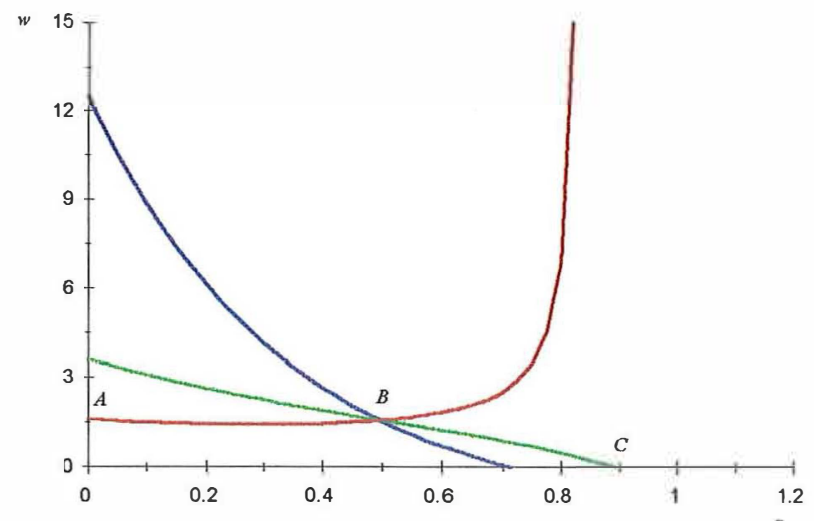

b)

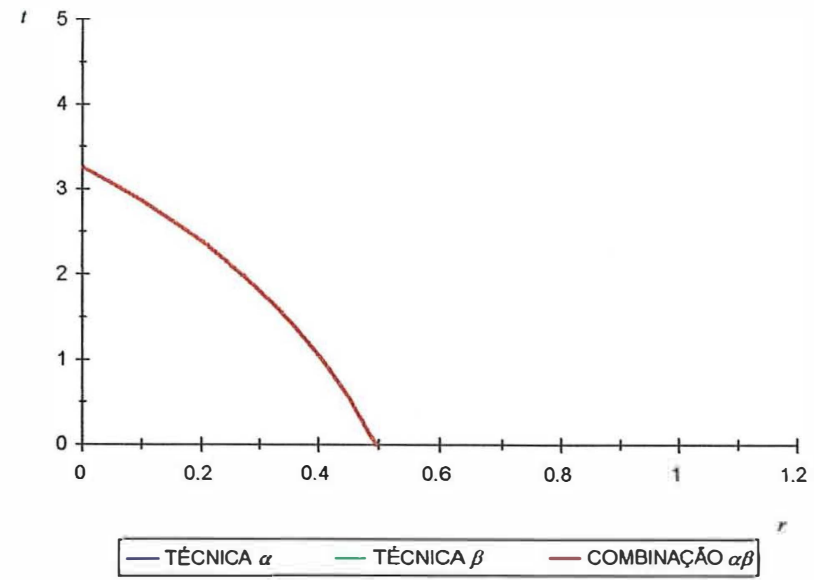

c)

Figura. 4.15 Relações $\theta-r, w-r$ e $t-r$, modelo sraffiano-marxista em termos de preços de produção com terras homogêneas, segundo exemplo numérico. 
exemplo, para $w$ igual a 1,5 podemos ter três possíveis valores para a taxa de lucro e para a renda da terra, que caracteriza um conflito distributivo entre capitalistas e proprietários de terra. Primeiro, podemos ter $r=0,125$ e uma renda positiva igual a 2,8 , como mostra a figura 4.15.c. Segundo, podemos ter uma taxa de lucro um pouco maior que a anterior $(r=0,425)$, mas uma renda menor $(t=0,8)$. Por fim, este sistema econômico também é viável a uma taxa de lucro de $r=0,52$ e uma renda da terra nula, considerando $w=1,5$. Assim, a solução para este sistema não dependerá apenas de aspectos econômicos, mas incluirá questões políticas e sociais.

Existe uma renda da terra positiva apenas na faixa de variação da taxa de lucro entre 0 e 0,5 , como apresenta a figura $4.15 \mathrm{c}$, correspondente à faixa em que as técnicas $\alpha$ e $\beta$ estão sendo empregadas lado a lado.

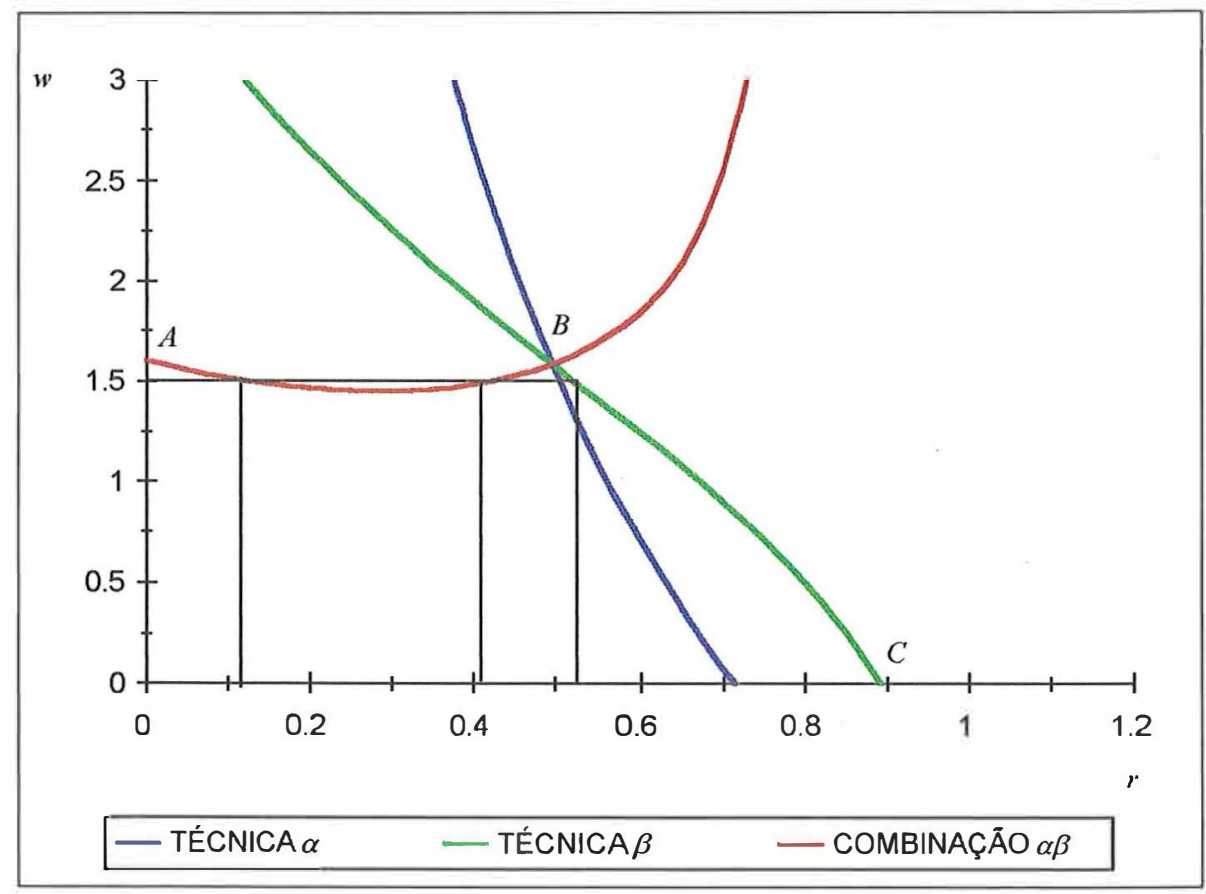

Figura 4.16 Relação $w-r$ em um modelo sraffiano-marxista em termos de preços de produção. 
Esta renda positiva pode ser relacionada com o que discutimos sobre o custo por unidade de produto. Quando a técnica com maior custo por unidade de produto tiver a maior produtividade, teremos uma renda positiva. No caso deste exemplo podemos verificar isto através da figura 4.17.

Se o custo por unidade de produto na técnica com a maior produtividade é maior que aquele da técnica com menor produtividade, a competição entre os capitalistas tornará a terra escassa e vai capacitar os proprietários a obter uma renda da terra. A escassez da terra depende de duas condições. A primeira é que existe pelo menos uma técnica, daquelas consideradas, que mesmo se fosse empregada em toda a terra disponível não atenderia à demanda por cereal da economia. Segundo, é necessário que esta técnica tenha a menor produtividade. Daí esta segunda condição pode ou não ocorrer, dependendo do montante estabelecido para o salário real e da respectiva taxa de lucro.

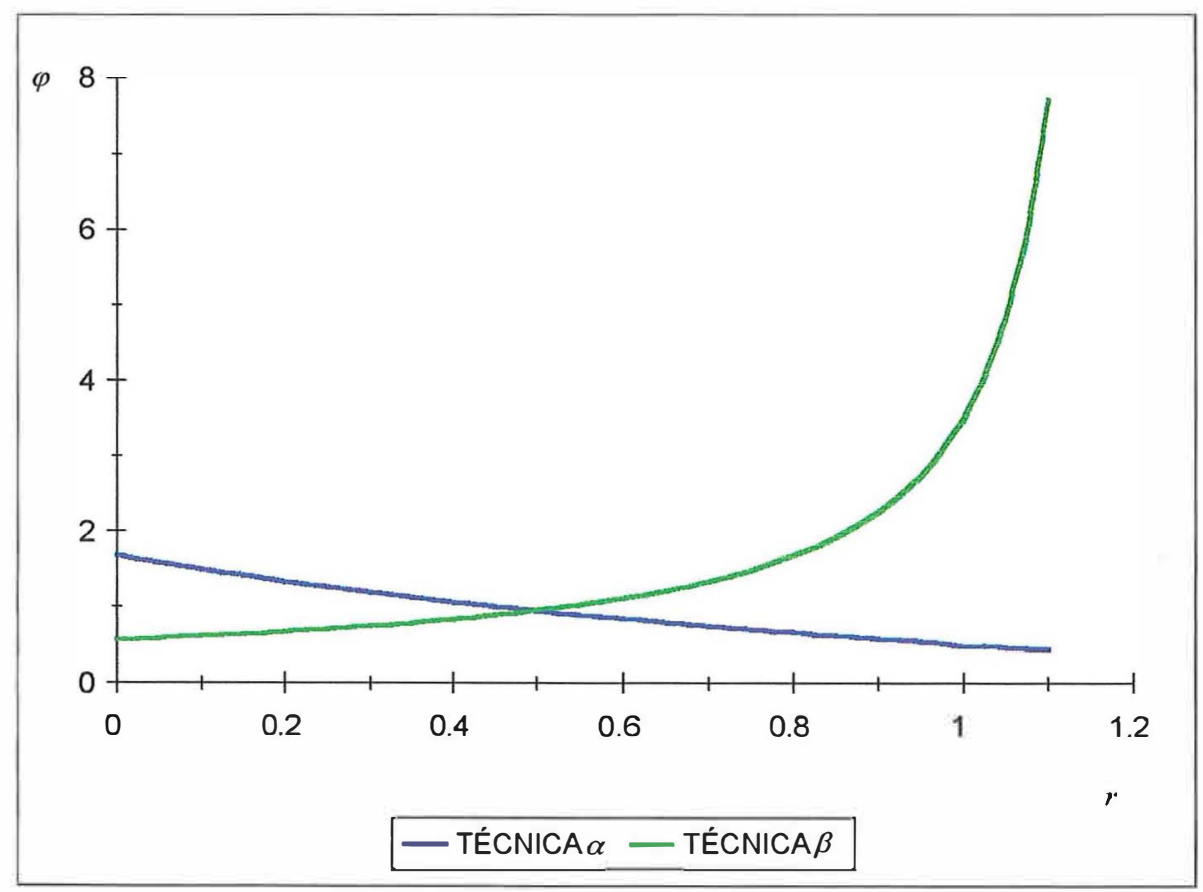

Figura 4.17 Relação $\varphi-r$ em um modelo sraffiano-marxista em termos de preços de produção. 
Com isto, podemos concluir que a escassez de terra depende não somente da extensão da demanda por cereal da economia, mas também da distribuição de renda.

Vamos analisar a seguir o sistema em termos de valores-trabalho. Considerando o sistema econômico indicado nas eqs. (4.161)-(4.163), podemos obter $v_{y}$ utilizando o seguinte problema de programação linear:

$$
\text { Minimizar } \quad\left[\begin{array}{lll}
b_{1} & b_{2} & b_{3}
\end{array}\right]\left[\begin{array}{l}
q_{1} \\
q_{2} \\
q_{3}
\end{array}\right]
$$

com

$$
\begin{gathered}
{\left[\begin{array}{ccc}
1-a_{11} & -a_{12} & -a_{13} \\
-a_{21} & 1-a_{22} & 1-a_{23}
\end{array}\right]\left[\begin{array}{l}
q_{1} \\
q_{2} \\
q_{3}
\end{array}\right] \geq\left[\begin{array}{l}
y_{1} \\
y_{2}
\end{array}\right]} \\
{\left[\begin{array}{ll}
h_{\alpha} & h_{\beta}
\end{array}\right]\left[\begin{array}{l}
q_{1} \\
q_{2}
\end{array}\right] \leq s}
\end{gathered}
$$

com $q_{i} \geq 0$, para $i=1,2$ e 3 .

Com isto, obtemos o valor verdadeiro do produto líquido igual a 2,55. Considerando o salário real estabelecido na eq. (4.164), chegamos às figuras 4.18 e 4.19, como anteriormente. Como pode ser observado, o comportamento destas figuras é similar ao descrito nos exemplos anteriores. Deve-se salientar que neste caso, como a mercadoria agrícola é básica teremos $\sigma>r$, como observamos nos sistemas com terras de diferentes qualidades.

Lembrando o problema de maximização representado nas eqs. (4.134)-(4.136), podemos calcular os valores-trabalho ótimos da mercadoria industrial $(0,20294)$ e do cereal $(0,62353)$. Verifica-se que:

$$
v_{y}=2,55<\sum v_{o i} y_{i}=6,62647
$$




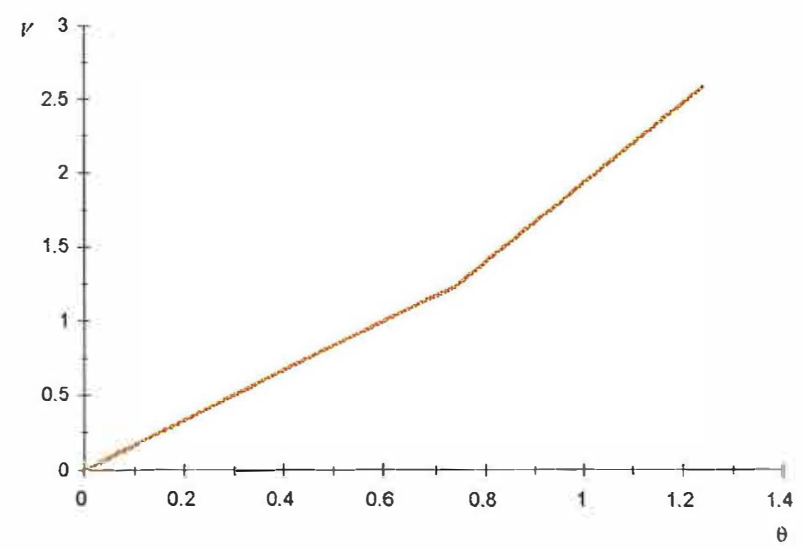

a)

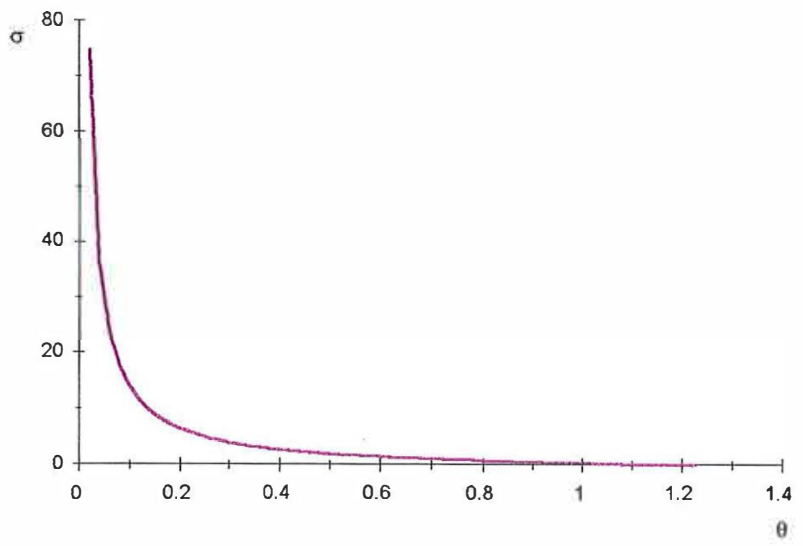

b)

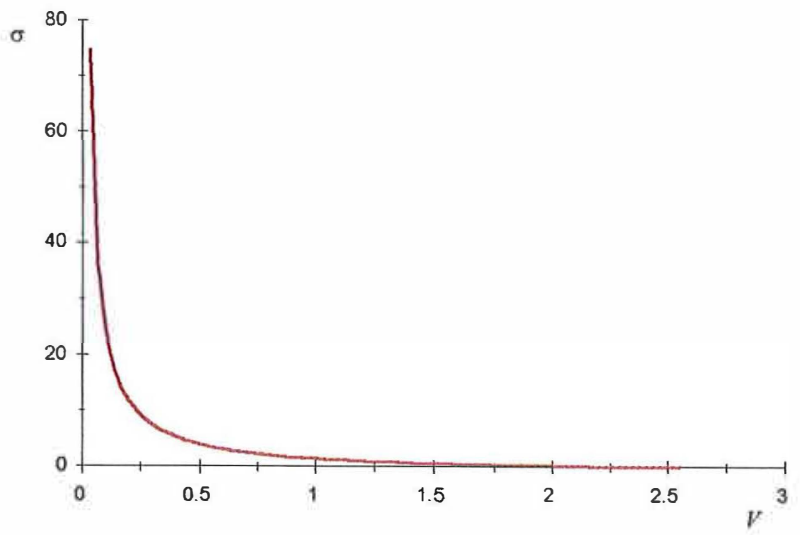

c)

Figura 4.18 Relações $V-\theta, \sigma-\theta$ e $\sigma-V$, para o modelo marxista com terras homogêneas, segundo o exemplo numérico. 


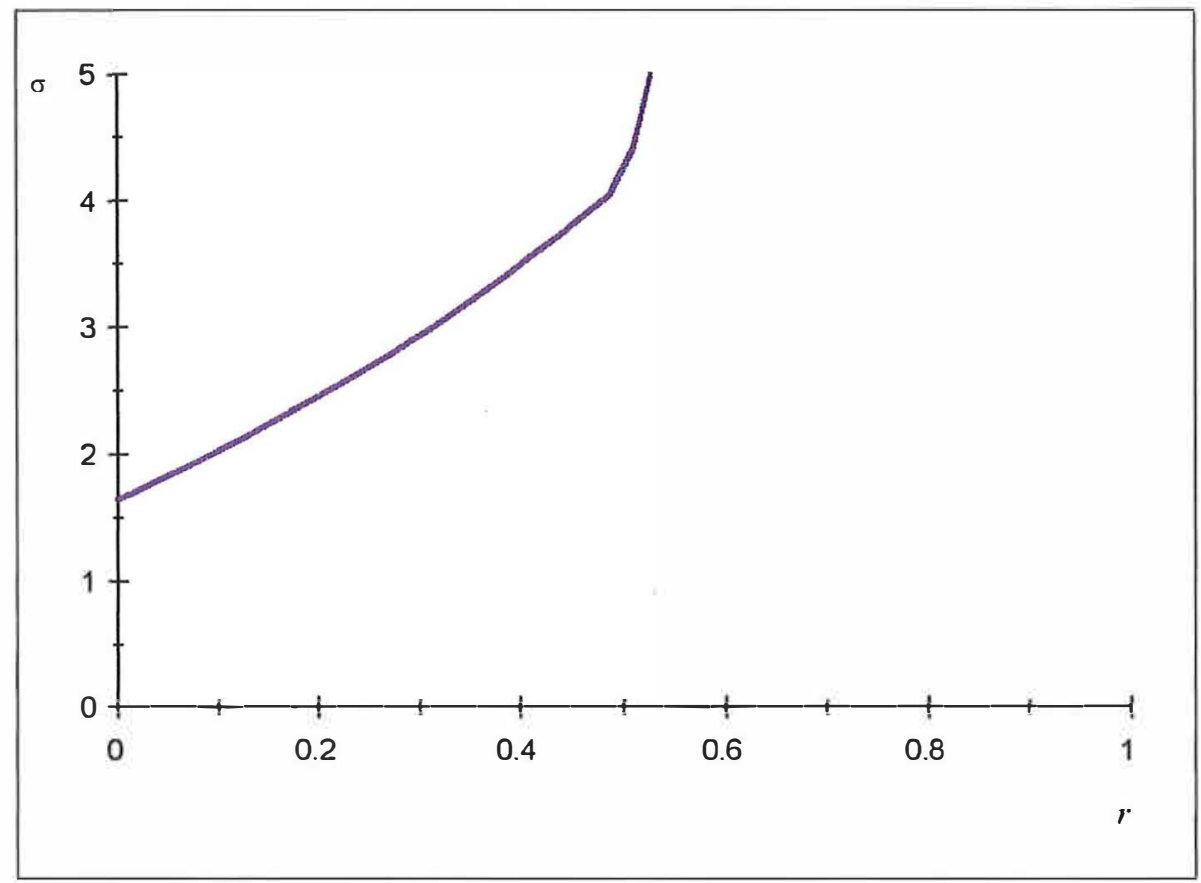

Figura 4.19 Relação $\sigma-r$ para modelos com terra homogênea, segundo o exemplo numérico.

Podemos obter os valores-trabalho verdadeiros dessas duas mercadorias utilizando o problema acima, eqs. (4.165)-(4.167) e verificar que:

$$
v_{y}=2,55>\sum v_{y i} y_{i}=(0,13499)(5)+(0,07999)(9)=1,39499
$$

Verificamos, portanto, que estas desigualdades se mantém em sistemas com terras homogêneas. 


\section{CONSIDERAÇÕES FINAIS}

Com base na abordagem sraffiana e na contribuição de Morishima para a análise dos valores-trabalho, podemos verificar que, havendo um setor agrícola com escassez de algum tipo de terra, a existência de uma taxa de mais-valia positiva é condição necessária mas não suficiente para a existência de lucros positivos. Além disso, os valores verdadeiros são positivos. Notamos, também, que a renda da terra, como uma parcela do valor monetário do excedente, só aparece no domínio dos preços de produção.

Verificamos que três afirmações presentes no trabalho de 1980 de Morishima e Catephores deixam de ser válidas em um sistema econômico com uso de terras escassas. Primeiro, a taxa de mais-valia calculada para um trabalhador individual pode ser maior do que aquela calculada para todos os trabalhadores do sistema, ou seja, $e_{2}>e_{1}$, diferentemente do que pensavam Morishima e Catephores $\left(e_{2}=e_{1}\right)$. Segundo, nesse sistema econômico os valores ótimos, da mesma maneira que os valores verdadeiros individuais, não são aditivos. E, por fim, a soma dos valores individuais verdadeiros de cada mercadoria multiplicados pelas respectivas quantidades do seu produto líquido no sistema pode ser menor que o valor verdadeiro do produto líquido do sistema.

Os sistemas econômicos com o setor agrícola desenvolvidos neste trabalho representam uma extensão da abordagem sraffiana. Partindo de um sistema em unidades fisicas, analisamos tanto sistemas em termos dos preços de produção quanto em termos dos valores-trabalho, e, além disso, traçamos relações entre os mesmos.

Por se tratar de uma abordagem formal, o modelo sraffiano-marxista em termos de preços de produção possui alguns aspectos não analisados por Marx. Enquanto Marx considera sempre os resultados da aplicação de um determinado montante de capital, 
nesses modelos doses desiguais de capital e trabalho podem ser aplicados em terras com diferentes qualidades ou de mesma qualidade com diferentes técnicas de produção.

No sistema de Sraffa os preços relativos são determinados simultaneamente aos parâmetros distributivos (salário, taxa de lucro e renda da terra). Nos esquemas de Marx sobre a determinação da renda diferencial II, foi considerada a possibilidade de alterações na renda da terra e no preço do cereal em decorrência de mudanças na quantidade de capital empregada na terra.

Uma conclusão obtida nesses modelos é que a ordem de eficiência das terras não representa uma característica naturalmente dada, mas depende da distribuição de renda e da demanda por cereal na economia. Ou seja, dada a demanda por cereal, a ordem de eficiência das terras pode mudar como consequência de uma mudança no salário real. Cabe salientar que, contrastando com as análises adotadas pelos autores clássicos e Marx, no enfoque sraffiano o salário não é mantido no nível de subsistência, permitindo uma análise mais realista do conflito distributivo em uma economia capitalista.

Uma outra questão refere-se ao fato de que a ordem de eficiência não corresponde, em geral, à ordem de rentabilidade das terras. Apenas nos modelos com duas qualidades de terra esta regra pode ser aplicada, mas quando se consideram duas ou mais qualidades de terra pode ocorrer que em determinado ponto da relação $w$-r uma qualidade de terra seja a mais eficiente e que no ponto corresponde da relação $t-r$ uma outra qualidade de terra seja a mais rentável.

Verificou-se, ainda, que nesses modelos pode ocorrer um retorno na ordem de eficiência das terras, aparecendo o fenômeno do retorno de técnicas em sistemas com o setor agrícola. O retorno ou reeleição de técnicas permite que uma técnica, depois de substituída por outra mais lucrativa, volte a ser utilizada em outros valores da taxa de lucro.

Os conceitos de renda da terra nos modelos de Sraffa permitem analisar situações não consideradas por Marx e Ricardo, tornando dificil traçar uma correspondência entre os mesmos. 
Como vimos no capítulo 2, a renda diferencial I de Marx está associada à produtividade diversa do emprego de doses iguais de capital e trabalho em áreas iguais de terras de qualidades diferentes. A renda diferencial II está ligada ao emprego adicional de capital e trabalho, mas, considerando, em geral, que a terra com pior qualidade não gera renda.

Podemos considerar que o modelo sraffiano com renda extensiva engloba tanto a renda diferencial I quanto a renda diferencial II, uma vez que nestes modelos consideramos terras de diferentes qualidades, sendo que a terra com pior qualidade não recebe renda, e não é feita nenhuma restrição quanto à quantidade de capital e trabalho aplicada nas diversas qualidades de terra.

No modelo sraffiano-marxista com terras de qualidades homogêneas, em que surge a renda intensiva, com duas técnicas de cultivo diferentes, temos diferentes doses de capital e trabalho sendo utilizadas. Desse modo, podemos associar a renda intensiva de Sraffa à renda diferencial II de Marx. No entanto, Marx não admitia a possibilidade de renda diferencial II em uma terra totalmente homogênea.

A renda absoluta de Marx também pode ser associada com a renda intensiva de Sraffa, uma vez que ambas são obtidas quando temos uma terra homogênea. Contudo, as similaridades acabam por aí, dado que são obtidas em contextos totalmente diversos. Um pressuposto para o surgimento da renda absoluta é que a composição orgânica do capital empregado na agricultura seja inferior à do capital social médio.

Uma contribuição de Marx sobre as condições necessárias para o aparecimento da renda da terra foi sua ênfase no fato de que a renda da terra só é paga para alguém que é o proprietário da terra. A terra constitui-se em um meio de produção não produzido, escasso e que pode ser apropriado.

A renda da terra é uma consequência da escassez da terra. Quando temos diferentes qualidades de terra, só recebem renda aquelas qualidades de terra totalmente cultivadas e, portanto escassas, e quando temos uma terra de mesma qualidade onde duas técnicas de cultivo podem ser empregadas, a renda aparece apenas quando as duas técnicas estão sendo utilizadas lado a lado e esta terra homogênea é escassa. 
Ressaltamos que a análise desenvolvida neste trabalho não tem sua aplicação limitada ao estudo de modelos que incluam o insumo terra, mas pode ser utilizada para analisar outros meios de produção não produzidos, tais como os depósitos minerais. 


\section{REFERÊNCIAS BIBLIOGRÁFICAS}

BARROS LISBOA, M. Preços de produção, método de longo prazo e equilíbrio geral: uma crítica à teoria neo-ricardiana dos preços relativos. Rio de Janeiro: BNDS, 1993. $168 \mathrm{p}$.

BLAUG, M. História do pensamento econômico. Lisboa: Dom Quixote, 1990, v.2.

BRYAN, D. "Natural" and "improved" land in Marx's theory of rent. Land Economics, v.66, n. 2, p.176-181, May, 1990.

CHIANG, A.C. Matemática para economistas. São Paulo: McGraw-Hill, 1982. 684p.

FINE, B. On Marx's theory of agricultural rent. Economy and Society, v.8, n.3., p.241278, Aug. 1979.

FLICHMAN, G. Sobre a teoria da renda fundiária. Estudos CEBRAP, v.20, p.29-73, abr./jun. 1977.

GARAGNANI, P. Sobre a teoria da distribuição e do valor em Marx e nos economistas clássicos. In: GAREGNANI, P.; STEINDL, J.; SYLOS-LABINI, P. et al. Progresso técnico e teoria econômica. São Paulo: Hucitec; Unicamp, 1977. p.1-38. 
GIBSON, B.; MCLEUD, D. Non-produced means of production in Sraffa's system: basics, non-basics and quasi-basics. Cambridge Journal of Economics, v.7, n.2, p.197-116, June 1983.

GONTIJO, C. A lei do valor em condições de produção conjunta. Revista Brasileira de Economia, v.48, n.3, p.389-398, set. 1994.

HARCOURT, G.C. Some cambridge controversies in the theory of capital. Cambridge: University Press, 1972. 272p.

HARCOURT, G.C.; LIANG, N.F. Capital and growth. Middlesex: Penguim Books, 1971. 383p.

HOFFMANN, R. Raíz característica de uma matriz e as propriedades das matrizes não-negativas. Piracicaba: ESALQ, 1983. 48p. (Série Didática, 44)

HOFFMANN, R. Produtividade e preços em sistemas sraffianos. Piracicaba: ESALQ, 1995. 87p. (Série Didática, 107)

HOFFMANN, R; VENTER, P. A renda extensiva da terra em um sistema econômico. Pesquisa e Planejamento Econômico, v.20, n.3, p.601-612, dez. 1990.

HUNT, E.K. História do pensamento econômico. 5.ed. Rio de Janeiro: Editora Campus, 1987. $518 \mathrm{p}$.

KURZ, H. Rent theory in a multisectoral model. Oxford Economic Papers, v.30, n.1, p.16-37, 1980 .

LENZ, M.H. A categoria econômica renda da terra. Porto Alegre: Fundação de Economia e Estatística, 1981. 102p. 
LICHTENSTEIN, P.M. An introduction to post-keynesian and marxian theories of value and price. New York: M.E.Sharpe, 1983. 206p.

MARX, K. O capital: crítica da economia política. 4.ed. São Paulo: DIFEL, 1985. v.6, $375 p$.

MARSHALL, A. Princípios de economia. São Paulo: Abril Cultural, 1982. v.2, 442p. (Os Economistas)

MÉDIO, A. Profits and surplus-value: appearance and reality in capitalist production. In: HUNT, E.K.; SCHWARTZ, J.G. (Ed.) A critique of economic theory. Hardmonsworth: Penguin Books, 1973. p.312-346.

MONTANI, G. La teoria ricardiana della rendita. L'Industria, n.2/3, p.221-243, 1972.

MONTANI, G. Scarce natural resources and income distribution. Metroeconomica. v.17, n.1, p.68-101, Jan./Abr. 1975.

MORISHIMA, M. Marx's economic's: a dual theory of value and growth. Cambridge: University Press, 1973. 198p.

MORISHIMA, M. Marx in the light of modern economic theory. Econometrica, v.42, n.4, p.611-632, July 1974.

MORISHIMA, M. Positive profts with negative surplus value - a comment. The Economic Journal, v.86, p.599-603, Sept. 1976.

MORISHIMA, M; CATEPHORES, G. Valor, exploração e crescimento: marx à luz da teoria econômica moderna. Rio de janeiro: Zahar, 1980. 232p. 
NAPOLEONI, C. Smith, Ricardo e Marx: considerações sobre a história do pensamento econômico. 2. ed. Rio de Janeiro: Graal, 1981. 239p.

PASINETTI, L.I. Lectures on the theory of production. New York: Columbia University Press, 1977. 285p.

PASINTETTI, L.I. Essays on the theory of joint production. London:Macmillan, 1980. p. 12-17: Introductory note: joint production.

POSSAS, M.L. Apresentação. In: Sraffa, P. Produção de mercadorias por meio de mercadorias. 2.ed. São Paulo: Abril Cultural, 1985. p.151-171. (Os Economistas)

POSSAS, M.L. Preços e distribuição em Sraffa: uma reconsideração. Pesquisa e Planejamento Econômico, v.13, n.2, p 575-618, ago, 1983.

QUADRIO-CURZIO, A. Rent, income distribuition, and orders of efficiency and rentability. In: PASINETTI, L.L. Essays on theory of joint production. Nova York: Columbia University Press, 1980. P.218-240.

QUADRIO-CURZIO, A. Land rent. In: EATWELL, J.; MILGATE, M.; NEWMAN, P., (Ed.) The new palgrave dictionary of economics. London: Macmillan Press, 1987. v.3, p.118-121.

QUESNAY, F. Quadro econômico dos fisiocratas. 2.ed., São Paulo: Abril Cultural, 1986. p.245-350. (Os Economistas)

RANKIN, S. Exploitation and the lobour theory of value: a neo-marxian reply. Capital and Class. p.105-116, 1988. 
RAVINDRAN, A.; PHILLIPS, D.T.; SOLBERG, J.J. Operations research: principles and practice. 2.ed. New York: Jonh Wiley, 1987. 637p.

RICARDO, D. Princípios de economia política e tributação. São Paulo: Abril Cultural, 1982. 286p. (Os Economistas)

RONCAGLIA, A. Sraffa and the theory of prices. New York: John Wiley, 1978. 637p.

ROWTHORN, B. Capitalismo, conflito e inflação. Rio de Janeiro: Zahar, 1982. p.1745: Neoclassicismo, neo-ricardianismo e marxismo.

SALVATORI, N. On a new variety of rent. Metroeconomica, v.35, p.73-85, 1983.

SALVATORI, N. Land and choice of techniques within the Sraffa framework. Australian Economic Papers, v.25, n.46, p.94-105, 1986.

SILBERBERG, E. The structure of economics: a mathematical analysis. New York: McGraw-Hill, 1978. 543p.

SILVA, E.A. Absolute rent. In: EATWELL, J.; MILGATE, M.; NEWMAN, P. (Ed.) The new palgrave dictionary of economics. London: Macmillan Press, 1987. v.l, p.4-5.

SMITH, A. A riqueza das nações: investigação sobre sua natureza e suas causas. São Paulo: Abril Cultural, 1983. v.1. 415p. (Os Economistas)

SECHACZEWSKI,A.C.; SERRA, J. Renda diferencial, renda absoluta e progresso técnico na agricultura ricardiana. Estudos CEBRAP, v.27, p.57-81, 1980. 
SRAFFA, P. Produção de mercadorias por meio de mercadorias: prelúdio a uma crítica da teoria econômica. 2.ed., São Paulo: Abril Cultural, 1985. p.172-258. (Os Economistas)

SRAFFA, P. Apresentação. In: Ricardo, D. Princípios de economia política e tributação. São Paulo: Abril Cultural, 1982. p.3-35. (Os Economistas)

STEEDMAN, I. Positive profits with negative surplus value. The Economic Journal, v.85, n.337, p.114-123, Mar. 1975.

STEEDMAN, I. Positive profits with negative surplus value: a reply. The Economic Journal, v.86, p.604-608, Sept. 1975.

STEEDMAN, I. Marx after Sraffa. London: Unwin Brothers, 1977. 218p.

STEEDMAN, I. The value controversy. London: Verso Editions and NLB, 1981. 300p.

SWANSON, P.A. The labor theory of value and fixed capital. Review of Radical Political Economics, v.18, n.3, p.44-64, 1986.

TOLIPAN, R. A ironia na história do pensamento econômico. Rio de Janeiro: INPES; IPEA, 1990. 84p.

VIVO, G. Corn model. In: EATWELL, J.; MILGATE, M.; NEWMAN, P. (Ed.) The new palgrave dictionary of economics. London: Macmillan Press, 1987. v.3, p. 671-672.

VENTER, P.R.; HOFFMANN, R. A renda intensiva em sistemas sraffianos. Revista de Economia e Sociologia Rural, v.29, n.3, p.183-208, jul-set, 1991. 
VENTER, P.R. A renda da terra no sistema econômico sraffiano. Piracicaba, 1990. 167p. Dissertação (Mestrado) - Escola Superior de Agricultura "Luiz de Queiroz", Universidade de São Paulo.

WOODS, J.E., The production of commodities: an introduction to sraffa. Basingstoke: Macmillan, 1990. p.344. 